\title{
MICROCHANNEL HEAT EXCHANGERS WITH CARBON DIOXIDE
}

Final Report

Date Published - September 2001

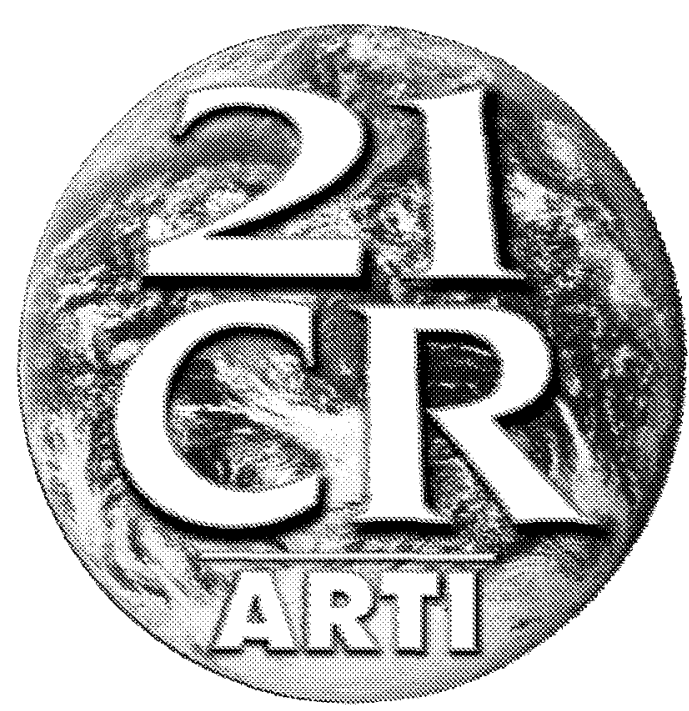

Y. Zhao, M.M. Ohadi, R. Radermacher

Center for Environmental Energy Engineering

Department of Mechanical Engineering

University of Maryland, College Park

College Park, MD 20742

Prepared for the

AIR-CONDITIONING AND REFRIGERATION TECHNOLOGY INSTITUTE 4301 N. Fairfax Drive, Suite 425, Arlington, Virginia 22203

Distribution A - Approved for public release; further dissemination unlimited. 


\section{DISCLAIMER}

This report was prepared as an account of work sponsored by the Air-Conditioning and Refrigeration Technology Institute (ARTI) under its "HVAC\&R Research for the $21^{\text {st }}$ Century" (21-CR) program. Neither ARTI, the financial supporters of the 21-CR program, or any agency thereof, nor any of their employees, contractors, subcontractors, or employees thereof, make any warranty, expressed or implied; assume any legal liability or responsibility for the accuracy, completeness, any third party's use of, or the results of such use of any information, apparatus, product, or process disclosed in this report, nor represent that its use would not infringe privately owned rights. Reference herein to any specific commercial product, process, or service by trade name, trademark, manufacturer, or otherwise, does not necessarily constitute nor imply its endorsement, recommendation, or favoring by ARTI, its sponsors, or any agency thereof, including their contractors or subcontractors. The views and opinions of the authors expressed herein do not necessarily state or reflect those of ARTI, the 21-CR program sponsors, or any agency thereof.

Funding for the 21-CR program provided by (in order of support magnitude):

- U.S. Department of Energy (DOE Cooperative Agreement No. DE-FC05-99OR22674)

- Air-Conditioning and Refrigeration Institute (ARI)

- Copper Development Association (CDA)

- New York State Energy Research and Development Authority (NYSERDA)

- Refrigeration Service Engineers Society (RSES)

- Heating, Refrigeration, and Air-Conditioning Institute of Canada (HRAI)

Available to the public from:

U.S. Department of Commerce

National Technical Information Service

5285 Port Royal Road

Springfield, VA 22161

(703) 487-4650

Available to The U.S. Department of Energy and its contractors in paper from:

U.S. Department of Energy

Office of Scientific and Technical Information

P.O. Box 62

Oak Ridge, TN 37831

(423) 576-8401 


\section{MICROCHANNEL HEAT EXCHANGERS WITH CARBON DIOXIDE}

Final Report

Date Published - September 2001

\section{Y. Zhao}

M.M. Ohadi

R. Radermacher

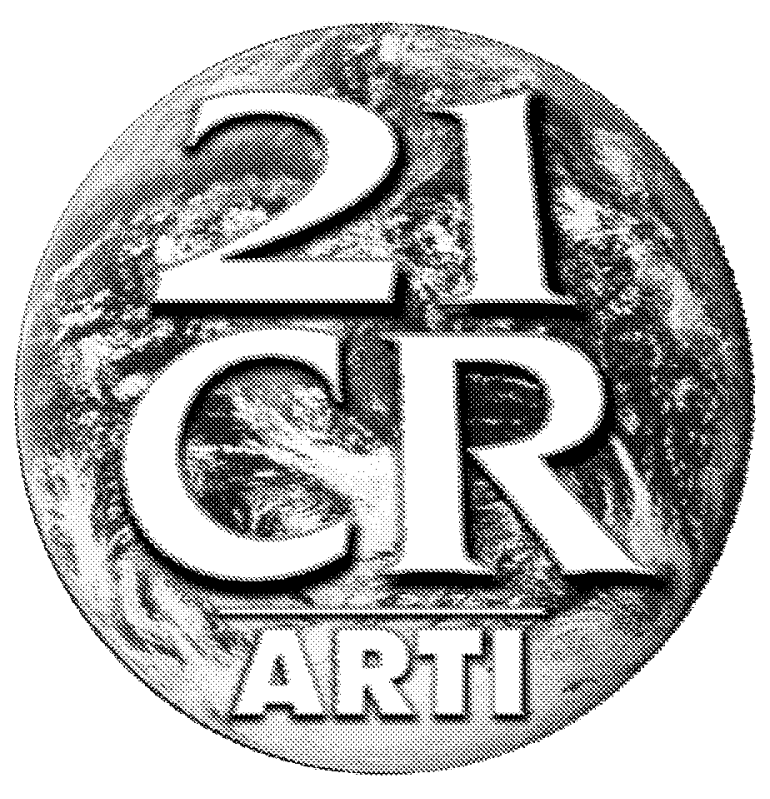

Prepared for the 


\section{EXECUTIVE SUMMARY}

The objective of the present study was to determine the performance of $\mathrm{CO}_{2}$ microchannel evaporators and gas coolers in operational conditions representing those of residential heat pumps. A set of breadboard prototype microchannel evaporators and gas coolers was developed and tested. The refrigerant in the heat exchangers followed a counter cross-flow path with respect to the airflow direction. The test conditions corresponded to the typical operating conditions of residential heat pumps. In addition, a second set of commercial microchannel evaporators and gas coolers was tested for a less comprehensive range of operating conditions. The test results were reduced and a comprehensive data analysis, including comparison with the previous studies in this field, was performed. Capacity and pressure drop of the evaporator and gas cooler for the range of parameters studied were analyzed and are documented in this report. A gas cooler performance prediction model based on non-dimensional parameters was also developed and results are discussed as well.

In addition, in the present study, experiments were conducted to evaluate capacities and pressure drops for sub-critical $\mathrm{CO}_{2}$ flow boiling and transcritical $\mathrm{CO}_{2}$ gas cooling in microchannel heat exchangers. An extensive review of the literature failed to indicate any previous systematic study in this area, suggesting a lack of fundamental understanding of the phenomena and a lack of comprehensive data that would quantify the performance potential of $\mathrm{CO}_{2}$ microchannel heat exchangers for the application at hand.

All experimental tests were successfully conducted with an energy balance within $\pm 3 \%$. The only exceptions to this were experiments at very low saturation temperatures 
$\left(-23{ }^{\circ} \mathrm{C}\right)$, where energy balances were as high as $10 \%$. In the case of evaporators, it was found that a lower saturation temperature (especially when moisture condensation occurs) improves the overall heat transfer coefficient significantly. However, under such conditions, air side pressure drop also increases when moisture condensation occurs. An increase in airflow rate also increases the overall heat transfer coefficient. Air side pressure drop mainly depends on airflow rate. For the gas cooler, a significant portion of the heat transfer occurred in the first heat exchanger module on the refrigerant inlet side. The temperature and pressure of $\mathrm{CO}_{2}$ significantly affect the heat transfer and fluid flow characteristics due to some important properties (such as specific heat, density, and viscosity). In the transcritical region, performance of $\mathrm{CO}_{2}$ strongly depends on the operating temperature and pressure.

Semi-empirical models were developed for predictions of $\mathrm{CO}_{2}$ evaporator and gas cooler system capacities. The evaporator model introduced two new factors to account for the effects of air-side moisture condensate and refrigerant outlet superheat. The model agreed with the experimental results within $\pm 13 \%$. The gas cooler model, based on nondimensional parameters, successfully predicted the experimental results within $\pm 20 \%$.

Recommendations for future work on this project include redesigning headers and/or introducing flow mixers to avoid flow mal-distribution problems, devising new defrosting techniques, and improving numerical models. These recommendations are described in more detail at the end of this report. 


\section{ACKNOWLEDGMENTS}

This work was sponsored by the Air-conditioning and Refrigeration Technology Institute under ARTI 21-CR Program Contract Number 605-10020. The feedback and technical guidance of the project monitoring subgroup, including Michael Blanford, Karim Amrane, Piotr Domanski, Steve Memory, Michael Heidenreich, and Richard Cawley, is greatly acknowledged. We are also grateful to Glen Hourahan of ARTI for his feedback and many useful technical comments. The project manager was Mr. Michael Blanford, whose efforts in coordinating the various tasks of the project were invaluable. His continuous interactions with our team were critical for the successful completion of the project. We also would like to thank Dr. Yunho Hwang from our department who participated in many technical discussions and for his other contributions to the project. 


\section{TABLE OF CONTENTS}

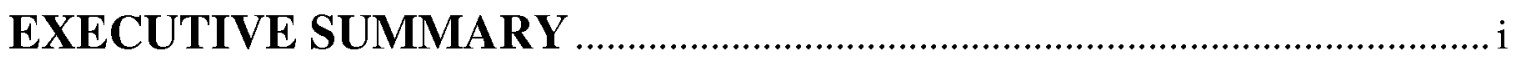

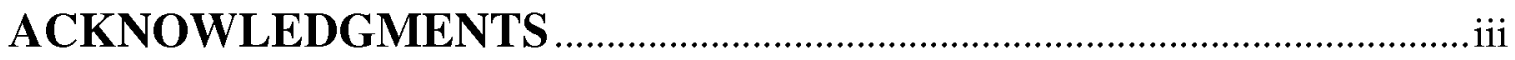

TABLE OF CONTENTS ................................................................................. iv

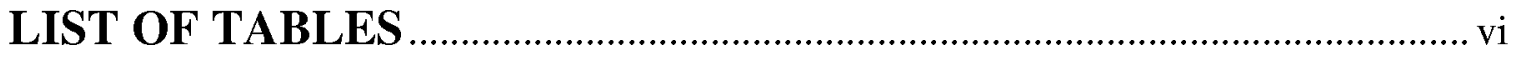

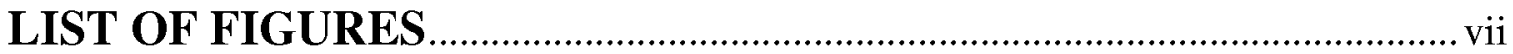

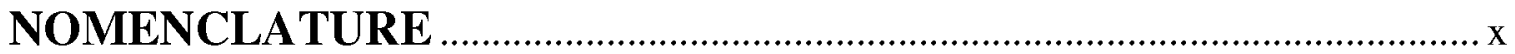

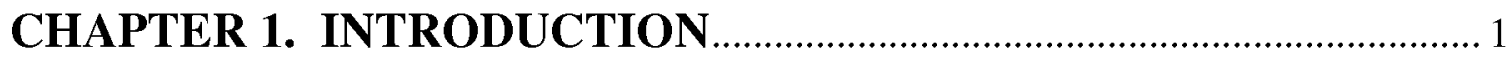

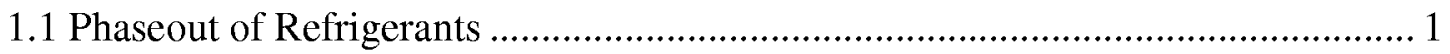

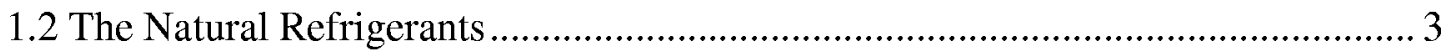

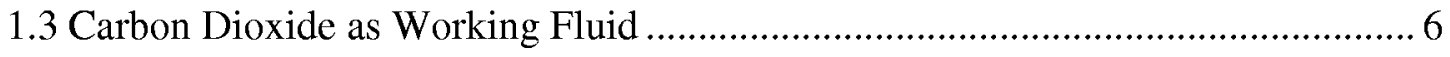

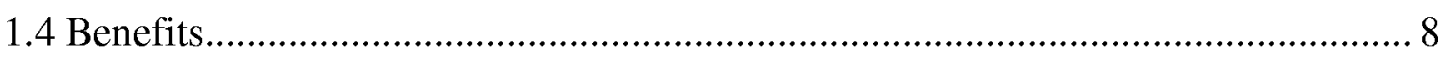

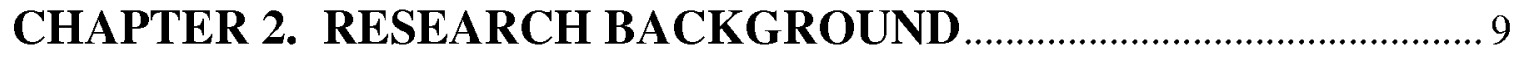

2.1 Previous $\mathrm{CO}_{2}$ Heat Transfer Studies ............................................................ 9

2.2 Previous Microchannel Heat Transfer Studies........................................................ 11

2.3 Recent Microchannel Experimental Work in Our Laboratory ............................. 17

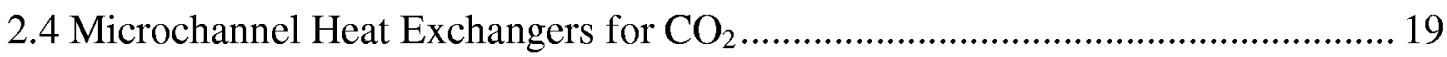

CHAPTER 3. TEST FACILITIES AND SYSTEM COMPONENTS .... 22

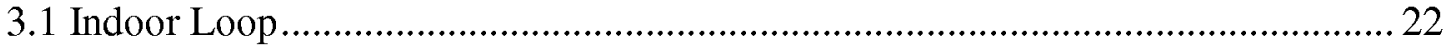

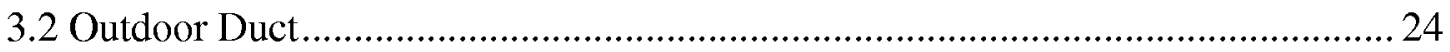

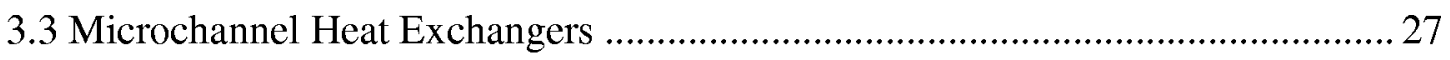

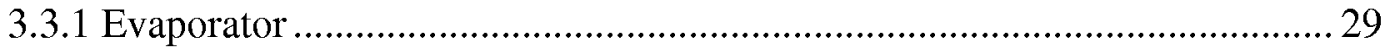

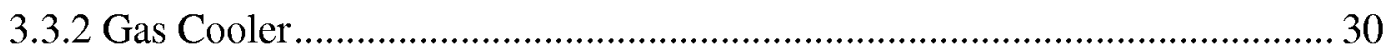

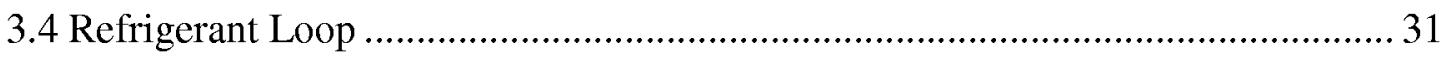

3.5 Compressor

3.6 Data Acquisition System .........................................................................................3 
3.7 Instrumentation and Measurements ....................................................................... 35

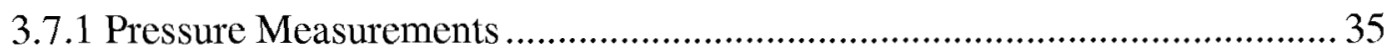

3.7.2 Air Stream Temperature Measurements ........................................................ 36

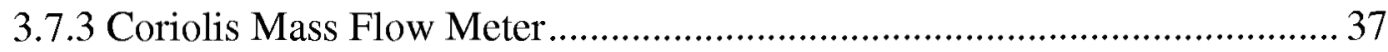

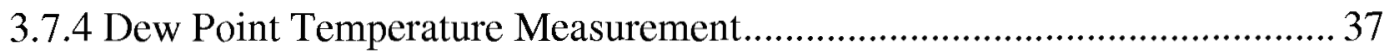

CHAPTER 4. EXPERIMENTAL RESULTS FOR MICRO-CHANNEL

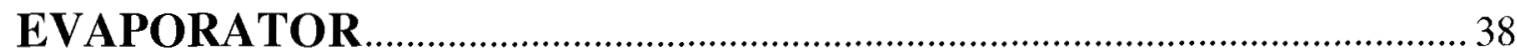

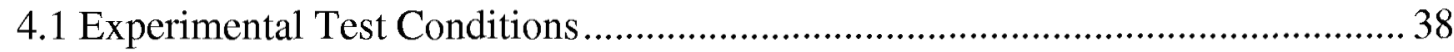

4.2 Experimental Test Results................................................................................. 41

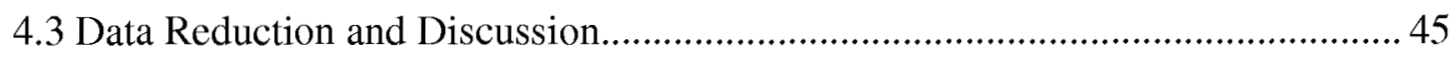

4.4 Capacity Predictive Model for Microchannel Evaporators..................................... 51

CHAPTER 5. EXPERIMENTAL RESULTS FOR MICRO-CHANNEL GAS COOLER

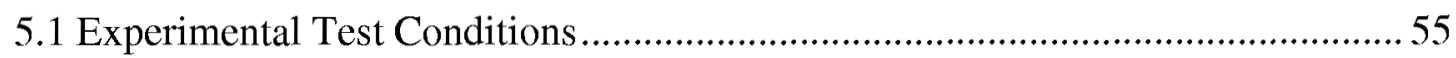

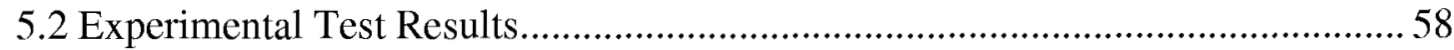

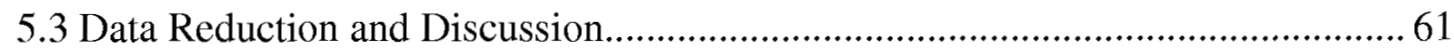

5.4 Models for Predicting the Capacity of a Gas Cooler ............................................ 74

CHAPTER 6. CONCLUSIONS AND PROPOSED FUTURE WORK.. 78

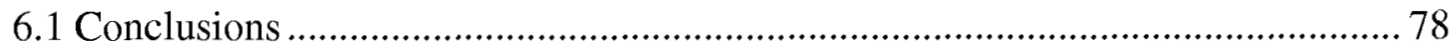

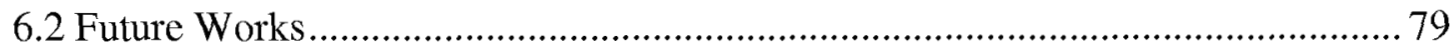

6.2.1 Two-Phase Flow Mal-distribution for a Microchannel Evaporator .............. 79

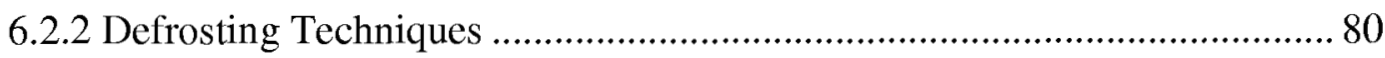

6.2.3 Model Developments and Improvements .................................................. 81

6.2.4 Recommendations for Heat Exchanger Design ............................................ 81

APPENDIX A. DESIGN OF OBSTRUCTION FLOW METER ............. 83

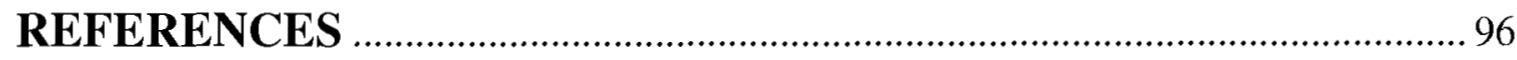




\section{LIST OF TABLES}

Table 1.1 Overview of selected natural refrigerants.............................................. 5

Table 1.2 Thermophysical properties of $\mathrm{CO}_{2}$ and $\mathrm{R}-134 \mathrm{a}$ at $5 / 10 / 15^{\circ} \mathrm{C}$.................... 7

Table 2.1 Summary of studies on single-phase flow in microchannels ........................ 16

Table 2.2 Summary of studies on two-phase flow in microchannels ............................ 17

Table 4.1 Experimental test conditions for evaporation (English Units) ....................... 39

Table 4.2 Experimental test conditions for evaporation (SI Units) ............................... 40

Table 4.3 Experimental data for evaporation (SI Units) ......................................... 43

Table 5.1 Experimental test conditions for gas cooler (English Units) .......................56

Table 5.2 Experimental test conditions for gas cooler (SI Units) ..............................57

Table 5.3 Experimental data for gas cooling (SI Units) ..........................................5 


\section{LIST OF FIGURES}

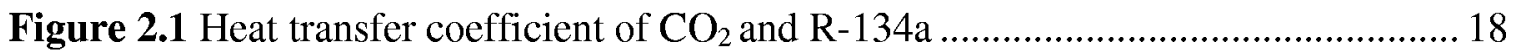

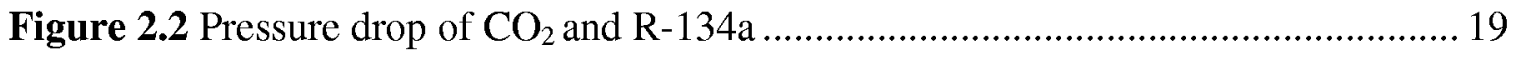

Figure 3.1 Schematic of indoor loop ................................................................ 23

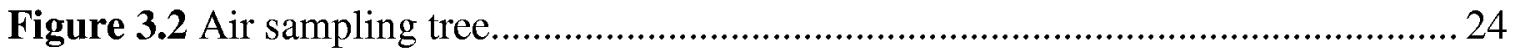

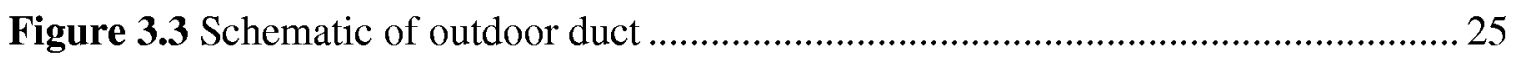

Figure 3.4 Energy balance for the calibrated obstruction flow meter............................ 26

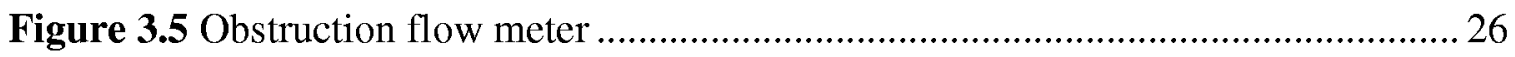

Figure 3.6 Microchannels from Hydro Aluminum ................................................... 27

Figure 3.7 Schematic of a microchannel unit slab ............................................... 28

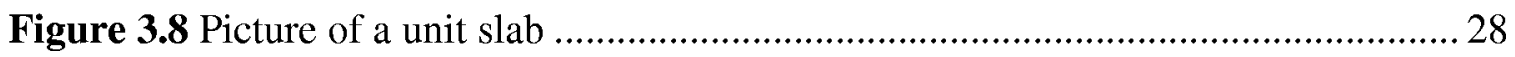

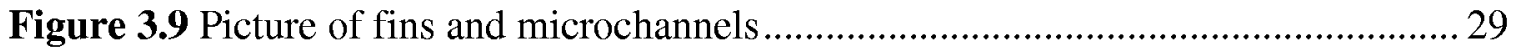

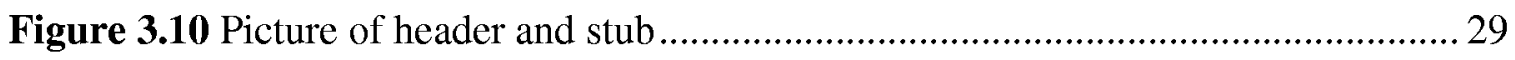

Figure 3.11 Schematic of the evaporator stack layout .......................................... 30

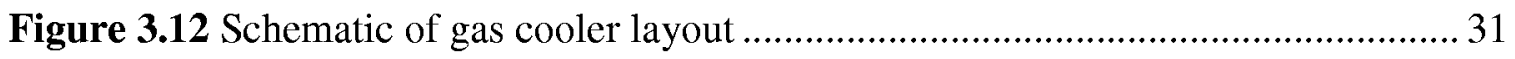

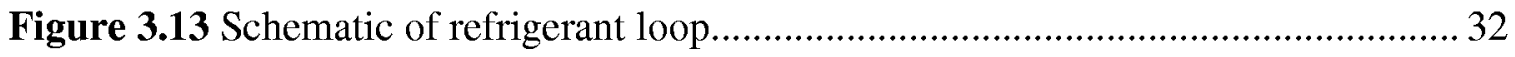

Figure 3.14 A photograph of the Dorin semi-hermetic $\mathrm{CO}_{2}$ compressor........................ 33

Figure 3.15 Screen shot of the data acquisition program written for the system ............ 35

Figure 3.16 Deviations between upstream average temperature and downstream average

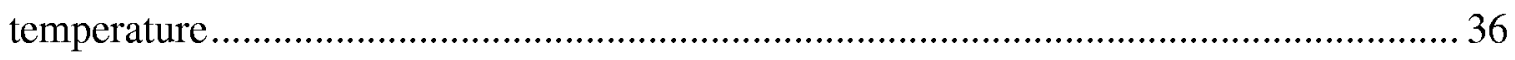

Figure 4.1 Energy balance for evaporation test results .......................................... 45

Figure 4.2 Capacity of the evaporator vs. $\mathrm{CO}_{2}$ mass flow rate (MFR) ....................... 46

Figure 4.3 Overall heat transfer coefficient vs. air flow rate (AFR) ........................... 48 
Figure 4.4 Ratio of latent heat to total heat of air side vs. air flow rate (AFR) .............. 48

Figure 4.5 Overall heat transfer coefficient vs. air flow rate (AFR) ............................. 49

Figure 4.6 Ratio of latent heat to total heat of air side vs. air flow rate (AFR) ................50

Figure 4.7 Pressure drop of air vs. air flow rate .................................................... 50

Figure 4.8 Pressure drop of air vs. air flow rate ................................................... 51

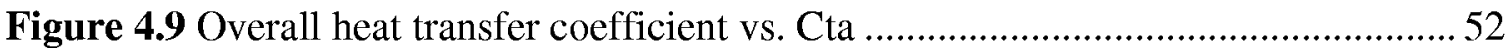

Figure 4.10 Overall heat transfer coefficient vs. Bta ........................................... 53

Figure 4.11 Comparison between the model predictions and experimental results.........54

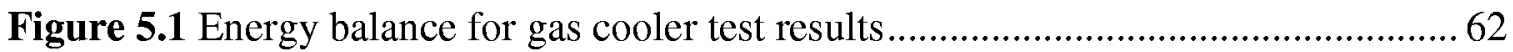

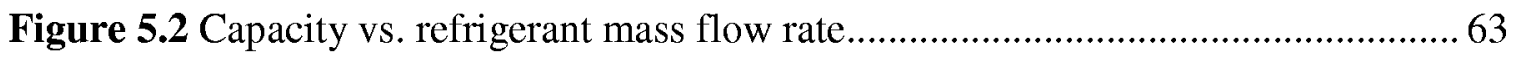

Figure 5.3 Typical temperature profiles of air stream and refrigerant ......................... 64

Figure 5.4 Typical heat transfer rate profile for each HX unit............................... 65

Figure 5.5 Percentage of heat transferred by each HX vs. refrigerant inlet pressure...... 66

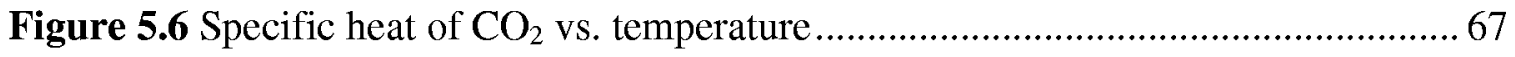

Figure 5.7 Heat transfer effectiveness vs. number of HXs ....................................69

Figure 5.8 Heat transfer effectiveness vs. number of $\mathrm{HXs}$ for a $\mathrm{CO}_{2}$ pressure of $7 \mathrm{MPa} 70$

Figure 5.9 Heat transfer effectiveness vs. number of HXs for Serial No. 1 condition .... 71

Figure 5.10 Air side pressure drop as a function of air velocity ................................. 72

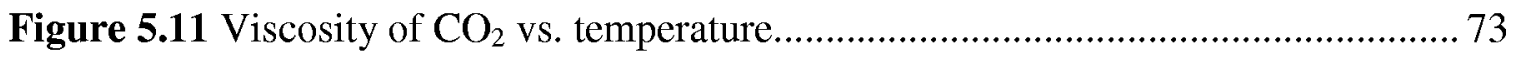

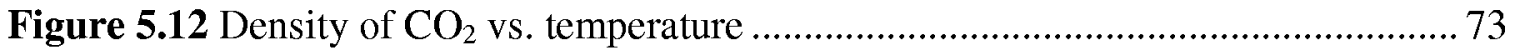

Figure 5.13 Predicted effectiveness vs. number of HX...................................... 76

Figure 5.14 Predicted effectiveness vs. number of HX........................................ 77

Figure 5.15 Comparison between the model predictions and experimental results ........ 77 
Figure 6.1 Schematic diagram of the proposed header design ................................... 82

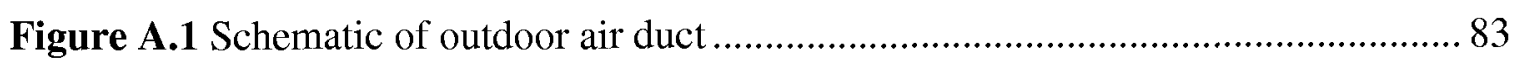

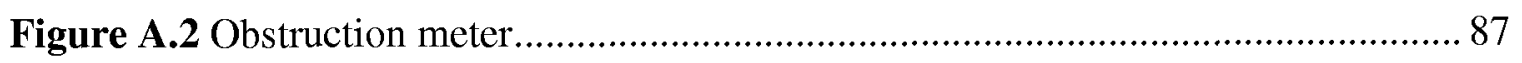

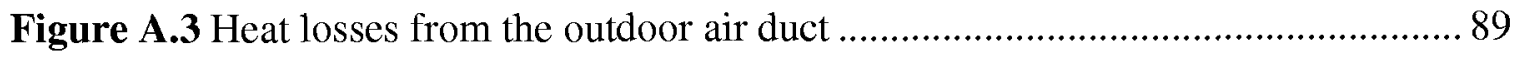

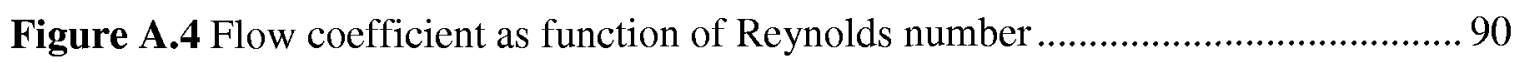

Figure A.5 Comparison between the heating determined by air and by heaters $(Q=2.2$

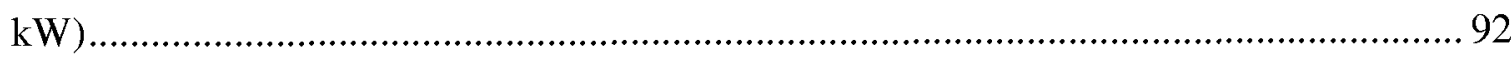

Figure A.6 Comparison between the heating determined by air and by heaters $(\mathrm{Q}=1.5$

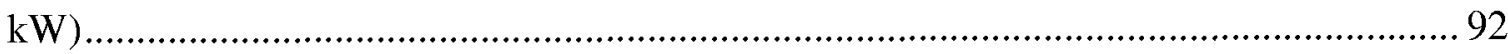

Figure A.7 Comparison between the heating determined by air and by heaters after

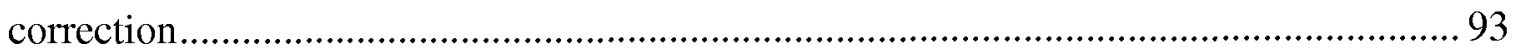

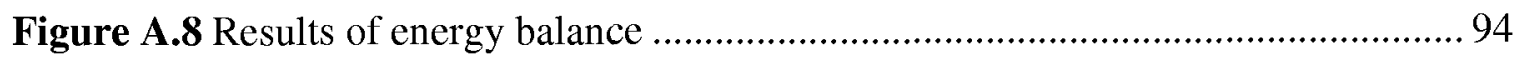

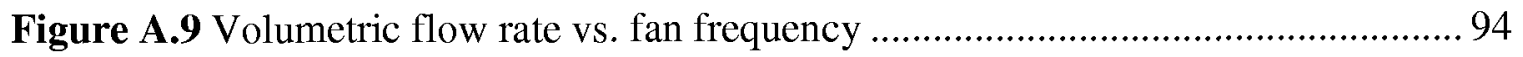




\section{NOMENCLATURE}

A surface area, $\mathrm{m}^{2}$

AFR air flow rate, $\mathrm{m}^{3} / \mathrm{h}$

Bta superheat related factor, Bta $=\frac{T_{r e f-o u t}-T_{r e f-s a t}}{T_{a i r-i n-d r y}-T_{r e f-s a t}}$

C specific heat, $\mathrm{kJ} / \mathrm{kgK}$

Cta moisture condensate factor, $C t a=\frac{T_{a i r-i n-d e w}-T_{r e f-s a t}}{T_{a i r-i n-d r y}-T_{r e f-s a t}}$

$D \quad$ diameter, $\mathrm{m}$

$\mathrm{D}_{\mathrm{h}} \quad$ hydraulic diameter, $\mathrm{m}$

DP pressure drop, $\mathrm{kPa}$

DT temperature difference, ${ }^{\circ} \mathrm{C}$

eff heat exchanger effectiveness

$G$ mass flux, $\mathrm{kg} / \mathrm{m}^{2} \mathrm{~s}$

$h \quad$ specific enthalpy, $\mathrm{kJ} / \mathrm{kg}$

$h_{f g} \quad$ latent heat, $\mathrm{kW} / \mathrm{kg}$

$j \quad$ fin related coefficient

k thermal conductivity, $\mathrm{W} / \mathrm{mK}$

K flow coefficient

$L \quad$ length, $\mathrm{m}$

LMTD log mean temperature difference

$\dot{\mathrm{m}}$ mass flow rate, $\mathrm{kg} / \mathrm{s}$

MFR mass flow rate of refrigerant, gr/s

$N T U$ number of exchanger heat transfer units

$\mathrm{Nu} \quad$ Nusselt Number, $(\mathrm{hD} / \mathrm{k})$

$\mathrm{P}$ pressure, $\mathrm{kPa}$

Pr Prant Number

$Q \quad$ rate of heat transfer, $\mathrm{kW}$

Re Reynolds Number, (GD/ $\mu$ ) 


$$
\begin{array}{ll}
S & \text { specific entropy, } \mathrm{kJ} / \mathrm{kgK} \\
S t & \text { Stanton Number, } \mathrm{Nu} /(\mathrm{Re} \cdot \mathrm{Pr}) \\
\mathrm{T} & \text { temperature, }{ }^{\circ} \mathrm{C} \\
U & \text { overall heat transfer coefficient, } \mathrm{W} / \mathrm{m}^{2} \mathrm{~K} \\
\mathrm{x} & \text { vapor quality } \\
Z & \text { capacity rate ratio }
\end{array}
$$

\section{Greek Symbols}

$$
\begin{array}{cc}
\mu & \text { viscosity, } \mathrm{Pa} \cdot \mathrm{s} \\
\beta & \text { Diameter ratio } \\
\delta & \text { fin spacing, } \mathrm{m} \\
\rho & \text { density, } \mathrm{kg} / \mathrm{m}^{3}
\end{array}
$$

\section{Subscripts}

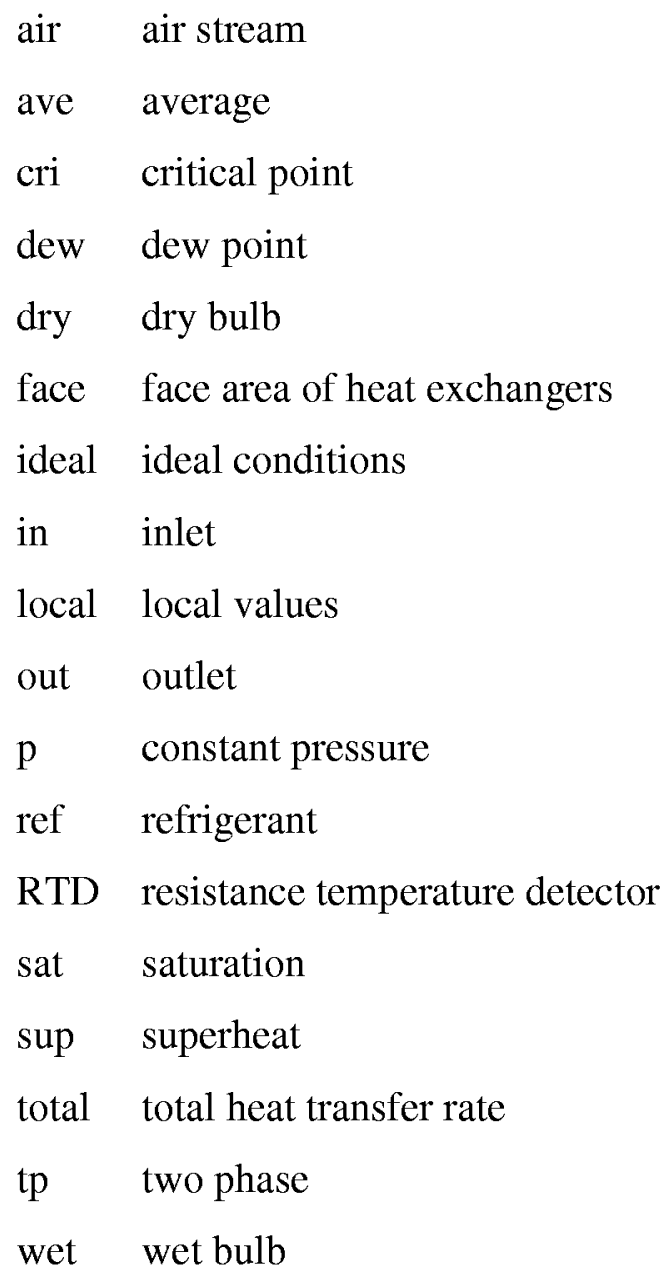




\section{CHAPTER 1 INTRODUCTION}

The objective of the present study was to determine the performance of $\mathrm{CO}_{2}$ microchannel evaporators and gas coolers in operational conditions representing those of residential heat pumps.

A set of breadboard prototype microchannel evaporators and gas coolers was developed and tested. The refrigerant in the heat exchangers followed a counter crossflow path with respect to the airflow direction. The test conditions corresponded to the typical operating conditions of residential heat pumps. Capacity and pressure drop of the evaporator and gas cooler for the range of parameters studied were analyzed and are documented in this report. Semi-empirical models wee also developed for prediction of $\mathrm{CO}_{2}$ evaporator and gas cooler capacities. The experimental results are discussed in this report. This chapter presents an overview of natural refrigerants.

\subsection{Phase-out of Refrigerants}

Refrigerants are the working fluids in refrigeration, air-conditioning, and heat pump systems. An "ideal" refrigerant is chemically stable and inert, has excellent thermal and fluid flow characteristics, is compatible with common materials, is soluble in lubricating oils, is nontoxic, nonflammable, has low cost, and is environmentally acceptable. Since no single fluid meets all these attributes, a variety of refrigerants have been developed and applied in HVAC\&R systems.

The Montreal Protocol is an international treaty that controls the production of ozone-depleting substances, including refrigerants containing chlorine and/or bromine 
(U.N. 1994, 1996). The first version of the Protocol was signed September 16, 1987, by the European Economic Community (currently the European Union) and 24 nations, including the United States. As described in Chapter 18 of the ASHRAE Handbook of Fundamentals (2001), the Montreal Protocol was enacted on January 1, 1989, and limits the 1998 production of specified carbofluorocarbons (CFCs) to $50 \%$ of their 1986 levels. Starting in 1992, the production of specified halons (including R-13B1) was frozen at 1986 levels. Developing countries were granted additional time to meet these deadlines.

On June 14, 1994, the Copenhagen Amendment to the Montreal Protocol, ratified by 58 parties, was enacted. It called for a complete cessation of the production of CFCs by January 1, 1996, and of halons by January 1, 1994. Continued use from the existing (reclaimed or recycled) stock is permitted. Allowance is also provided for continued production for very limited "essential uses." In addition, hydrocarbofluorocarbons (HCFCs, including R-22) are to be phased out--according to a 1989 reference level for developed countries. Production was frozen at the reference level on January 1, 1996. Production will be limited to $65 \%$ of the reverence level by January 1, 2004; to $35 \%$ by January 1,2010 ; to $10 \%$ by January 1,2015 ; and to $0.5 \%$ of the reference level by January 1,2020 . Complete cessation of the production of HCFCs is called for by January 1, 2030. In addition to the international agreement, individual countries may have domestic regulations for ozone-depleting compounds.

The production and use of hydrofluorocarbon (HFC) refrigerants (such as R-32, $\mathrm{R}-125$, R-134a, and R-143a and their mixtures) are not regulated by the Montreal Protocol because they are not considered ozone depleting compounds. However, HFCs do have global warming potential because of their carbon content. Some individual 
countries are beginning to regulate HFCs. Denmark, for example, is moving away from the use of HFC refrigerants. These facts indicate that the extensive use of synthetic refrigerants may be limited in the future and therefore should be used with caution. They also suggest that an alternative to HFC refrigerants could be useful if, in the future, these are phased out.

\subsection{The Natural Refrigerants}

"Natural refrigerants" refer to those naturally occurring substances, such as air, ammonia, carbon dioxide, isobutane, propane, and water. An overview of selected natural refrigerants is provided in Table 1.1. Since these substances are naturally occurring in our atmosphere, the use of these substances is expected to have minimal adverse effects on the environment.

The original application of natural refrigerants dates back to the middle of the nineteenth century when Linde, Perkins, Harrison, and others introduced pioneering refrigeration systems. In 1834, Perkins introduced the first refrigerant, sulfuric ether. From the 1840s through 1920s, the main refrigerants in practical use were ammonia $\left(\mathrm{NH}_{3}\right)$ for large and medium size stationary systems, sulfur dioxide $\left(\mathrm{SO}_{2}\right)$ for household refrigerators and small commercial plants, and carbon dioxide $\left(\mathrm{CO}_{2}\right)$ for ship installations, with brine as a secondary refrigerant. $\mathrm{CO}_{2}$ was also often used in stationary systems (Elefsen et al., 1995).

Midgley and Henne (1930) published papers on fluorochemical refrigerants as a result of searching for stable, nontoxic, nonflammable, efficient refrigerants. In 1931, dichlorodifluoromethane, CFC-12, was commercially produced (Downing, 1966). After 
the introduction of fluorochemical refrigerants, the early refrigerants, including $\mathrm{CO}_{2}$, were replaced by many other CFCs, and later HCFCs. This course of action led to a drastic decline in the use of refrigerants other than CFCs and HCFCs after World War II. Only ammonia remained in use, though it was predominantly used only in large industrial systems.

Ohadi and Mo (1998) conducted a detailed review of natural refrigerants. The role of natural refrigerants in preventing or mitigating the problems associated with global warming and ozone depletion was addressed. Thermophysical properties and cycle performance of selected natural refrigerants were discussed and compared with their counterpart HCFC and HFC refrigerants. It was concluded that while HFC blends have been able to address acceptable Ozone Depletion Potential (ODP), their Global Warming Potential (GWP) is high enough to warrant a continued search for environmentally friendly refrigerants. The use of natural refrigerants appears to be one solution to this problem for immediate, as well as future applications. Research work on natural refrigerants is receiving renewed attention. 
Table 1.1 Overview of selected natural refrigerants

\begin{tabular}{|c|c|c|c|}
\hline Refrigerant & General Characteristics & Major Advantages & Major Disadvantages \\
\hline $\begin{array}{l}\text { Ammonia } \\
\left(\mathrm{NH}_{3}\right)\end{array}$ & $\begin{array}{l}\text { Ammonia is a well-known } \\
\text { refrigerant in large scale } \\
\text { industrial refrigeration } \\
\text { plants. It has been used as a } \\
\text { refrigerant for more than } 120 \\
\text { years, but until now it has } \\
\text { not been widely used in } \\
\text { small plants. }\end{array}$ & $\begin{array}{l}\text {-More than } 120 \text { years of practical } \\
\text { use } \\
\text {-Excellent thermodynamic and } \\
\text { thermophysical properties } \\
\text {-Higher energy efficiency in most } \\
\text { temperature ranges } \\
\text {-Well known oil tolerance } \\
\text {-Great tolerance to water } \\
\text { contamination } \\
\text {-Simple and immediate leak } \\
\text { detection } \\
\text {-No ODP or GWP } \\
\text {-Lower cost } \\
\text {-Smaller pipe dimensions leading } \\
\text { to lower plant investments }\end{array}$ & $\begin{array}{l}\text {-Toxic at low } \\
\text { concentrations in air } \\
\text { (above 500ppm) } \\
\text {-No tolerance to some } \\
\text { materials, e.g. copper } \\
\text {-No miscibility with } \\
\text { most known oils } \\
\text {-High discharge } \\
\text { temperatures } \\
\text {-Flammable at } 15-30 \% \\
\text { Vol. }\end{array}$ \\
\hline $\begin{array}{l}\text { Water } \\
\left(\mathrm{H}_{2} \mathrm{O}\right)\end{array}$ & $\begin{array}{l}\text { Environmentally attractive, } \\
\text { water has potential as a long- } \\
\text { term acceptable refrigerant. } \\
\text { Water offers high plant } \\
\text { energy efficiency. }\end{array}$ & $\begin{array}{l}\text {-Higher Carnot COP due to the } \\
\text { use of direct heat exchanger } \\
\text {-High mechanical efficiency of } \\
\text { compressor } \\
\text {-Production of vacuum ice } \\
\text {-Low energy consumption } \\
\text {-No ODP or GWP }\end{array}$ & $\begin{array}{l}\text {-Process under vacuum } \\
\text {-Good only for cooling/ } \\
\text { refrigeration above } 0^{\circ} \mathrm{C}\end{array}$ \\
\hline $\begin{array}{l}\text { Carbon } \\
\text { Dioxide } \\
\left(\mathrm{CO}_{2}\right)\end{array}$ & $\begin{array}{l}\text { In recent years, after the } \\
\text { Montreal Protocol, much } \\
\text { development activity has } \\
\text { been devoted to } \mathrm{CO}_{2} \text { as a } \\
\text { refrigerant. This } \\
\text { development is based on new } \\
\text { material technology which } \\
\text { allows high pressures in the } \\
\text { thermodynamic cycle. } \mathrm{CO} 2 \\
\text { is quite harmless; it is } \\
\text { environmentally attractive, } \\
\text { and is neither toxic, } \\
\text { flammable nor explosive. }\end{array}$ & $\begin{array}{l}\text {-Low weight and small } \\
\text { dimensions of plant } \\
\text {-Large refrigeration capacity } \\
\text {-Tolerance with well known oils } \\
\text {-Low compression ratio } \\
\text {-Low environmental impact } \\
\text {-Low price, ample supply }\end{array}$ & $\begin{array}{l}\text {-High pressure } \\
\text {-Low critical } \\
\text { temperature }\left(31^{\circ} \mathrm{C}\right)\end{array}$ \\
\hline $\begin{array}{l}\text { Hydro- } \\
\text { carbons }\end{array}$ & $\begin{array}{l}\text { The measures taken to find } \\
\text { suitable "natural" } \\
\text { refrigerants as substitutes for } \\
\text { CFC and HCFC have called } \\
\text { attention to two } \\
\text { hydrocarbons (propane and } \\
\text { isobutane) that have } \\
\text { properties similar to the most } \\
\text { widely used CFCs and } \\
\text { HCFCs. }\end{array}$ & $\begin{array}{l}\text {-Compatible with materials } \\
\text { normally used in refrigeration } \\
\text { plants, such as copper and } \\
\text { mineral oil } \\
\text {-Similar physical properties to } \\
\text { CFC-12 (isobutane) and HCFC- } \\
22 \text { (propane) } \\
\text {-Small amount of refrigerant } \\
\text { needed } \\
\text {-Lower prices than HFCs } \\
\text {-Low environmental impact }\end{array}$ & $\begin{array}{l}\text {-Flammable at } \\
\text { concentration of } 1-10 \% \\
\text { v/v (requires additional } \\
\text { safety measures) } \\
\text {-Smaller volumetric } \\
\text { cooling capacity }\end{array}$ \\
\hline
\end{tabular}




\subsection{Carbon Dioxide as Working Fluid}

The development of refrigeration systems using $\mathrm{CO}_{2}$ as a refrigerant dates back to 1866 when Thaddeus created an ice production machine using $\mathrm{CO}_{2}$ (Thevenot, 1979). In 1880, Windhausen designed the first $\mathrm{CO}_{2}$ compressor (Gosman, 1927). After the late 1800 s, the use of $\mathrm{CO}_{2}$ refrigeration systems increased. As a result of continuous efforts to improve efficiency, two-stage $\mathrm{CO}_{2}$ machines were developed in 1889 in Great Britain (Thevnot, 1979). Later, the multiple-effect $\mathrm{CO}_{2}$ cycle was developed by Voorhess in 1905 (Thevenot, 1979).

Although the use of $\mathrm{CO}_{2}$ as a refrigerant declined drastically in the 1930s due to the appearance of $\mathrm{CFCs}$ and $\mathrm{HCFCs}, \mathrm{CO}_{2}$ as a natural and environmentally favorable refrigerant has gained more attention recently. One of the solutions to minimize ozone depletion and global warming concerns is the use of natural refrigerants. Hydrofluorocarbons (HFCs) are replacement candidates, but have the disadvantages of relatively high GWP, high cost, and unresolved issues regarding environmental impact. Natural refrigerants, such as $\mathrm{NH}_{3}$ and $\mathrm{CO}_{2}$, have a low GWP, no ODP, and no adverse environmental effects (Lorentzen, 1995). Its low toxicity, nonflammability, and low cost make $\mathrm{CO}_{2}$ the preferred refrigerant when compared with $\mathrm{NH}_{3}$.

In addition to its environmental advantages, $\mathrm{CO}_{2}$ offers certain attractive thermal characteristics. General physical and chemical properties of $\mathrm{CO}_{2}$, as well as comparisons with those of other refrigerants, are listed in Chapter 18 of the ASHRAE Handbook of Fundamentals (1997). The thermophysical properties listed include the standard designation of characteristic properties, such as molecular mass, critical points, etc. Electrical properties, performance comparisons with other refrigerants, a safety 
classification, and $\mathrm{CO}_{2}$ 's effect on several other materials are also provided. A brief chart and a saturated table of thermodynamic properties are given in Chapter 19 of the ASHRAE Handbook of Fundamentals (1997).

As a refrigerant, $\mathrm{CO}_{2}$ offers more variation in thermodynamic and transport properties than other conventional refrigerants, as mentioned by Devotta et al. (2000). Since the critical temperature of $\mathrm{CO}_{2}$ is $31^{\circ} \mathrm{C}$ for air-conditioning applications, the heat rejection above $31^{\circ} \mathrm{C}$ is not by condensation, as in conventional systems, which will necessarily lead to some changes in system design. Due to its higher volumetric capacity, which is five times higher than that of HCFC-22, the size of the system can be reduced considerably.

Some important thermophysical properties of $\mathrm{CO}_{2}$ and comparisons with R-134a are listed in Table 1.2. Carbon dioxide has a much smaller surface tension and liquid viscosity than R-134a. Lower surface tension facilitates bubble formation, thus resulting in higher heat transfer coefficients. Lower liquid viscosity causes a smaller pressure drop when $\mathrm{CO}_{2}$ flows in a tube or channel.

Table 1.2 Thermophysical properties of $\mathrm{CO}_{2}$ and R-134a at $5 / 10 / 15{ }^{\circ} \mathrm{C}$

\begin{tabular}{|l|l|l|}
\hline Refrigerant & $\mathrm{CO}_{2}$ & $\mathrm{R}-134 \mathrm{a}$ \\
\hline $\mathrm{P}_{\text {sat }}(\mathrm{MPa})$ & $3.969 / 4.502 / 5.086$ & $0.350 / 0.414 / 0.488$ \\
\hline Latent Heat $(\mathrm{kJ} / \mathrm{kg})$ & $214.6 / 196.8 / 176.2$ & $194.8 / 190.9 / 186.7$ \\
\hline Surface Tension $(\mathrm{mN} / \mathrm{m})$ & $3.53 / 2.67 / 1.88$ & $11.0 / 10.3 / 9.6$ \\
\hline Liq. Density $\left(\mathrm{kg} / \mathrm{m}^{3}\right)$ & $899.6 / 861.5 / 821.3$ & $1277.1 / 1260.2 / 1242.8$ \\
\hline Vap. Density $\left(\mathrm{kg} / \mathrm{m}^{3}\right)$ & $114.8 / 135.3 / 161.0$ & $17.1 / 20.2 / 23.7$ \\
\hline Liq. Viscosity $(\mu \mathrm{Pa} \cdot \mathrm{s})$ & $95.9 / 86.7 / 77.2$ & $270.3 / 254.3 / 239.7$ \\
\hline Vap. Viscosity $(\mu \mathrm{Pa} \cdot \mathrm{s})$ & $15.4 / 16.1 / 17.0$ & $11.2 / 11.4 / 11.7$ \\
\hline Liq. $\mathrm{C}_{\mathrm{p}}(\mathrm{kJ} / \mathrm{kg} \cdot \mathrm{K})$ & $2.73 / 3.01 / 3.44$ & $1.35 / 1.37 / 1.38$ \\
\hline Vap. $\mathrm{C}_{\mathrm{p}}(\mathrm{kJ} / \mathrm{kg} \cdot \mathrm{K})$ & $2.21 / 2.62 / 3.30$ & $0.91 / 0.93 / 0.96$ \\
\hline
\end{tabular}




\subsection{Benefits}

The research work preformed here will provide a design methodology platform for enhanced/compact heat exchangers for high pressure working fluids such as $\mathrm{CO}_{2}$. The research results will have significant effects on the heat exchanger industries, from design and manufacturing/operation to integration in practical $\mathrm{CO}_{2}$ systems. The findings in this study will contribute to the development and production of a new generation of high performance heat exchangers that are suitable for high pressure refrigerants such as $\mathrm{CO}_{2}$, while offering significantly reduced size, weight, and consumed materials for the heat exchanger. A more in-depth understanding of the corresponding heat transfer and pressure drop phenomena and their empirical modeling is another inherent benefit of this research. 


\section{CHAPTER 2 RESEARCH BACKGROUND}

This chapter presents a brief review of the fundamentals of heat transfer in boiling and an extensive overview of the prior research efforts that have been conducted to investigate the heat transfer characteristics of pure refrigerant and refrigerant/oil mixtures in smooth tubes, enhanced tubes, and microchannels.

\subsection{Previous Studies on $\mathrm{CO}_{2}$ Heat Transfer}

The open literature on $\mathrm{CO}_{2}$ heat transfer is limited. Bredesen et al. (1997) investigated flow boiling of $\mathrm{CO}_{2}$ in a smooth tube. The test section was a $7 \mathrm{~mm}$-diameter aluminum tube with direct heating. Temperatures were measured at 10 different positions and the local heat transfer coefficient was calculated. Bredesen et al. found that $\mathrm{CO}_{2}$ has a much higher heat transfer coefficient and much lower pressure drop than that experienced with halocarbons. In addition, their experimental results showed that as the heat flux was increased, the heat transfer coefficient increased considerably without pressure loss penalty. Moreover, high heat transfer coefficients could be obtained even with smaller mass flux and pressure drop. However, the explanation of this unexpected phenomenon was unconvincing in the paper.

Based on the experimental results of Bredesen et al. (1997), Hwang et al. (1997) investigated the applicability of six commonly used empirical correlations reported by Chen (1966), Bennett-Chen (1980), Gungor-Winston (1987), Shah (1976), SchrockGrossman (1959), and Liu-Winteron (1991). It was found that the correlations had a large deviation (from $20 \%$ to $80 \%$ ) when predicting the boiling heat transfer coefficient of $\mathrm{CO}_{2}$. Hwang et al. proposed a new empirical model, the Modified Bennett-Chen 
correlation, for $\mathrm{CO}_{2}$ flow boiling in horizontal smooth tubes. They claimed that the new correlation could predict the heat transfer coefficients, consistent with Bredesen's results, to within a mean deviation of $14 \%$.

Zhao et al. (1997) studied the boiling heat transfer characteristics of ammonia and $\mathrm{CO}_{2}$ in horizontal smooth tubes. The test section was a tube with an inner diameter of $5.44 \mathrm{~mm}$ and a length of $1.78 \mathrm{~m}$. A water-heating method was applied, and the average heat transfer coefficient was determined. Zhao et al. reported a slightly smaller heat transfer coefficient compared to that of Bredesen et al. (1997). The deviation between the two results could be due to different thermal-boundary conditions, i.e. constant heat flux vs. the convection boundary condition, and different boiling temperatures. Their results, however, showed the same trend as Bredesen's data. They also compared the typical values of the heat transfer coefficient of $\mathrm{CO}_{2}$ with those for R-134a, R-12, and R-22, and found that the transfer coefficient of $\mathrm{CO}_{2}$ is substantially higher.

Olson and Allen (1998) investigated the heat transfer characteristics of supercritical $\mathrm{CO}_{2}$ in turbulent flow in a heated horizontal tube. The tested tube was 10.9 $\mathrm{mm} \mathrm{ID} \mathrm{and} \mathrm{was} \mathrm{heated} \mathrm{over} \mathrm{a} \mathrm{length} \mathrm{of} 2.47 \mathrm{~m}$. Operating pressure was varied from 7.8 $\mathrm{MPa}$ to $13.1 \mathrm{MPa}$. It was found that the measured Nusselt number agreed with the constant-property Petukhov-Gnielinski correlation for turbulent tube flow to within $6.6 \%$ at high operation pressure. As the pressure was reduced toward the critical pressure (7.38 $\mathrm{MPa}$ ), the measured Nusselt number diverged from the constant-property correlation. At low pressures, the heat transfer coefficient increased with increasing mass flux and/or heat flux. 
A review of the existing literature on $\mathrm{CO}_{2}$ studies indicates that most of the $\mathrm{CO}_{2}$ research studies conducted so far have been focused on heat exchanger design for heat pumps or refrigerators. This fact indicates that experimental investigation of the heat transfer coefficient and the modeling of $\mathrm{CO}_{2}$ has received less attention.

\subsection{Previous Studies on Microchannel Heat Transfer}

Heat transfer and fluid flow in microchannels have wide practical applications in highly specialized fields, such as bioengineering, microfabricated fluidic systems, and microelectronics. Lately, microchannels have been intensively used by the automotive air conditioning industry. The advantage of the microchannel lies in its high heat transfer coefficient and significant potential in decreasing the size of heat exchangers. Microchannels have almost completely replaced circular tubes in automotive condensers and have recently become the subject of study for automotive evaporators.

Compared with channels of normal size, microchannels have many heat transfer advantages. Since microchannels have an increased heat transfer surface area and a large surface-to-volume ratio, they provide a much higher heat transfer. This feature allows heat exchangers to become compact and light-weight. In addition, microchannels can support high heat flux with small temperature gradients. However, microchannels also have weaknesses, such as large pressure drop, high cost of manufacture, dirt clogging, and flow mal-distribution, especially for two-phase flows.

The hydraulic diameters of microchannels are quite small, typically $1 \mu \mathrm{m}$ to 2000 $\mu \mathrm{m}$, and the fluid flow and heat transfer in microchannels are expected to be, in some cases, substantially different from those encountered in the normal-sized tubes and 
channels. A review of microchannel heat transfer indicates that the previous studies can be divided into single-phase and two-phase (condensation and evaporation) forced convection. In two-phase flows, the studies are concentrated on heat transfer coefficient, pressure drop, and critical heat flux.

Wang and Peng (1994), Peng and Wang (1994), and Peng et al. (1996, 1998) performed a series of tests on rectangular microchannels (with hydraulic diameters of $0.133-0.747 \mathrm{~mm}$ ) machined into stainless steel plates. They found that the flow transition for single-phase flow occurred at a Reynolds number $\left(\operatorname{Re}=\rho \mathrm{uD}_{\mathrm{h}} / \mu\right)$ of $200-$ 700. This critical Re for the flow transition was strongly affected by the hydraulic diameter of the microchannel, and it decreased for smaller hydraulic diameters. In addition, the range of flow transition was diminished and the fully developed turbulent flow occurred at a much lower Re. For flow boiling in microchannels, the small size of the microchannel resulted in a dramatically higher heat flux for liquid nucleation when the microchannel was sufficiently small. However, microchannel size, flow velocity, and inlet sub-cooling temperature had no significant effect on the heat transfer coefficient in the fully nucleate boiling regime.

Ravigururajan et al. $(1996,1998)$ studied the impact of size and geometry of microchannels on their heat transfer characteristics. For single-phase flow, they found that microchannels provided significantly higher heat transfer coefficients. They indicated that the higher heat-transfer coefficients might be attributed to the thinning of the boundary layer in the microchannels, although the use of microchannels increased the surface area significantly. They also found that parallel geometry microchannels could give a better heat transfer coefficient than diamond geometry microchannels. For flow 
boiling, they inferred that the large number of channels per unit width (e.g. typically 25 or more channels per inch) results in a significantly higher heat transfer area. The twophase flow heat transfer coefficients strongly depend on the channel's geometry, surface, and shape. The heat transfer coefficient decreases with increasing saturation temperature, and the pressure drop increases with increasing heat flux.

Tran et al. (1996) investigated laminar and turbulent boiling heat transfer in small circular and rectangular channels. They found that for wall superheats larger than $2.75^{\circ} \mathrm{C}$, the nucleate boiling mechanism dominates the forced convection effect. Yang and Webb (1996) compared commonly used correlations with their experimental results. They found that Shah's (1979) correlation overpredicts the heat transfer coefficient, and that the correlation by Akers et al. (1959) is suitable for small mass fluxes. They also indicated that pressure drop increases with increasing mass flux and heat flux. Surface tension was found to play an important role in heat transfer.

Bau (1998) numerically investigated the optimization of channel shape in micro heat exchangers. An approximate theory was derived to compute the thermal resistance of flat-plate micro heat exchangers whose surfaces are heated with uniform flux. It was demonstrated that the thermal resistance could be minimized by proper selection of uniform channel geometry. The maximum hot surface temperature and its gradient could be further reduced by changing the channel cross-sectional dimensions as a function of the axial coordinate.

Tong et al. (1997) studied pressure drop with highly subcooled flow boiling in small-diameter tubes. In designing heat-removal systems utilizing high-heat-flux subcooled boiling, pressure drop is an important consideration. Tong et al. performed an 
experimental investigation to identify the important parameters affecting pressure drop across small-diameter tubes in highly subcooled flow boiling. The effects of mass flux, inlet temperature, exit pressure, tube internal diameter, and length-to-diameter ratio on both single and two-phase pressure drop were studied and evaluated. The experimental results indicated that mass flux, tube diameter, and length-to-diameter ratio were the major parameters that altered the pressure-drop curves. Both single- and two-phase pressure drops increased with increasing mass flux and length-to-diameter ratio, but decreased with increasing internal diameter. Inlet temperature and exit pressure were shown to have a significant effect on two-phase pressure drop but a negligible effect on single-phase pressure drop.

Tables 2.1 and 2.2 summarize the studies of fluid flow and heat transfer in microchannels. A review of the single-phase and two-phase heat transfer characteristics in microchannels indicates that the two-phase heat transfer in microchannels is superior to single-phase. As indicated by Bowers and Mudawar (1994), single-phase microchannel heat exchangers react to high surface heat fluxes by a large stream-wise increase in coolant temperature, and a corresponding stream-wise increase in the heat sink temperature. This temperature increase is often detrimental to temperature-sensitive devices, such as electronic components. Two-phase heat sinks, on the other hand, rely mainly on latent heat, and maintain a stream-wise uniform coolant and heat sink temperature at a level set by the coolant saturation temperature. To diminish the detrimental effect of a stream-wise temperature increase, microchannel heat sinks that operate in single-phase often need a large flow rate. Two-phase heat sinks, on the other hand, utilize the latent heat of liquid evaporation, and require minimal coolant flow rates. 
However, since flow boiling has a critical heat flux, if the applied heat flux exceeds the critical heat flux, the dry-out phenomenon may occur. Under dry-out conditions, the heat transfer coefficient will be dramatically reduced, resulting in a rapid increase in wall temperature. Therefore, in two-phase microchannel heat sinks, a safety factor should be considered. 
Table 2.1 Summary of studies on single-phase flow in microchannels

\begin{tabular}{|c|c|c|c|}
\hline Investigator & $\begin{array}{l}\text { Channel } \\
\text { Geometry and } \\
\text { Size }(\mu \mathrm{m})\end{array}$ & $\begin{array}{l}\text { Reynolds } \\
\text { Number, } \\
\text { Fluid } \\
\end{array}$ & Remarks \\
\hline Lancet, 1959 & Gap: 580 to 640 & $\begin{array}{l}8,000- \\
40,000, \text { air }\end{array}$ & $\begin{array}{l}\text { Experimental } \mathrm{f} \text { is much larger than the } \\
\text { correlation prediction value up to } 100 \%\end{array}$ \\
\hline $\begin{array}{l}\text { Gambill and } \\
\text { Bundy, } 1961\end{array}$ & $\begin{array}{l}\text { Rectangular } \\
\text { channel } \\
\mathrm{D}_{\mathrm{h}}: 1910-2670\end{array}$ & $\begin{array}{l}9,000- \\
270,000 \\
\text { water }\end{array}$ & $\begin{array}{l}\text { - Experimental } \mathrm{f} \text { matches correlation prediction } \\
\text { - Experimental } \mathrm{Nu} \text { is only slightly smaller than } \\
\text { correlation prediction }\end{array}$ \\
\hline $\begin{array}{l}\text { Wu and Little, } \\
1983\end{array}$ & $\begin{array}{l}\text { Trapezoidal } \\
\text { channel } \\
D_{\mathrm{h}}: 56-83\end{array}$ & $\begin{array}{l}100- \\
15,000, \mathrm{~N}_{2} \\
\mathrm{H}_{2}, \mathrm{Ar}\end{array}$ & $\begin{array}{l}\text { - } \\
\text { - Criction factor depends on roughness } \\
\text { roughness }(350<\operatorname{Re}<900) \\
\text { Experimental } \mathrm{f} \text { is larger than correlation's } \\
\text { prediction }\end{array}$ \\
\hline $\begin{array}{l}\text { Wu and Little, } \\
1984\end{array}$ & $\begin{array}{l}\text { Trapezoidal } \\
\text { channel } \\
\mathrm{D}_{\mathrm{h}}: 56-83\end{array}$ & $\begin{array}{l}400- \\
15,000, \mathrm{~N}_{2}\end{array}$ & $\begin{array}{l}\text { - Critical Re from } 1000 \text { to } 3000 \\
\text { - Turbulent Nu higher than standard correlation } \\
\text { prediction } \\
\text { - Reynolds analogy not valid }\end{array}$ \\
\hline Acosta, 1985 & $\begin{array}{l}\text { Rectangular } \\
\text { channel } \mathrm{D}_{\mathrm{h}}: 960- \\
380\end{array}$ & $\begin{array}{l}500- \\
15,000 \\
\text { water }\end{array}$ & $\begin{array}{l}\text { Experimental } \mathrm{f} \text { and Nu match correlation's } \\
\text { prediction }\end{array}$ \\
\hline $\begin{array}{l}\text { Pfahler et al., } \\
1991\end{array}$ & $\begin{array}{l}\text { Trapezoidal } \\
\text { channel } \\
\mathrm{D}_{\mathrm{h}}: 0.96-39.7\end{array}$ & $0.0005-70$ & $\begin{array}{l}\text { - Experimental } \mathrm{f} \text { is slightly smaller than the } \\
\text { prediction value (by less than } 25 \% \text { ) }\end{array}$ \\
\hline $\begin{array}{l}\text { Choi et al., } \\
1991\end{array}$ & $\begin{array}{l}\text { Circular channel } \\
\mathrm{D}_{\mathrm{h}}: 3 \text { to } 81.2\end{array}$ & $20-2500$ & $\begin{array}{l}\text { - The critical Re for flow transition is } 2300 \\
\text { - For both laminar and turbulent flows, real } \mathrm{f} \text { is } \\
25 \% \text { smaller than correlation prediction } \\
\text { - Experimental } \mathrm{Nu} \text { is larger than that predicted } \\
\text { by Dittus-Boelter correlation }\end{array}$ \\
\hline $\begin{array}{l}\text { Peng and } \\
\text { Peterson, } 1996\end{array}$ & $\begin{array}{l}\text { Rectangular } \\
\text { channel } \\
\mathrm{D}_{\mathrm{hl}}: 311 \text { to } 367\end{array}$ & $\begin{array}{l}50-4000, \\
\text { water }\end{array}$ & $\begin{array}{l}\text { - Critical Re in the range of } 200 \text { to } 1500 \\
\text { - Flow transition occurs at smaller Re as the } \\
\text { size of channel is decreased } \\
\text { - Friction factor depends on the height-to-width } \\
\text { ratio of the channel. }\end{array}$ \\
\hline $\begin{array}{l}\text { Wang and } \\
\text { Peng, } 1994\end{array}$ & $\begin{array}{l}\text { Rectangular } \\
\text { channel } \\
\mathrm{D}_{\mathrm{h}}: 311 \text { to } 747\end{array}$ & $\begin{array}{l}50-4000, \\
\text { water, } \\
\text { methanol }\end{array}$ & $\begin{array}{l}\text { Experimental Nu is lower than that predicted } \\
\text { by the Dittus-Boelter correlation } \\
\text { - The critical Re is in the range of } 1000 \text { to } 1500\end{array}$ \\
\hline $\begin{array}{l}\text { Yang and } \\
\text { Webb, } 1996\end{array}$ & $\begin{array}{l}\text { Rectangular } \\
\text { channel } \\
D_{\mathrm{ll}}: 1564 \text { to } 2637\end{array}$ & $\begin{array}{l}2500- \\
25,000, \mathrm{R}- \\
12, \mathrm{R}-134 \mathrm{a}\end{array}$ & $\begin{array}{l}\text { Experimental data agree with the predictions } \\
\text { of the Petukhov correlation (within } 10 \% \text { ) }\end{array}$ \\
\hline $\begin{array}{l}\text { Webb and } \\
\text { Zhang, } 1997\end{array}$ & $\begin{array}{l}\text { Rectangular } \\
\text { channel } \\
\mathrm{D}_{\mathrm{h}}: 960 \text { to } 1310\end{array}$ & $\begin{array}{l}5000- \\
25,000, \mathrm{R}- \\
134 \mathrm{a}\end{array}$ & $\begin{array}{l}\text { - Experimental results match those predicted by } \\
\text { the Petukhov and Dittus-Boelter correlations }\end{array}$ \\
\hline $\begin{array}{l}\text { Ravigururajan } \\
\text { et al., } 1996\end{array}$ & $\begin{array}{l}\text { Rectangular } \\
\text { channel } \\
D_{\mathrm{h}}=425\end{array}$ & $\begin{array}{l}4650-3990, \\
\mathrm{R}-124\end{array}$ & $\begin{array}{l}\text { - The thinning of the boundary layer is the } \\
\text { major contributor to high heat transfer } \\
\text { coefficient. } \\
\text { Channel arrangement affects the heat transfer } \\
\text { coefficient }\end{array}$ \\
\hline $\begin{array}{l}\text { Adams et al., } \\
1998\end{array}$ & $\begin{array}{l}\text { Rectangular } \\
\text { channel } \\
\mathrm{D}_{\mathrm{h}}: 760 \text { to } 1090\end{array}$ & $\begin{array}{l}2600- \\
23,000 \\
\text { water }\end{array}$ & $\begin{array}{l}\text { Experimental } \mathrm{Nu} \text { is larger than that predicted } \\
\text { by the Gnielinski correlation, and the } \\
\text { deviation increases with increasing } \mathrm{D}_{\mathrm{h}} \text { and } \mathrm{Re}\end{array}$ \\
\hline
\end{tabular}


Table 2.2 Summary of studies on two-phase flow in microchannels

\begin{tabular}{|c|c|c|c|c|}
\hline Investigator & Approach & Fluid & $\begin{array}{l}\text { Channel } \\
\text { Geometry (mm) }\end{array}$ & Studied \\
\hline $\begin{array}{l}\text { Bowers and } \\
\text { Mudawar } \\
\text { (1994) }\end{array}$ & Experimental & R-113 & $\begin{array}{l}\text { Circular } \\
\mathrm{D}=0.51\end{array}$ & $\begin{array}{l}\text { Boiling, } \mathrm{h}, \Delta \mathrm{P} \text {, Critical Heat } \\
\text { Flux }\end{array}$ \\
\hline $\begin{array}{l}\text { Yang and Webb } \\
\text { (1996) }\end{array}$ & Experimental & $\begin{array}{l}\mathrm{R}-12, \mathrm{R}- \\
134 \mathrm{a}\end{array}$ & $\begin{array}{l}\text { Rectangular } \\
1.564<\mathrm{D}_{\mathrm{h}}<2.637\end{array}$ & $\begin{array}{l}\text { Condensation, } \mathrm{h}, \Delta \mathrm{P} \text {, } \\
\text { Correlations }\end{array}$ \\
\hline $\begin{array}{l}\text { Tran et al. } \\
\text { (1996) }\end{array}$ & Experimental & R-12, R-113 & $\begin{array}{l}\text { Circular and } \\
\text { rectangular } \\
D_{h}=2.46\end{array}$ & $\begin{array}{l}\text { Boiling, flow regime, } \\
\text { Correlations }\end{array}$ \\
\hline $\begin{array}{l}\text { Peng et al. } \\
\text { (1996) }\end{array}$ & Experimental & $\begin{array}{l}\text { Water / } \\
\text { methanol } \\
\text { mixture }\end{array}$ & $\begin{array}{l}\text { Rectangular } \\
0.133<\mathrm{D}_{\mathrm{h}}<0.367\end{array}$ & $\begin{array}{l}\text { Boiling, } h \text {, concentration of } \\
\text { mixtures, and number of } \\
\text { channels }\end{array}$ \\
\hline Kureta (1997) & Experimental & water & $\begin{array}{l}\text { Circular } \\
2.0<\mathrm{D}<6.0\end{array}$ & $\mathrm{~h}, \Delta \mathrm{P}$, and correlations \\
\hline $\begin{array}{l}\text { Tong et al. } \\
\text { (1997) }\end{array}$ & Experimental & $\mathrm{R}-134 \mathrm{a}$ & $\begin{array}{l}\text { Rectangular } \\
1.05<D_{\mathrm{h}}<2.44\end{array}$ & $\begin{array}{l}\text { Flow boiling, } \\
\Delta \mathrm{P}\end{array}$ \\
\hline $\begin{array}{l}\text { Petterson et al. } \\
\text { (1998) }\end{array}$ & Experimental & $\mathrm{CO}_{2}$ & $\begin{array}{l}\text { Microchannel heat } \\
\text { exchanger }\end{array}$ & $\begin{array}{l}\text { Overall heat transfer } \\
\text { coefficient }\end{array}$ \\
\hline $\begin{array}{l}\text { Peng et al. } \\
\text { (1998) }\end{array}$ & Numerical & $\begin{array}{l}\text { Water, } \\
\text { methanol, } \\
\text { R-12 }\end{array}$ & $\begin{array}{l}\text { Rectangular } \\
0.15<D_{\mathrm{h}}<0.646\end{array}$ & $\begin{array}{l}\text { Boiling, presence of } \\
\text { bubbles, new definitions: } \\
\text { evaporating space, } \\
\text { fictitious boiling }\end{array}$ \\
\hline $\begin{array}{l}\text { Ravigururajan } \\
\text { (1998) }\end{array}$ & Experimental & R-124 & $\begin{array}{l}\text { Rectangular and } \\
\text { diamond } \\
\mathrm{D}_{\mathrm{h}}=0.425\end{array}$ & $\begin{array}{l}\text { Boiling heat transfer and } \\
\text { pressure drop }\end{array}$ \\
\hline
\end{tabular}

\subsection{Recent Microchannel Experimental Work in Our Laboratory}

Extensive tests in the Advanced Heat Exchangers Laboratory at the Center for Environmental Energy Engineering at the University of Maryland have revealed attractive features of flow boiling of $\mathrm{CO}_{2}$ in commercial microchannels. Figures 2.1 and 2.2 compare the heat transfer coefficient and pressure drop of $\mathrm{CO}_{2}$ and $\mathrm{R}-134 \mathrm{a}$ for flow boiling in the same microchannels and for the same test conditions. The saturation temperature was $283 \mathrm{~K}$. The inlet and outlet vapor qualities were 0.05 and 0.30 , 
respectively. Figure 2.1 indicates that the heat transfer coefficient of $\mathrm{CO}_{2}$ is much higher (up to $200 \%$,) than that of R-134a. Figure 2 indicates that the pressure drop of $\mathrm{CO}_{2}$ is much lower $(60 \%)$ than that of $\mathrm{R}-134 \mathrm{a}$. Thus, $\mathrm{CO}_{2}$ exhibits outstanding heat transfer characteristics compared to R-134a. The excellent characteristics of $\mathrm{CO}_{2}$ are attributed to its unique thermal properties. At $283 \mathrm{~K}$, the surface tension of $\mathrm{CO}_{2}$ is $2.67 \mathrm{mN} / \mathrm{m}$, which is only $1 / 4$ that of $\mathrm{R}-134 \mathrm{a}$. Moreover, the viscosity of $\mathrm{CO}_{2}$ at $283 \mathrm{~K}$ is $86.7 \mu \mathrm{Pa} \bullet \mathrm{s}$, which is much smaller than that of $\mathrm{R}-134 \mathrm{a}(254.3 \mu \mathrm{Pa} \bullet \mathrm{s})$. Therefore, $\mathrm{CO}_{2}$ has a much higher heat transfer coefficient and lower pressure drop than R-134a.

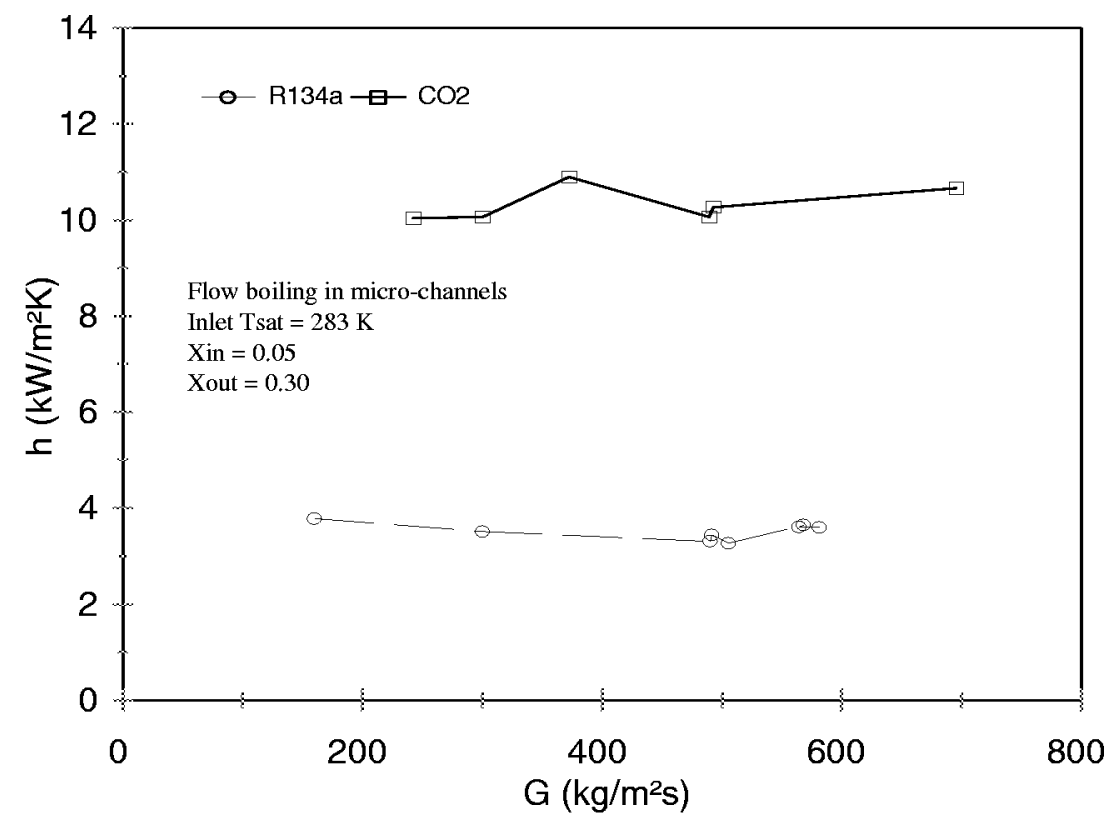

Figure 2.1 Heat transfer coefficient of $\mathrm{CO}_{2}$ and $\mathrm{R}-134 \mathrm{a}$ (from experiments performed in our Advanced Heat Exchangers Laboratory) 


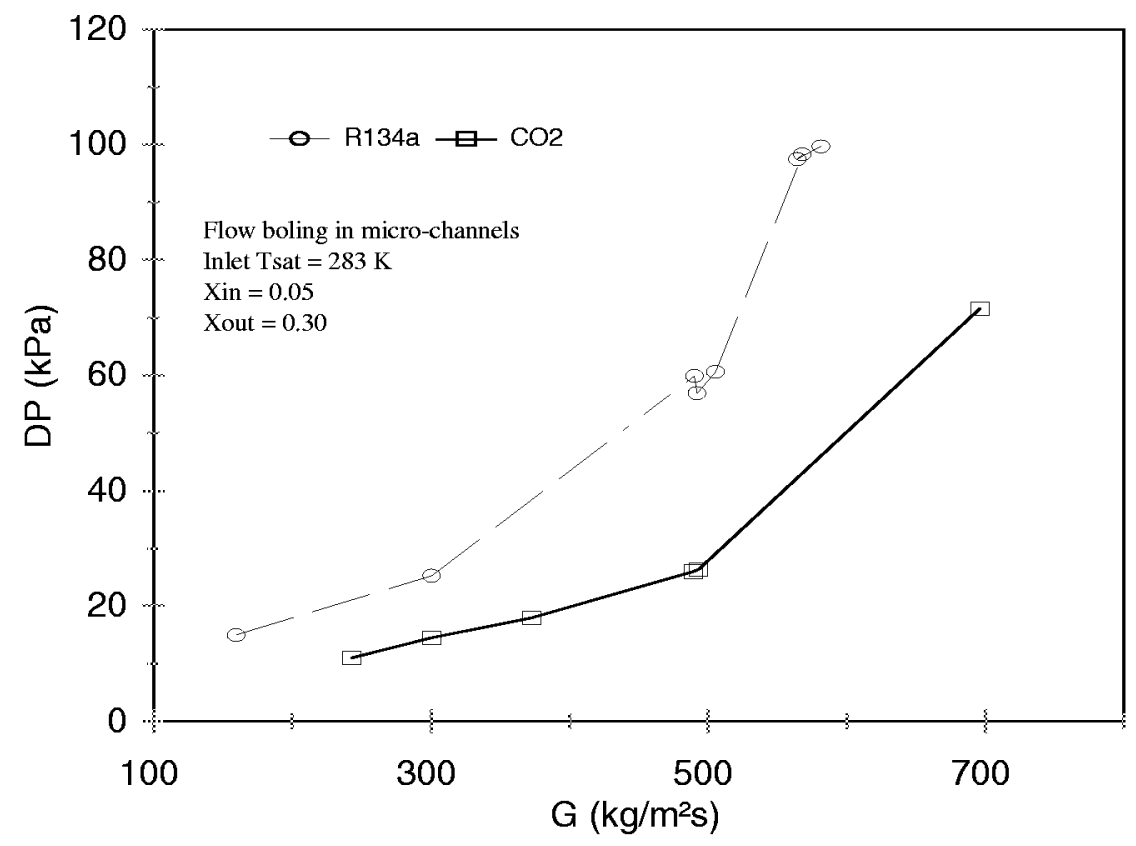

Figure 2.2 Pressure drop of $\mathrm{CO}_{2}$ and R-134a (from experiments performed in our Advanced Heat Exchangers Laboratory)

\subsection{Microchannel Heat Exchangers for $\mathrm{CO}_{2}$}

Microchannel heat exchangers for $\mathrm{CO}_{2}$ are different from those for an $\mathrm{R}-134 \mathrm{a}$ system in design and characteristics. This is because the operating pressure of a $\mathrm{CO}_{2}$ system is much higher than that of an R-134a system. And also, since the typical operating conditions of $\mathrm{CO}_{2}$ are near its critical region, the performance and heat transfer characteristics of the two kinds of heat exchangers are expected to be different.

The advantage of $\mathrm{CO}_{2}$ microchannel heat exchangers lies not only in the high performance of microchannel heat transfer and the environmentally friendly nature of $\mathrm{CO}_{2}$, but also on the fact that microchannels and $\mathrm{CO}_{2}$ can offset the weaknesses of each other. One of the main weaknesses of microchannels is the tremendous flow resistance. Fortunately, $\mathrm{CO}_{2}$ has very low viscosity, as shown in Table 1.2. Lower viscosity 
corresponds with a lower pressure drop as refrigerant flows through the exchangers. As shown in Figure 2.2, the pressure drop of $\mathrm{CO}_{2}$ is much lower (60\%) than that of R-134a. This suggests that mass flow rate of $\mathrm{CO}_{2}$ in microchannel heat exchangers can be designed to be much larger. In addition, $\mathrm{CO}_{2}$ systems have high operating pressures. Higher system operating pressure for a microchannel evaporator means the system can tolerate larger refrigerant pressure drop without affecting saturation temperature significantly. On the other hand, microchannels are also suitable for high operating pressure, which is one of the main disadvantages of $\mathrm{CO}_{2}$. As discussed above, smaller diameter tubes can withstand higher system pressures.

Research on microchannel heat exchangers for $\mathrm{CO}_{2}$ is relatively new and the available information is limited. Pettersen et al. (1998) developed a microchannel heat exchanger for $\mathrm{CO}_{2}$ and experimentally evaluated the overall heat transfer coefficient. They indicated that refrigerant-side heat transfer coefficients are higher than those of fluorocarbons, and therefore, the internal surface areas of heat exchangers can be reduced. Smaller tube and manifold dimensions reduce the heat exchanger size compared to those using R-134a. The temperature difference between the inlet air and the outlet refrigerant is much lower in $\mathrm{CO}_{2}$ gas coolers than in baseline $\mathrm{HFC}$ and/or HCFC system condensers of equal size and capacity. The reduced refrigerant exit temperature has a noticeable influence on the coefficient of performance. It appears that the microchannel heat exchanger has the best overall heat transfer coefficient.

Cutler et al. (2000) developed a transcritical carbon dioxide environmental control unit by applying microchannel heat exchangers. They reported that the capacity of a microchannel evaporator increases with increasing refrigerant mass flow rates. 
Pitla et al. (2000) numerically analyzed heat exchangers for transcritical $\mathrm{CO}_{2}$ systems. They suggested that experimental results were hard to predict when the operating conditions were close to the critical point.

Ortiz and Groll (2000) developed a finite-element model to study a microchannel $\mathrm{CO}_{2}$ evaporator. The model was based on the assumption that a refrigerant-side heat transfer coefficient has a negligible effect on volumetric capacity. They concluded that the volumetric cooling capacity of the microchannel evaporator increases with increasing air-side heat transfer coefficients and is nearly constant with respect to refrigerant-side heat transfer coefficients.

A search of the literature indicates that a clear understanding of the performance and potential of $\mathrm{CO}_{2}$ microchannel heat exchangers is lacking. Therefore, the intention of this project is to characterize the performance of a current generation of $\mathrm{CO}_{2}$ heat exchangers based on tests at controlled operating conditions. 


\section{CHAPTER 3 TEST FACILITIES AND SYSTEM COMPONENTS}

The test facility used in this study measures the capacities of microchannel heat exchangers, including the evaporator and gas cooler. During system operation, the gas cooler and evaporator will be separated from each other through the use of different air ducts in separate rooms, thus allowing for independent fine control of the inlet air stream conditions (including temperature and relative humidity) for each heat exchanger. Since the sizes of the available microchannel heat exchangers are large, available facilities (indoor loop and outdoor duct) at the CEEE Heat Pump Laboratory could not satisfy the test requirements. In order to fulfill the tasks set forth, a new indoor loop and an outdoor duct were built and tested.

\subsection{Indoor Loop}

As shown in Figure 3.1, the indoor loop contains an air handler unit, a fan, an upstream screen, an upstream thermocouple grid (3x3 thermocouples), an upstream air sampling tree, a microchannel evaporator, a downstream thermocouple grid $(3 \times 3$ thermocouples), a downstream air sampling tree, a screen, and a flow nozzle. The air handler unit is used to adjust the inlet air conditions (temperature and humidity), while the fan circulates the airflow inside the loop. The fan speed is adjustable, and thus airflow rate can be controlled. The screens help by allowing a more uniform airflow. The thermocouple grids are made from nine thermocouples, arranged $3 \times 3$ uniformly on the cross sectional area of the air duct, so that the mean temperature of the nine thermocouple readings can represent the bulk temperature of the air stream. Two dew point meters 
(chilled mirror type with an accuracy of $\pm 0.2{ }^{\circ} \mathrm{C}$ ) are used to determine the humidity of the upstream and downstream airflow. Single point measurement of the humidity might not be sufficient to determine the bulk humidity of the air stream since the humidity may slightly vary across the cross sectional area of the air duct. To determine the bulk humidity more accurately, air-sampling trees, shown in Figure 3.2, were designed to suck air uniformly from nine positions in the cross section of the air duct. The flow nozzle was used to measure the airflow rate inside the indoor loop.

The air duct was constructed from polypropylene and insulated with $25.4 \mathrm{~mm}$ thickness of thermal insulation material $(\mathrm{k}=0.04 \mathrm{~W} / \mathrm{mK})$.

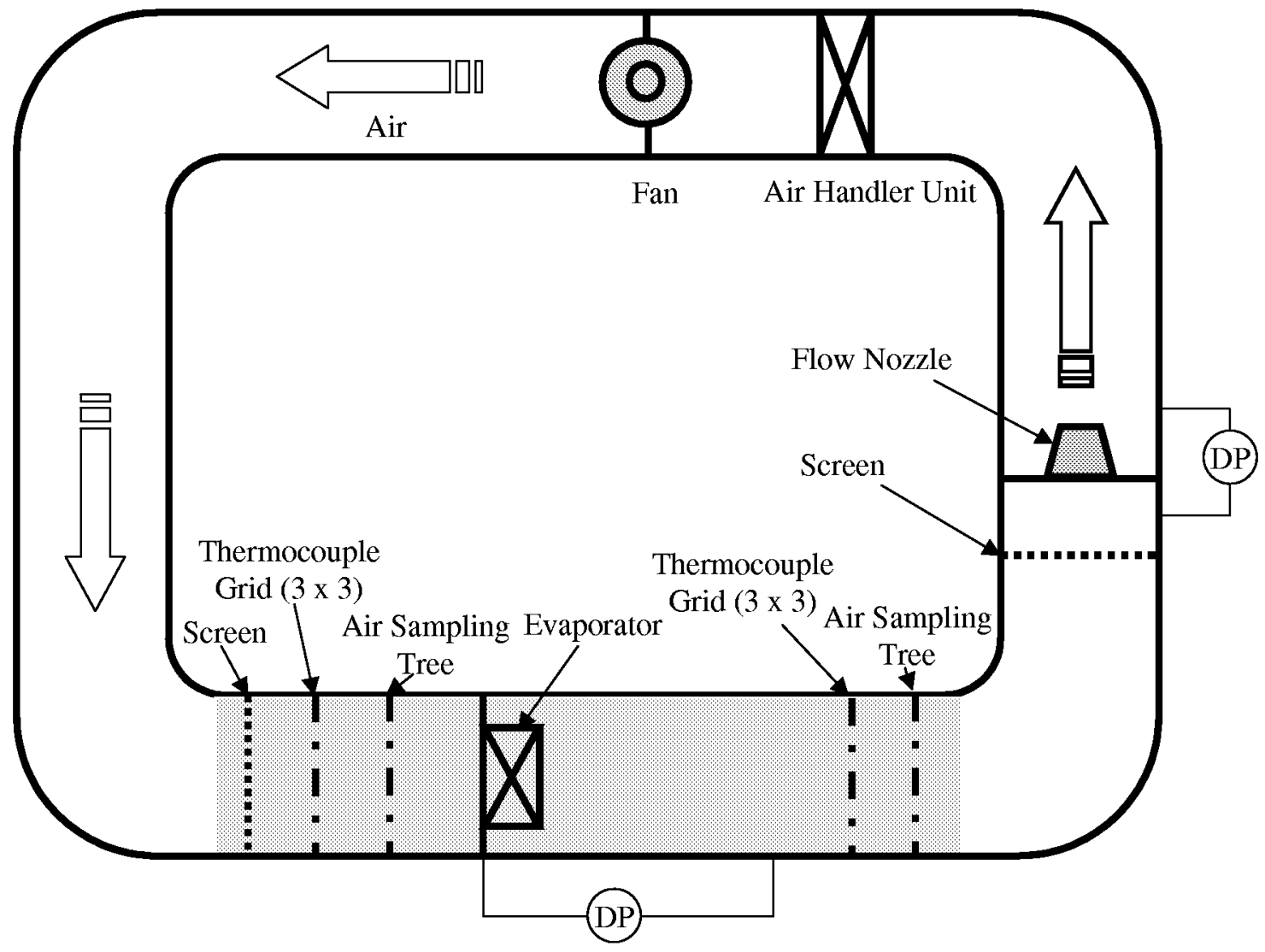

Figure 3.1 Schematic of indoor loop 


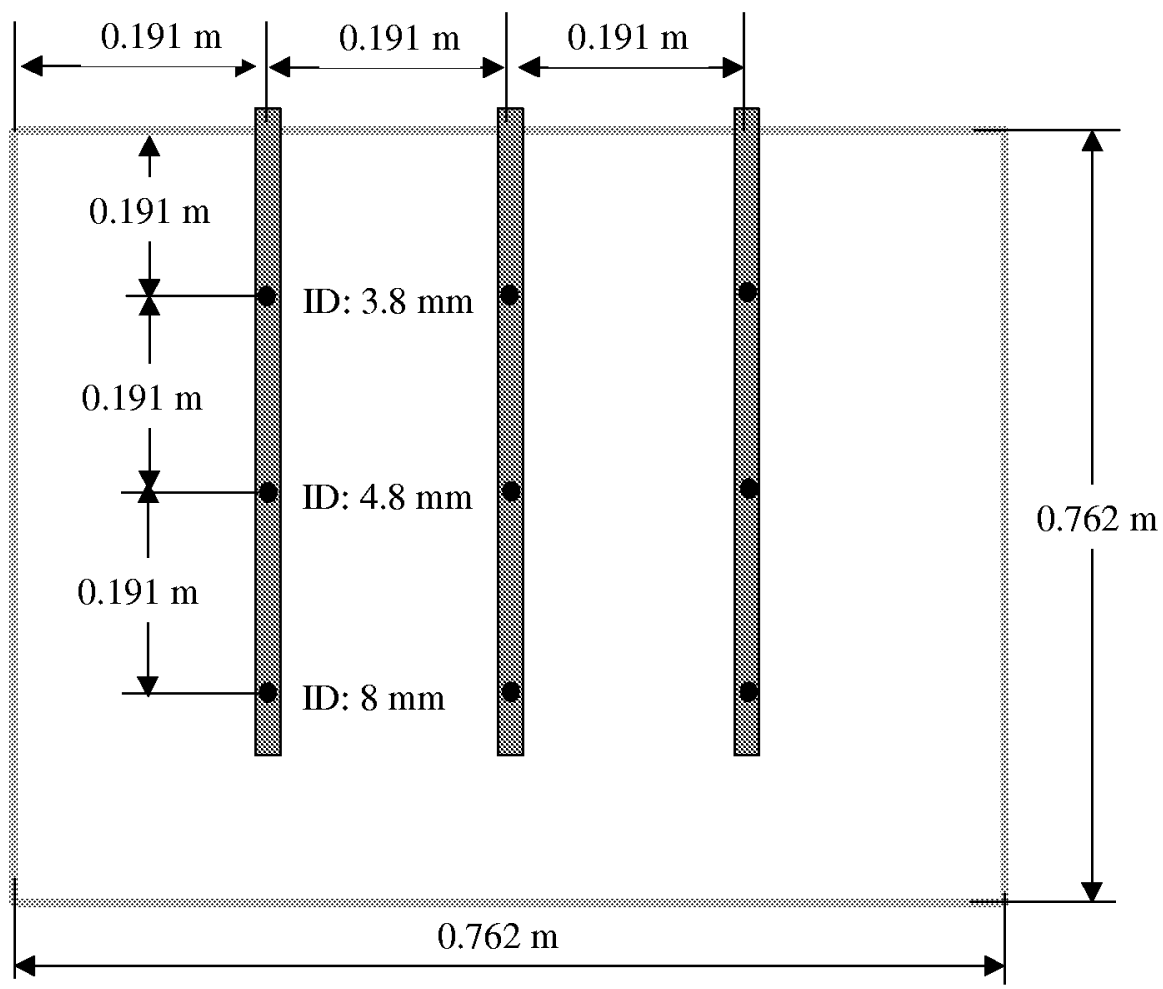

Figure 3.2 Air sampling tree

\subsection{Outdoor Duct}

The outdoor duct, shown in Figure 3.3, was built inside another environmental chamber. The outdoor duct houses the microchannel gas cooler. It is also constructed from polypropylene. The duct contains screens, upstream and downstream thermocouple grids, a gas cooler, an air mixer, an obstruction meter, and a large fan. Similar to that of the indoor loop, screens are used to make the air stream uniform while thermocouple grids measure the bulk temperatures of the air stream. The fan, controlled by a variable speed motor, was placed at the outlet of the duct where it draws air through the duct. The air duct is also insulated with $25 \mathrm{~mm}$ thickness of thermal insulation material $(\mathrm{k}=0.04$ $\mathrm{W} / \mathrm{mK})$. 


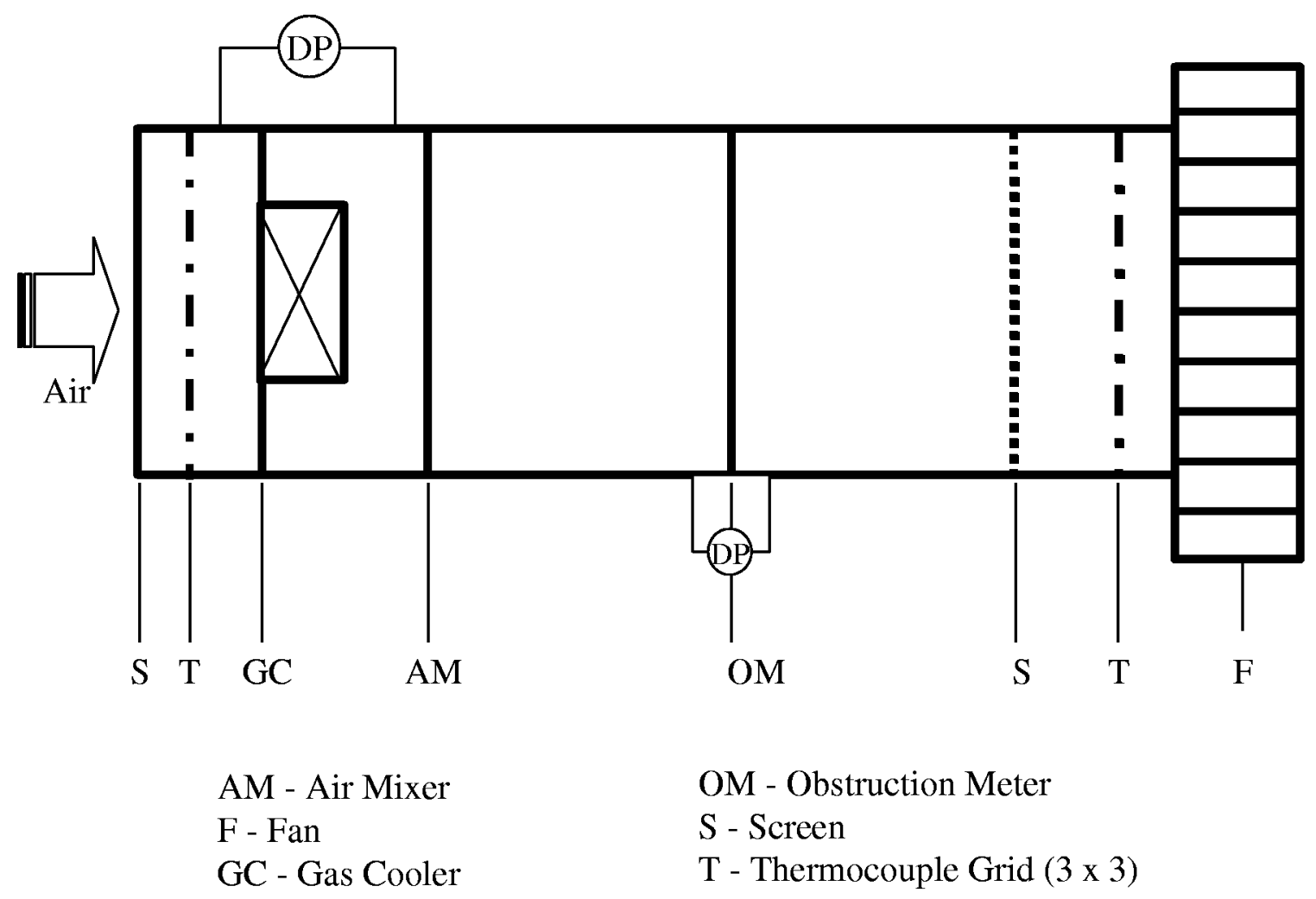

Figure 3.3 Schematic of outdoor duct

Due to the large cross sectional area of the outdoor duct $(1.219 \mathrm{~m} \mathrm{x} 0.914 \mathrm{~m})$, CEEE's current flow rate measurement devices (typically flow nozzles) were not suitable for this task. For this reason, an obstruction flow meter (shown in Figure 3.4) was designed, fabricated, and calibrated. The flow meter was made of 117 circular holes with a diameter of $25 \mathrm{~mm}$. Since these small holes were uniformly deployed across almost the entire cross sectional area of the test duct, the flow and thermal fields were relatively uniform for the present situation.

Fin strip heaters were used to calibrate the obstruction flow meter. Figure 3.5 shows the energy balance for the calibrated obstruction flow meter. For the airflow rate range of interest to this project, the obstruction flow meter can measure airflow rate within $\pm 2 \%$. For more details, see Appendix I. 


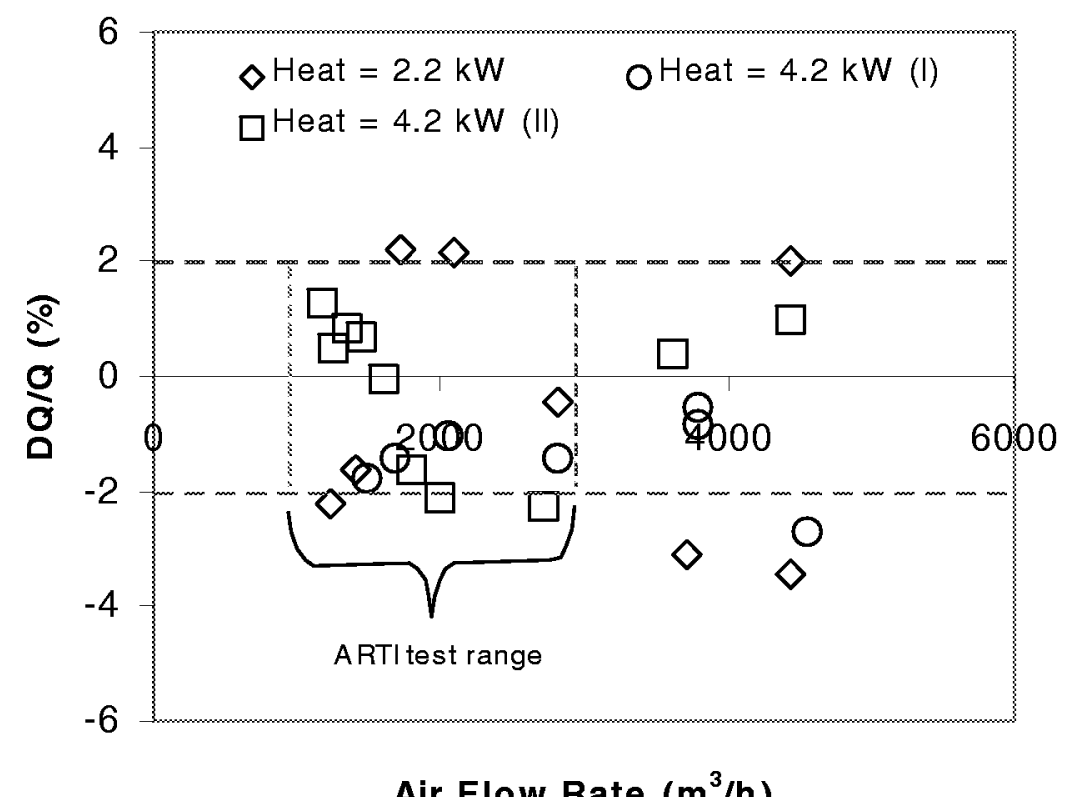

Figure 3.4 Energy balance for the calibrated obstruction flow meter

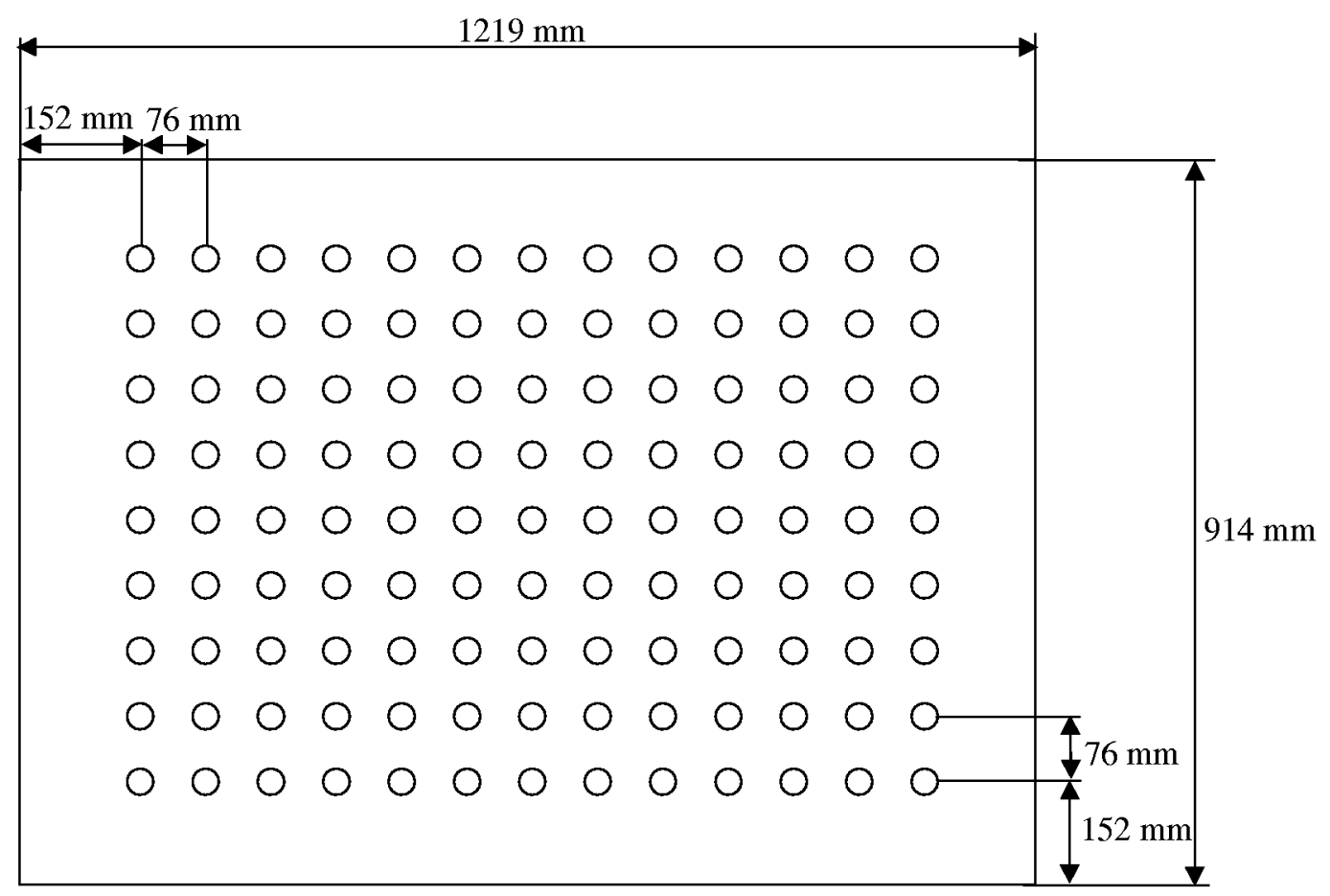

Orifice ID: $25 \mathrm{~mm}$

Number of orifices: $13 \times 9=117$

Figure 3.5 The obstruction flow meter 


\subsection{Microchannel Heat Exchangers}

Microchannel heat exchangers were provided by Hydro Aluminum. The microchannel used is shown in Figure 3.6.

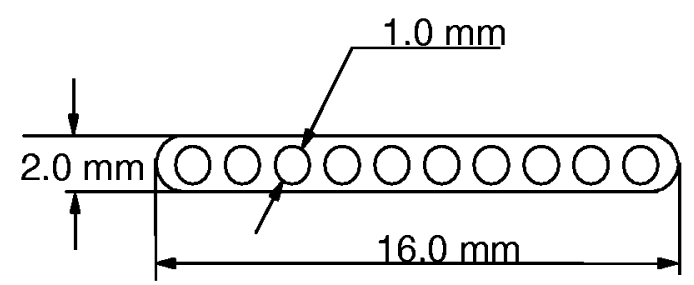

Figure 3.6 Microchannels from Hydro Aluminum

Both the evaporator and the gas cooler are made from several microchannel unit slabs. A schematic diagram and picture of one of these unit slabs are shown in Figures 3.7 and 3.8. It is important to note that the two halves of the heat exchange slab are noncommunicative, so that flexibility in choosing refrigerant paths may be ensured. Moreover, the stubs providing refrigerant access to the headers were placed in the middle of each section in order to reduce the possibility of flow mal-distribution, especially for the evaporator. The specifications of each unit slab are as follows:

- One unit has two passes of 17 parallel microchannels, overall surface area of $3 \mathrm{~m}^{2}$ (see Figures 3.7 and 3.8)

- $\mathrm{Al}$ 3003-O stub, $9.5 \mathrm{~mm}$ OD, $5.4 \mathrm{~mm}$ ID (see Figure 3.9)

- Header is single tube, $348 \mathrm{~mm}$ long, $21.3 \mathrm{~mm}$ OC, $17.7 \mathrm{~mm}$ ID (see Figure 3.9)

- Louvered fin density: 16 fins $/ 25.4 \mathrm{~mm}$, fin height: $8.0 \mathrm{~mm}$ (see Figure 3.10 )

- Total flow cross sectional area: $17 \times 10 \times(3.14 \times 1 \times 1) / 4=133.5 \mathrm{~mm}^{2}$

- Refrigerant side heat transfer area: $34 \times 10 \times(3.14 \times 1) \times 430=0.46 \mathrm{~m}^{2}$ 


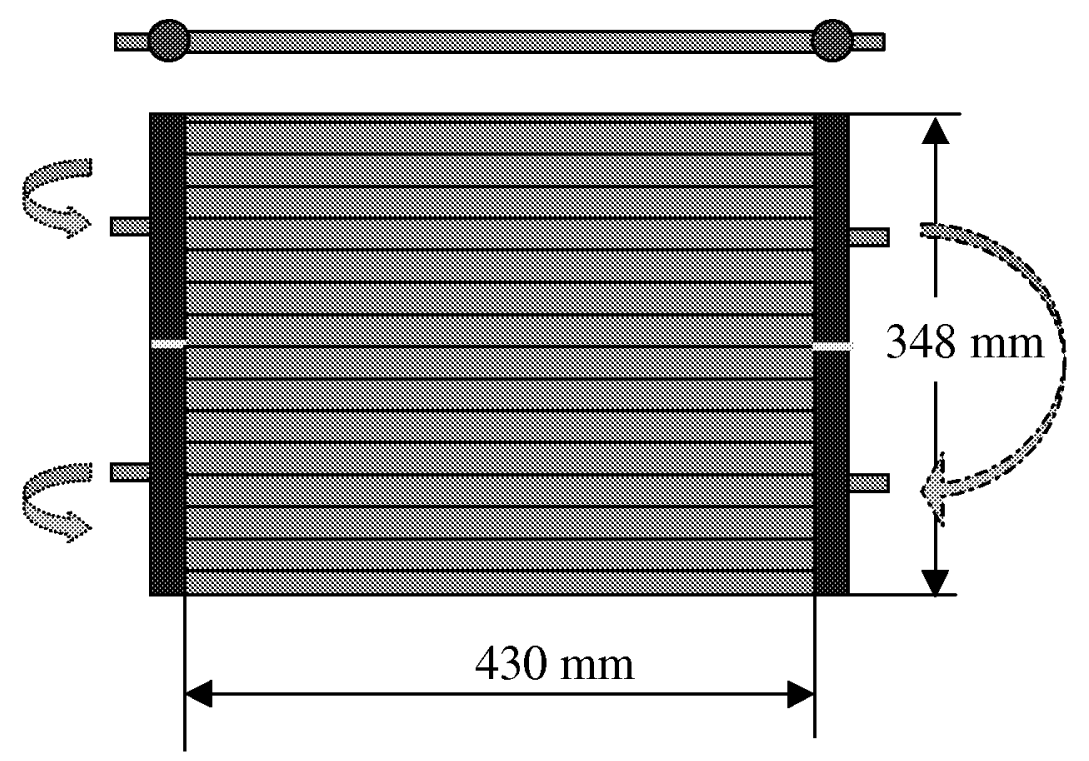

Figure 3.7 Schematic of a microchannel unit slab

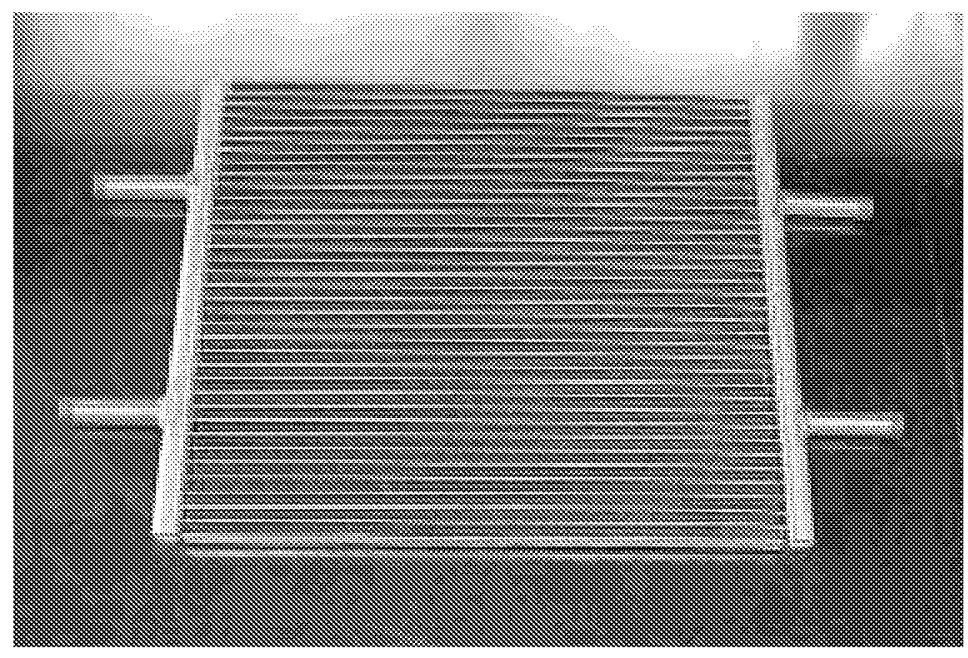

Figure 3.8 Picture of a unit slab 

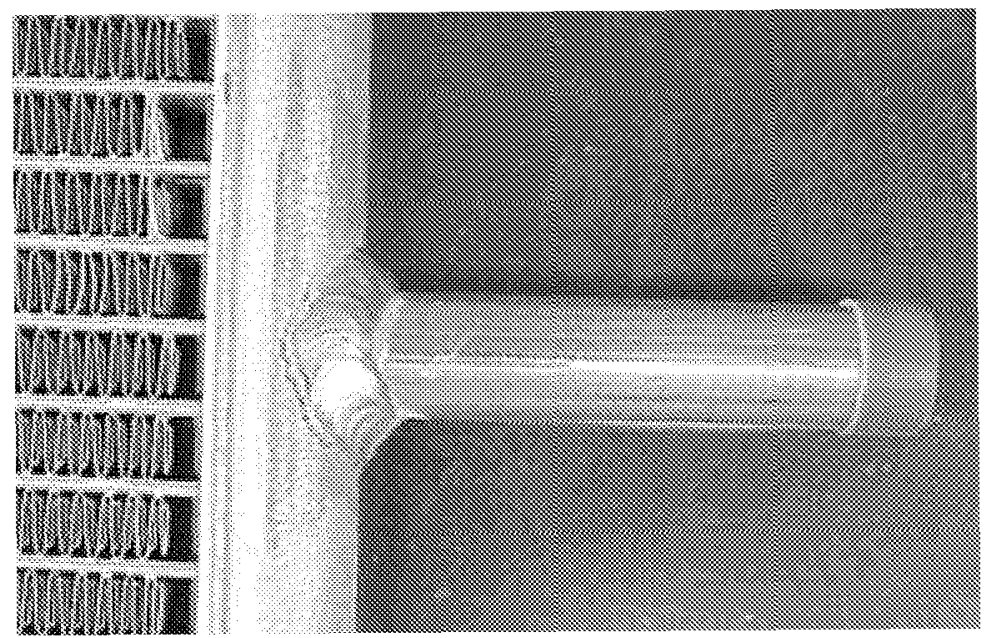

Figure 3.9 Picture of header and stub
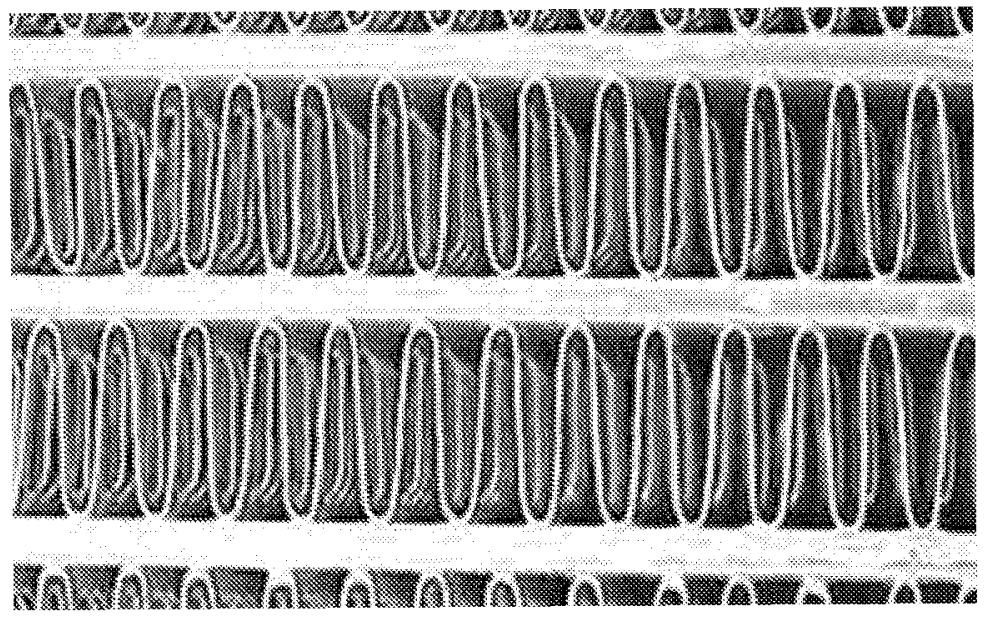

Figure 3.10 Picture of fins and microchannels

\subsubsection{Evaporator}

The evaporator is comprised of two microchannel unit slabs. Figure 3.11 shows a schematic of the two unit slabs placed side by side with the microchannels in a vertical orientation to allow for gravity driven condensation on the air side. Refrigerant flows in a serpentine fashion through each of the two halves of the two slabs. 


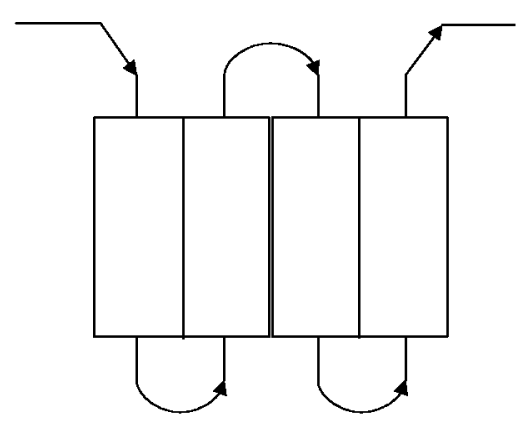

Figure 3.11 Schematic of the evaporator stack layout

\subsubsection{Gas Cooler}

The gas cooler, shown in Figure 3.12, is comprised of 10 microchannel unit slabs. Two slabs were set into a frame side by side, and then stacked parallel to the air flow five units deep. The refrigerant from the discharge of the compressor was brought to the rear of this unit, divided by two, and then routed through the two parallel stacks of slabs until it exited at the front of the stacks where the two streams were recombined. This exit point was the point where the incoming air stream entered. This design is a counter-crossflow pattern, which improves the heat transfer performance. Eleven thermocouples were mounted to measure the refrigerant temperatures along the flow path, as shown in Figure 3.12 by the letter $T$. These thermocouples help to determine the heat transfer rate of each individual slab. 


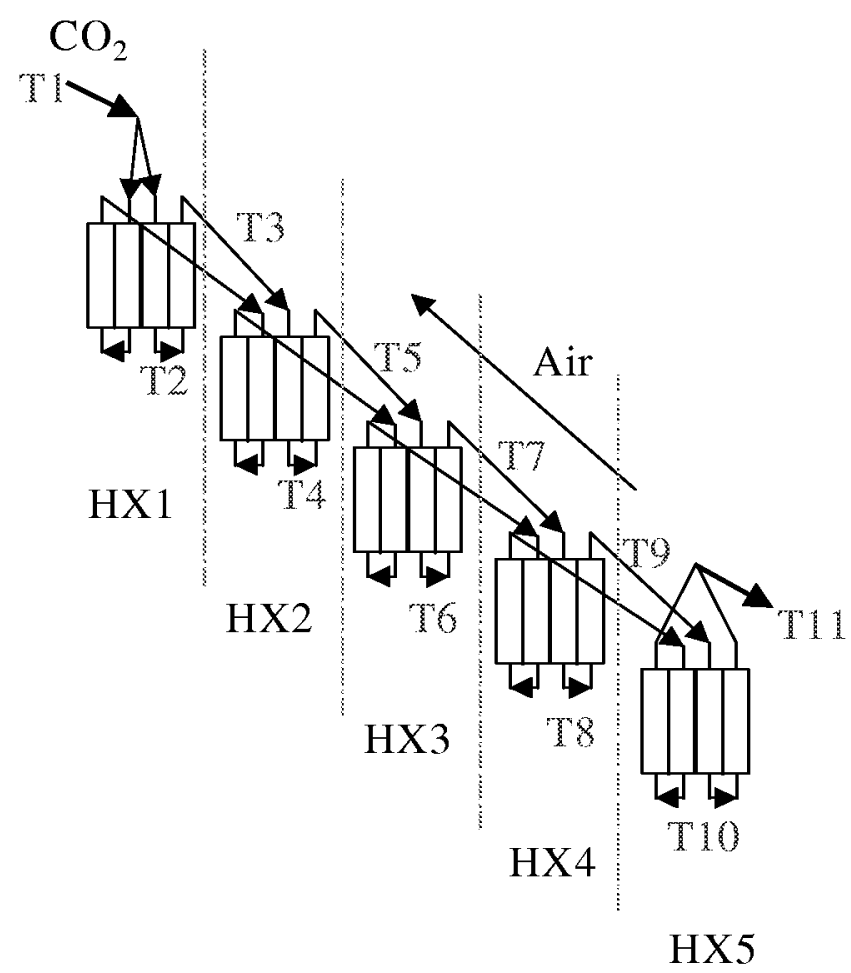

Figure 3.12 Schematic of gas cooler layout

\subsection{Refrigerant Loop}

The refrigerant loop, shown in Figure 3.13, is made up of two parts that are located in separate chambers: an indoor chamber and an outdoor chamber. The two parts are piped together by stainless steal tubes with an inner diameter of $12.3 \mathrm{~mm}$. In the indoor chamber, the refrigerant loop contains an expansion value, a microchannel evaporator, an accumulator, thermocouples, and pressure transducers. The refrigerant loop inside of the outdoor chamber is comprised of a $\mathrm{CO}_{2}$ compressor, an oil separator, a microchannel gas cooler, a Coriolis mass flow meter, a suction line heat exchanger, thermocouples, and pressure transducers. 


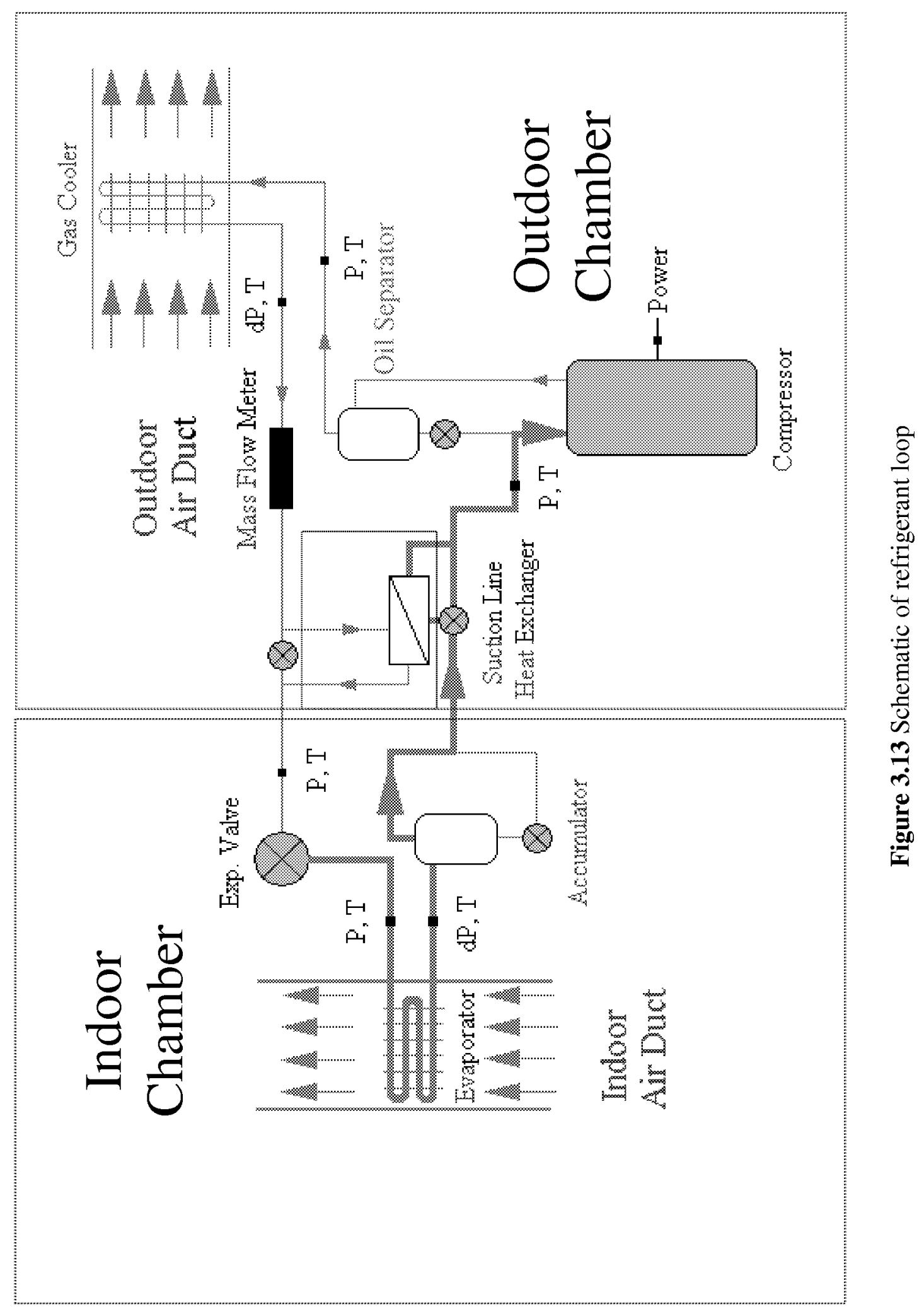




\subsection{Compressor}

The tests were carried out with the use of a prototype Dorin semi-hermetic $\mathrm{CO}_{2}$ compressor. The compressor is a constant speed/fixed displacement unit that runs at 1750 RPM and can provide a mass flow rate of $\mathrm{CO}_{2}$ up to $60 \mathrm{~g} / \mathrm{s}$. The compressor, which has logged more than 1500 hours of run time, and has shown no excessive wear, is shown in Figure 3.14. Its specifications are as follows:

Type: $\quad$ Reciprocating, Semi-hermetic

Piston Number: $\quad 2$

Displace Volume: $\quad 30.9 \mathrm{~cm}^{3}$

Clearance: $\quad 1.2 \%$ of cylinder volume

Motor: $\quad 3 \mathrm{~kW}, 1750 \mathrm{RPM}, 3$ Phase, $208-230 \mathrm{~V}, 60 \mathrm{~Hz}$

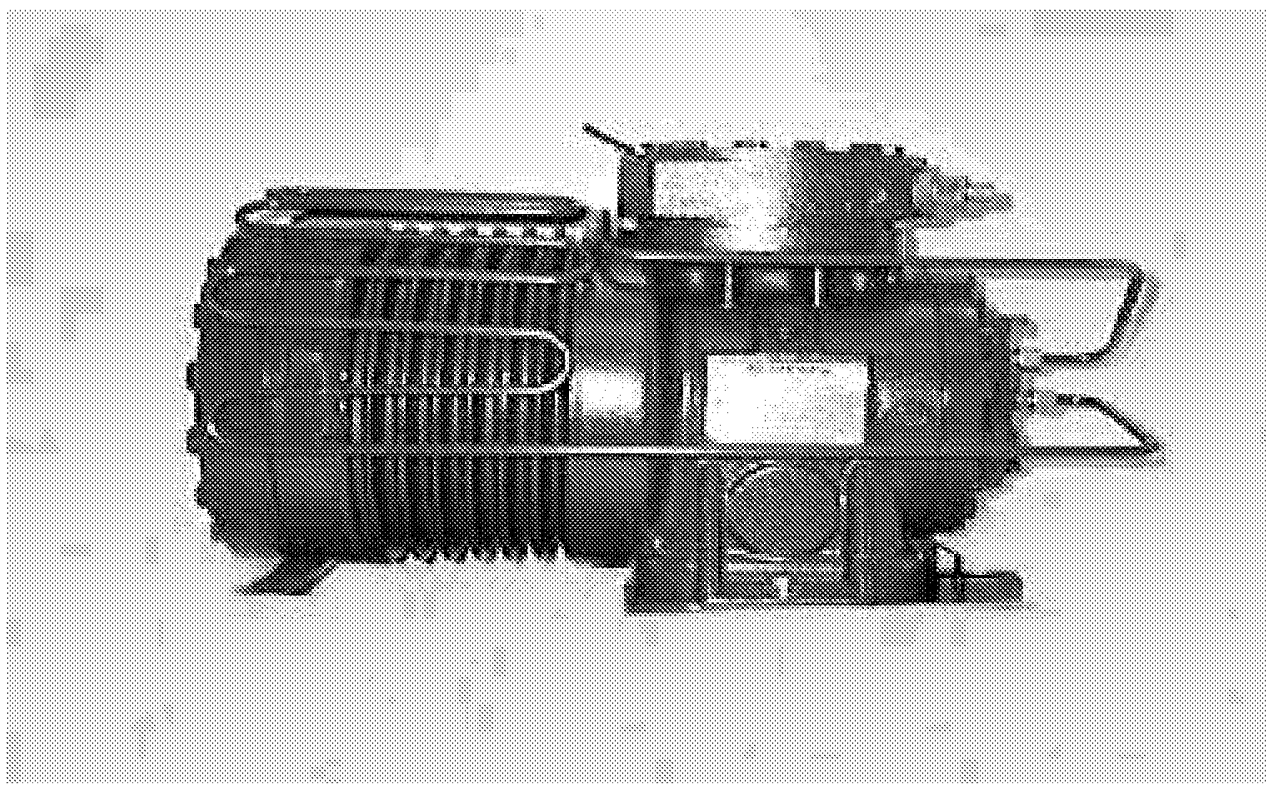

Figure 3.14 A photograph of the Dorin semi-hermetic $\mathrm{CO}_{2}$ compressor

\subsection{Data Acquisition System}

Signals from the air- and refrigerant-side measurement devices were fed to 
LabView data acquisition software through the use of National Instruments' Field Point DAQ modules. These modules allow for flexibility in instrumentation, as additional channels may be added or removed easily if needed. These modules (rather than the computer) may also be placed close to the individual parts of the experiment, eliminating both excessive cable lengths (through the use of an RS-485 networking scheme) and problems arising from incorrect wiring.

Currently, 96 channels of data are collected (64 thermocouple and 32 analog inputs) and sent to the computer for collation and instantaneous on-screen visualization of system parameters (e.g. pressures, temperatures, air flow rates, etc.). The smallest tested sampling rate of this system is 1 second.

Figure 3.15 shows a screen shot of the data acquisition program written for the experiment. Numeric outputs monitored include air side temperatures, air flow rates, dew points, performance (including COP, compressor work, and both latent and sensible cooling loads), refrigerant pressures, mass flow rate, and in-stream temperatures. The graphical portion of the program monitors the history of many of these same measurements in addition to a few additional data sets. 


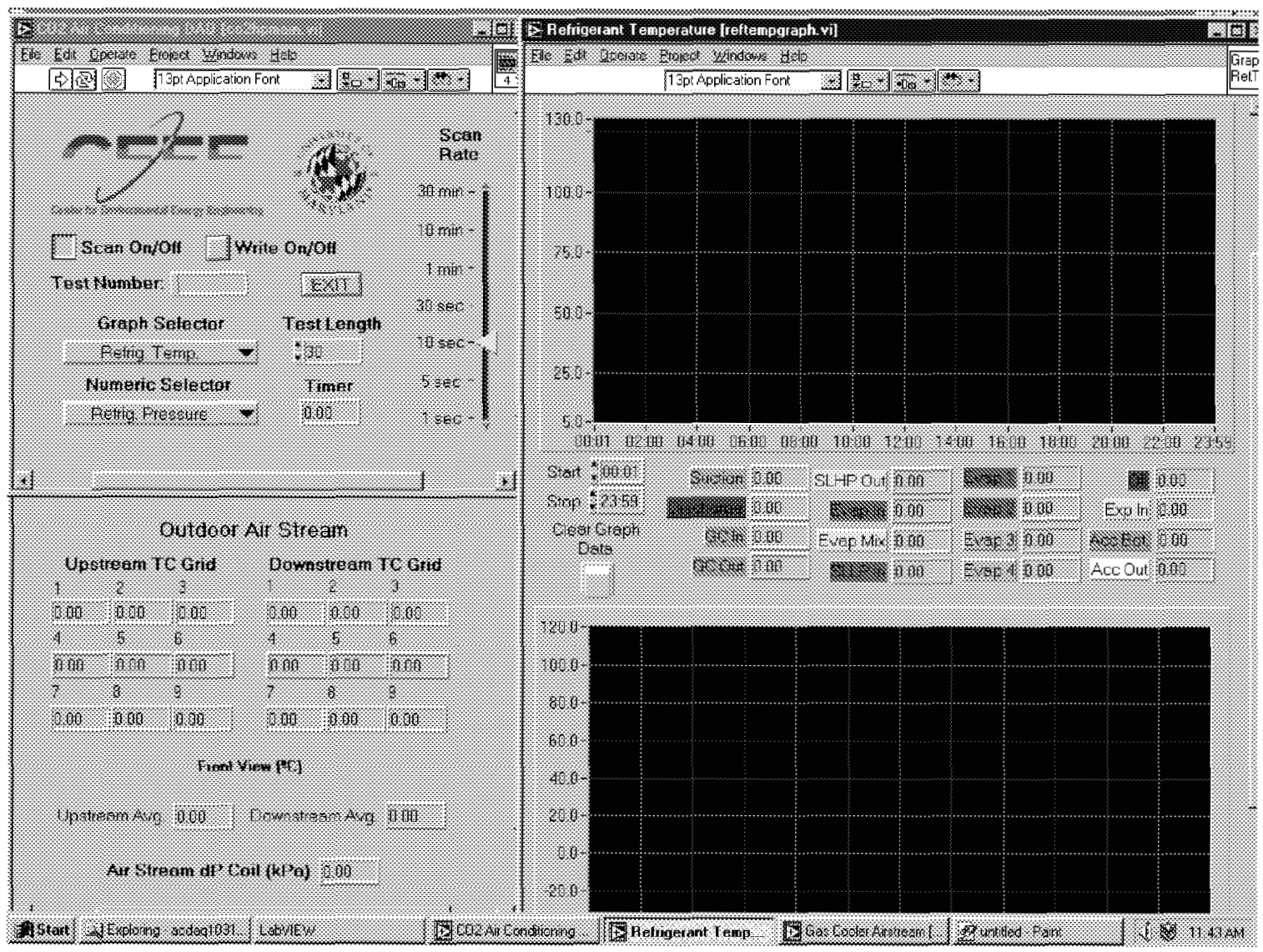

Figure 3.15 Screen shot of the data acquisition program written for the system

\subsection{Instrumentation and Measurements}

\subsubsection{Pressure measurement}

Pressure measurements are made using two types of instruments: absolute pressure transducers and differential pressure transducers. The absolute pressure transducers were used at the compressor suction and discharge and the expansion valve inlet and outlet. These measurements were made in conjunction with differential pressure transducers used to more accurately measure pressure drop across the heat exchanger stacks. The differential pressure transducers used for the evaporator and gas cooler stacks have an accuracy of $0.2 \%$ and $0.1 \%$ of full-scale output, respectively. 


\subsubsection{Air Stream Temperature Measurement}

Air stream temperatures are measured by thermocouple grids. Each grid has 9 (3x3) T-type thermocouples deployed uniformly across the cross sectional area. The thermocouples were calibrated before installation. Since the air side capacity is determined by the difference between average upstream temperature and average downstream temperature, specific tests were conducted to determine the deviations of the average upstream temperature and average downstream temperature with respect to RTD readings. The results are shown in Figure 3.16, where it is suggested that the deviations between the average upstream temperature and average down stream temperature are within $0.05{ }^{\circ} \mathrm{C}$.

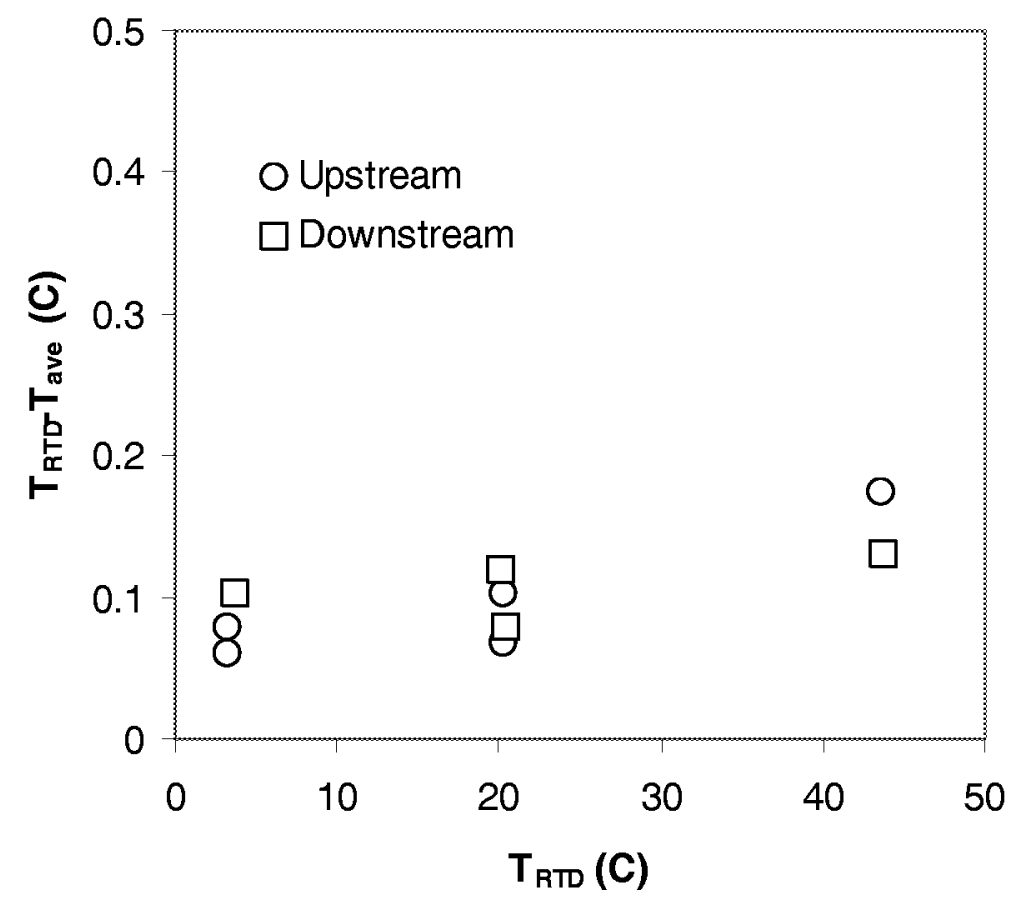

Figure 3.16 Deviations between upstream average temperature and downstream average temperature 


\subsubsection{Coriolis Mass Flow Meter}

Refrigerant mass flow was measured with a Coriolis type mass flow meter (Micro Motion R-Series) placed downstream of the single-phase gas cooler outlet. The output signal of 4-20 mA was adjusted to correspond to a range of $0-100 \mathrm{~g} / \mathrm{s}$, the operating range expected in the experimental system.

The Micro Motion R-Series flowmeter measures the mass and volume of liquids, gases and slurries within $0.5 \%$ of flow rate. It has no moving parts to wear out or break down, and mechanical installation is made easier with no straight run or flow conditioning requirements.

\subsubsection{Dewpoint Temperature Measurement}

The dewpoint temperatures of the air stream were measured by dewpoint meters. The dew point meters are Model M2 Plus from General Eastern. The Model M2 Plus is a general purpose chilled mirror hygrometer with advanced capabilities, suitable for use in a large number of applications. It utilizes advanced microprocessor control and includes General Eastern's patented PACER ${ }^{\mathrm{TM}}$ technology. PACER ${ }^{\mathrm{TM}}$ is designed to reduce contamination induced errors and to provide long, unattended operation in industrial applications. 4-20mA and 0-5 VDC analog outputs and RS-232C digital output are provided. The RS-232C port allows the analog outputs to be scaled and provides direct communication with a host computer. It can support an accuracy of $+/-0.2^{\circ} \mathrm{C}$ on dewpoint measurement. 


\section{CHAPTER 4 EXPERIMENTAL RESULTS FOR MICRO- CHANNEL EVAPORATOR}

\subsection{Experimental Test Conditions}

Experimental test conditions for evaporation, as specified in the proposal of Microchannel Heat Exchangers with Carbon Dioxide (Ohadi, et al., 1999), were tabulated in Table 4.1.

Vapor qualities at the inlet of the evaporator are specified in the proposed test conditions as $20 \%$ and $50 \%$ respectively. Since direct measurement of vapor quality at the inlet of the evaporator is almost impossible, inlet vapor qualities were determined by assuming an adiabatic process through the expansion valve. The state of the refrigerant at the outlet of the gas cooler can be easily determined by measuring the refrigerant pressure and temperature as long as a supercritical state of the refrigerant is secured in the gas cooler. The piping line and expansion valve were insulated by thermal insulation materials with a thermal conductivity of $0.04 \mathrm{~W} / \mathrm{mK}$.

To obtain the specified vapor quality at the inlet of the evaporator, the required states at the outlet of the gas cooler were calculated according to the adiabatic process through the expansion valve. The required states at the outlet of the gas cooler as well as all other proposed test conditions were converted into SI units and tabulated in Table 4.2. In the proposal, the refrigerant saturation temperatures for test conditions series No. $19-$ 22, were proposed as $-23{ }^{\circ} \mathrm{C}$, and air side conditions were $-8{ }^{\circ} \mathrm{C} /-9{ }^{\circ} \mathrm{C}$ (dry bulb/wet bulb). However, the present system could not reach a steady state because of frozen moisture on the outer surface of the evaporator. Thus, air conditions were adjusted to -8 ${ }^{\circ} \mathrm{C}$ dry air to avoid the formation of frost on the coil. 


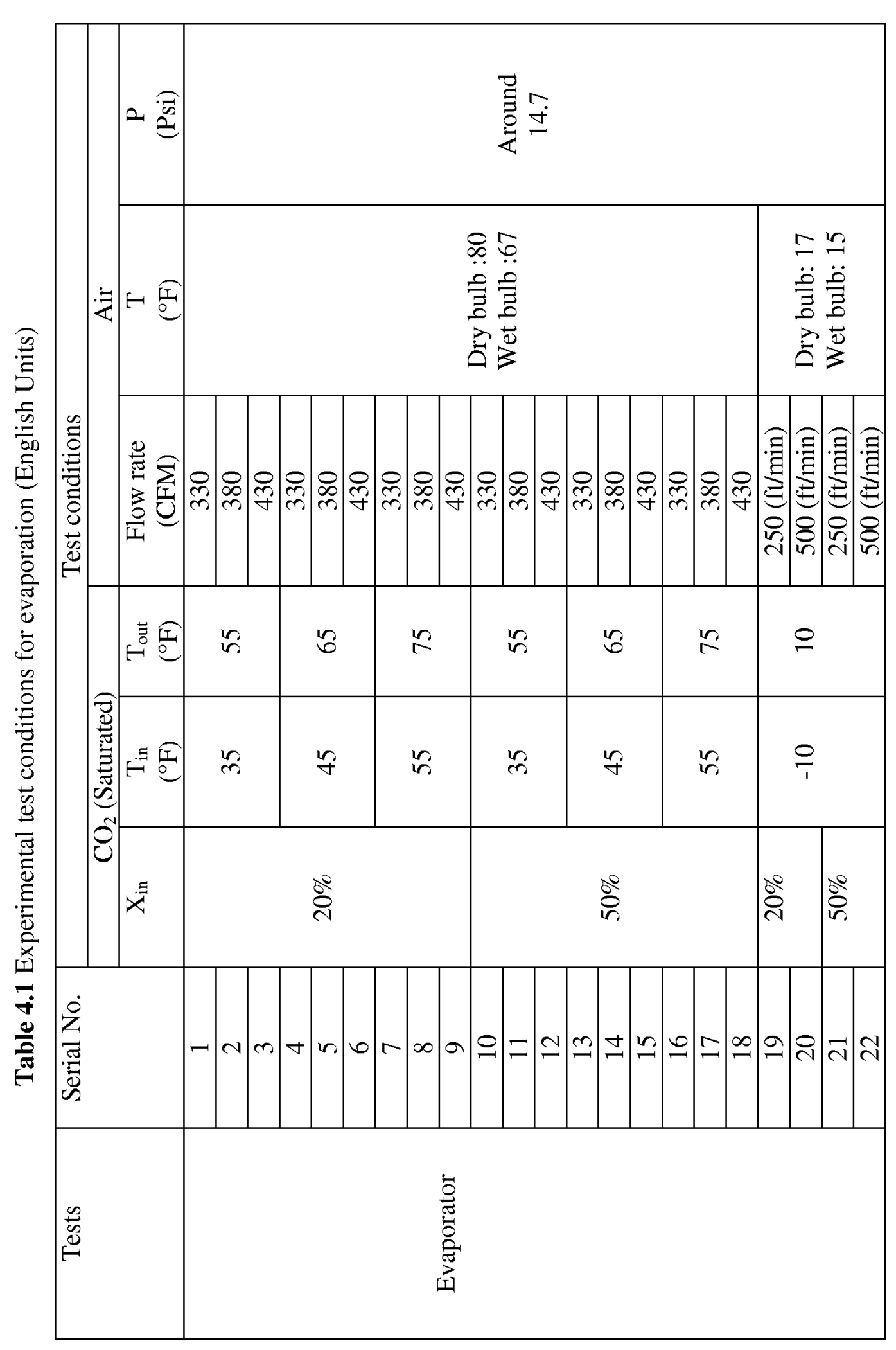




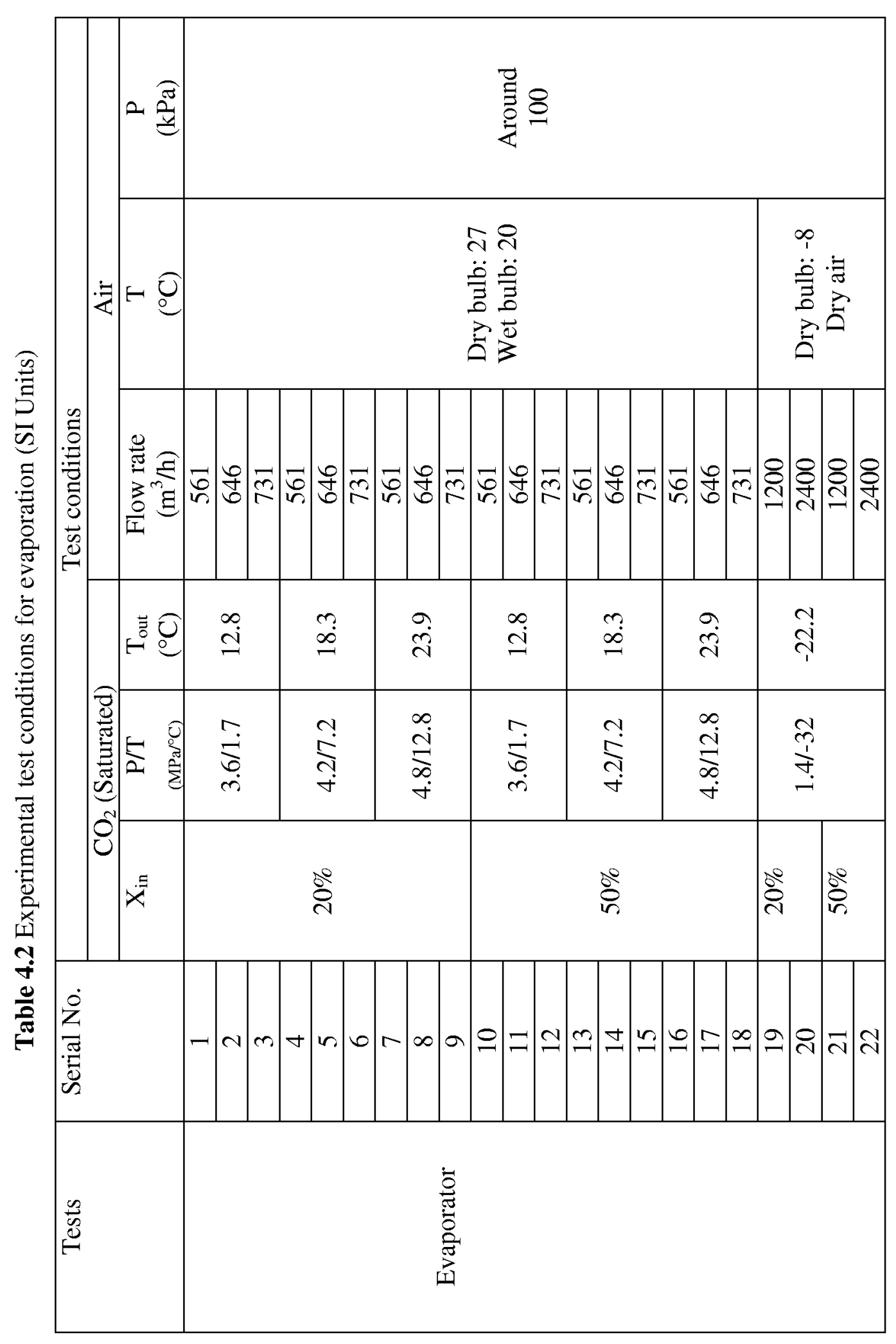




\subsection{Experimental Test Results}

The inlet and outlet air-side and refrigerant-side pressures and temperatures were measured during the evaporator tests. The measured data were used to determine the capacity and pressure drop. The air side capacity consists of two parts: the sensible heat part and latent heat part. The sensible heat part was calculated from the dry air enthalpy change and mass flow rate. The dry air enthalpy change was determined by the temperature difference multiplied by the air-specific heat. The latent heat part refers to the heat due to the moisture condensate. It was calculated from latent heat $h_{f g}$ and the condensate flow rate $\dot{m}_{\text {water-cond }}$ determined by collecting condensed water over a certain period (typical collecting period is $30-60$ minutes). The determined condensate flow rates were double-checked by calculating the condensate flow rate based on the humidity difference of air stream across the evaporator measured by the two dewpoint meters (chilled mirror type with an accuracy of $\pm 0.2^{\circ} \mathrm{C}$ )

The refrigerant-side capacity was determined by the mass flow rate and enthalpy difference between the inlet and outlet of the evaporator. Since the proposed inlet test conditions lay in the two-phase region, the enthalpy at the inlet of the evaporator could not be determined directly. However, the enthalpy at the inlet of the evaporator can be considered the same as the enthalpy at the outlet of the gas cooler since the piping line and expansion valve were perfectly insulated, and the process of expansion can be assumed as a constant enthalpy process. The data reduction uses the following equations:

$$
\begin{gathered}
Q_{\text {air-sensi. }}=\dot{m}_{\text {air }} \cdot C_{p} \cdot\left(T_{\text {air-out }}-T_{\text {air-in }}\right) \\
Q_{\text {air-latent }}=\dot{m}_{\text {water-cond. }} \cdot h_{f g} \\
Q_{\text {air }}=Q_{\text {air-sensi. }}+Q_{\text {air-latent }}
\end{gathered}
$$




$$
\begin{gathered}
Q_{\text {ref }}=\dot{m}_{\text {ref }} \cdot\left(h_{\text {ref-gc-out }}-h_{\text {ref-evp-out }}\right) \\
E B=\frac{Q_{\text {air }}-Q_{\text {ref }}}{Q_{\text {air }}}
\end{gathered}
$$




\begin{tabular}{|c|c|c|c|c|c|c|c|c|c|c|c|c|c|c|c|c|c|c|c|c|}
\hline \multirow{5}{*}{ 胥 } & $\mid \boldsymbol{I I}$ & $b^{\circ}$ & $\frac{9}{i}$ & 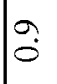 & $\stackrel{\text { I }}{-}$ & $?$ & $\stackrel{\infty}{-}$ & $\stackrel{\nabla}{i}$ & $\stackrel{\infty}{-}$ & 2 & c & $\vec{i}$ & in & $\exists$ & 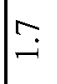 & $\stackrel{n}{-}$ & $\stackrel{\infty}{-}$ & $\stackrel{0}{\circ}$ & $\begin{array}{l}\infty \\
c i\end{array}$ & $\hat{\imath}$ \\
\hline & $\left|\begin{array}{|}\vec{\Phi} \\
\simeq\end{array}\right|$ & 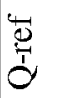 & 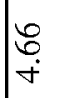 & $\stackrel{\vec{f}}{\vec{f}}$ & 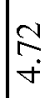 & $\vec{\gamma}$ & $\hat{\sigma}$ & $\begin{array}{l}a \\
\dot{v} \\
i\end{array}$ & $\begin{array}{l}\hat{n} \\
\bar{n}\end{array}$ & ir & $\hat{\jmath}$ & $\begin{array}{l}\hat{i} \\
\text { I }\end{array}$ & $\begin{array}{l}0 \\
\stackrel{\infty}{n} \\
\end{array}$ & ঙ্ & $\stackrel{m}{m}$ & ஜூ: & & 官 & ले & $\vec{m}$ \\
\hline & & 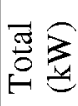 & $\underset{\sim}{\infty}$ & $\begin{array}{l}\stackrel{\circ}{+} \\
\dot{\sigma}\end{array}$ & $\stackrel{F}{F}$ & $\hat{\gamma}$ & $\begin{array}{l}\delta \\
0 \\
\dot{\theta}\end{array}$ & $\begin{array}{l}3 \\
i \\
i n\end{array}$ & $\begin{array}{l}\hat{\sigma} \\
\dot{i n}\end{array}$ & 8 & 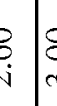 & $\begin{array}{l}8 \\
\dot{9} \\
\dot{1}\end{array}$ & $\begin{array}{l}\dot{m} \\
\dot{m}\end{array}$ & $\stackrel{n}{n}$ & ?ִ & ڤn & 占 & fُ & $\underset{\sim}{\tilde{f}}$ & $\stackrel{v}{\sim}$ \\
\hline & 安 & 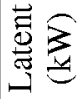 & $\stackrel{\infty}{\infty}$ & $\Omega_{2}^{\prime}$ & 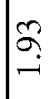 & ஓ & $\stackrel{\infty}{\sigma}$ & $\underset{\sim}{c}$ & $\stackrel{\partial}{i}$ & $\sqrt{6}$ & \begin{tabular}{c|c}
0 \\
0 \\
0
\end{tabular} & $\begin{array}{l}2 \\
\vdots \\
0\end{array}$ & $\mid \begin{array}{l}\infty \\
\stackrel{\infty}{0}\end{array}$ & $\stackrel{0}{0}$ & 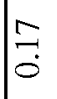 & $\stackrel{m}{0}$ & $\underset{0}{\rightleftharpoons}$ & $\stackrel{?}{=}$ & 疍 & 宐 \\
\hline & & 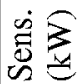 & $\stackrel{i}{i}$ & $\begin{array}{l} \pm \\
\infty \\
\text { ì }\end{array}$ & $\begin{array}{l}+ \\
\infty \\
\text { in }\end{array}$ & $\vec{\sigma}$ & $\begin{array}{l}\dot{U} \\
\dot{m}\end{array}$ & ro & 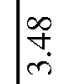 & ס & 8 & $\begin{array}{l}\vec{v} \\
\vec{v}\end{array}$ & io & 둘 & $\stackrel{2}{=}$ & ભે & $\ddot{n}$ & $\frac{\mathrm{i}}{\mathrm{i}}$ & ๙̊ & $\begin{array}{l}\curvearrowleft \\
\check{c}\end{array}$ \\
\hline \multirow{4}{*}{ 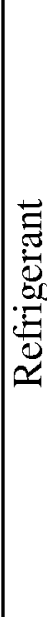 } & $\frac{\alpha}{\Sigma}$ & $\frac{0}{0}$ & $\stackrel{\infty}{\stackrel{\sim}{\sim}}$ & 畓 & רֶ. & $\begin{array}{l}\infty \\
\ddot{S} \\
\end{array}$ & ry & $\stackrel{a}{\bar{\lambda}}$ & $\mid \begin{array}{l}c \\
\infty \\
\infty \\
c\end{array}$ & $\stackrel{J}{\exists}$ & $\begin{array}{l}+ \\
\vdots \\
+\end{array}$ & 气ֶ. & $\begin{array}{l}0 \\
\infty \\
\infty\end{array}$ & $\frac{9}{1}$ & $\underset{\infty}{\sim}$ & $a$ & $\ddot{0}$ & $\begin{array}{l}\partial \\
\stackrel{\alpha}{d}\end{array}$ & $\begin{array}{l}a \\
\infty \\
\infty\end{array}$ & $\begin{array}{l}a \\
\infty \\
\dot{a}\end{array}$ \\
\hline & 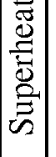 & $\begin{array}{l}0 \\
0\end{array}$ & $\because 6$ & n? & $\begin{array}{l}0 \\
i\end{array}$ & $\begin{array}{l}n \\
6\end{array}$ & $\dot{q}$ & $\vec{s}$ & $\begin{array}{l}0 \\
\text { in }\end{array}$ & is & \begin{tabular}{l|l}
$:$ & 0 \\
$\therefore$ & $v$
\end{tabular} & $\begin{array}{l}\infty \\
\dot{r}\end{array}$ & $\begin{array}{l}\infty \\
\dot{v}\end{array}$ & $\underset{\sim}{\infty}$ & $\begin{array}{l}\infty \\
\dot{\forall}\end{array}$ & 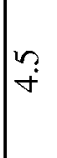 & $\begin{array}{l}\mathscr{0} \\
\dot{+}\end{array}$ & 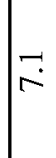 & $\vec{\infty}$ & $\mid \begin{array}{l}\tilde{y} \\
\infty\end{array}$ \\
\hline & $H^{\overrightarrow{0}}$ & 0 & Iִ & I. & $\stackrel{+}{-}$ & $=$ & $\begin{array}{l}0 \\
\text { in }\end{array}$ & $\stackrel{\circ}{-}$ & $\because$ & 7 & a & $?$ & 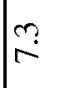 & $\hat{\mathrm{c}}$ & $\begin{array}{l}\infty \\
c \dot{c} \\
c\end{array}$ & à & $\hat{\mathrm{d}}$ & 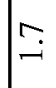 & $\stackrel{-}{-}$ & $\stackrel{\circ}{i}$ \\
\hline & $\left|x^{5}\right|$ & & $\stackrel{1}{3}$ & 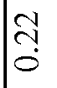 & 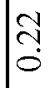 & $\stackrel{\vec{N}}{0}$ & ্ֻণি & $\stackrel{-}{0}$ & $\stackrel{\Xi}{0}$ & $\frac{0}{c}$ & $\stackrel{0}{\circ}$ & $\stackrel{9}{0}$ & $\frac{0}{0}$ & తి & ֻ̊ & กิ & $\vec{\jmath}$ & ڤ్రి & हे & ले \\
\hline \multirow{6}{*}{ 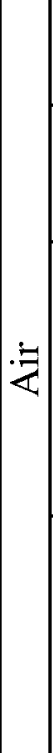 } & $\vec{a}$ & $\tilde{\infty}^{\infty}$ & $\stackrel{\sim}{\dot{\sigma}}$ & $\stackrel{\nabla}{\dot{r}}$ & $\stackrel{F}{+}$ & in & is & مُ & ف & $\gamma$ & $\begin{array}{lll} \\
\end{array}$ & $\begin{array}{l}\text { ra } \\
\text { in }\end{array}$ & ه & $\stackrel{r}{\sim}$ & $\stackrel{m}{q}$ & $\ddot{r i}$ & $\stackrel{0}{0}$ & $\underset{+}{+}$ & $\begin{array}{l}0 \\
\text { ir }\end{array}$ & $\begin{array}{l}b \\
i r \\
i\end{array}$ \\
\hline & $\frac{\alpha}{\pi}$ & ₹ & 离 & in & $\vec{n}$ & 过 & 递 & & $\stackrel{0}{i}$ & v & $\begin{array}{c}8 \\
6 \\
5\end{array}$ & 8 & קे & 吉 & $\frac{n}{i n}$ & 8 & $\stackrel{\cap}{n}$ & $\tilde{n}$ & ga & 18 \\
\hline & \multirow{2}{*}{ 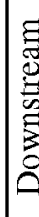 } & 童 & $\stackrel{1}{0}$ & $a$ & 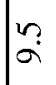 & $\stackrel{m}{0}$ & $\stackrel{1}{\dddot{c}}$ & $\hat{\sigma}$ & $\hat{\sigma}$ & r & $\dot{c}$ & $\stackrel{r}{\ddot{g}}$ & $\begin{array}{l}0 \\
\ddot{2}\end{array}$ & ?ִ & a & $\ddot{2}$ & $\begin{array}{l}n \\
n \\
n\end{array}$ & 占 & $\stackrel{\Xi}{\Xi}$ & ? \\
\hline & & 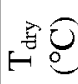 & בֶ & 9 & $\stackrel{\infty}{\beth}$ & $\begin{array}{l}\infty \\
\stackrel{I}{-1}\end{array}$ & $\stackrel{0}{\ddot{m}}$ & $\begin{array}{l}\infty \\
\text { c. } \\
\end{array}$ & $\infty$ & 5 & $\stackrel{0}{0}$ & $\underline{\varrho}$ & 只 & 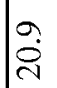 & $\hat{\stackrel{N}{N}}$ & $\ddot{\stackrel{\sim}{~}}$ & 苗 & $\stackrel{+}{\mathrm{I}}$ & $\begin{array}{l}\ddot{n} \\
\ddot{n}\end{array}$ & $\overrightarrow{\dot{\sigma}}$ \\
\hline & \multirow{2}{*}{ 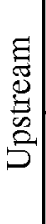 } & 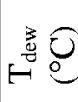 & 3 & 记 & ֶֻ & a & 官 & n & $\begin{array}{l}6 \\
\ddot{g} \\
-\end{array}$ & $\begin{array}{l}\alpha \\
v \\
v\end{array}$ & 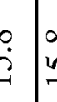 & $\begin{array}{l}\infty \\
\dot{\sim}\end{array}$ & $\ddot{\ddot{\theta}}$ & $\stackrel{-}{\circ}$ & $\underset{\bullet}{*}$ & $\ddot{0}$ & $\begin{array}{l}\infty \\
\ddot{n}\end{array}$ & 它 & $\dot{\sigma}$ & 웅 \\
\hline & & $\begin{array}{l}30 \\
-30 \\
1+0\end{array}$ & 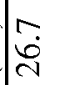 & 灾 & 官 & 吕 & $\begin{array}{l}0 \\
0 \\
\stackrel{0}{0} \\
\end{array}$ & 苂 & $\begin{array}{l}0 \\
\stackrel{0}{0} \\
0\end{array}$ & 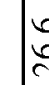 & $\stackrel{0}{0}$ & ڤ્ণ & 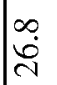 & 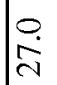 & ڤ్రి & 命 & స્ণ & ن্ণ & 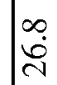 & 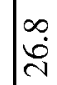 \\
\hline \multicolumn{3}{|c|}{ 高 } & $\stackrel{\Xi}{\sim}$ & 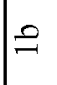 & $\stackrel{0}{\circ}$ & तु & तิ & $\stackrel{\pi}{m}$ & ले & $\nabla$ & t & $n$ & 6 & $\stackrel{\pi}{\sigma}$ & 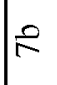 & $\infty$ & $a$ & 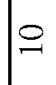 & $\stackrel{\sigma}{=}$ & $\underline{ }$ \\
\hline
\end{tabular}




\begin{tabular}{|c|c|c|c|c|c|c|c|c|c|c|c|c|c|c|c|c|c|c|c|c|c|}
\hline \multirow{5}{*}{ 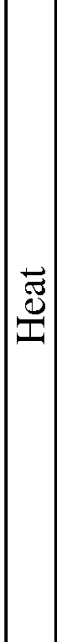 } & 壾 & $8^{\circ}$ & i & $\ddot{m}$ & $\hat{i}$ & $\mid \begin{array}{l}6 \\
i j\end{array}$ & $\begin{array}{l}0 \\
\text { r. }\end{array}$ & & $\infty$ & $\begin{array}{l}6 \\
i\end{array}$ & $\begin{array}{l}\infty \\
i \\
i\end{array}$ & $\stackrel{0}{0}$ & $\stackrel{+}{-}$ & $\infty$ & ij & is & \begin{tabular}{l|l}
$v$ & \\
$v$ &
\end{tabular} & $\frac{t}{i}$ & $\underset{\infty}{\infty}$ & $\stackrel{0}{0}$ & $?$ \\
\hline & $\stackrel{\overrightarrow{\mathbb{\Xi}}}{\simeq}$ & 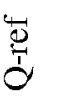 & 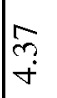 & 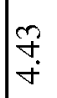 & $\stackrel{i}{i}$ & $\frac{0}{m}$ & $\frac{\eta}{r}$ & & $\begin{array}{l}n \\
m \\
m \\
m\end{array}$ & $\stackrel{\infty}{\stackrel{\infty}{r}}$ & $\begin{array}{l}\infty \\
\infty \\
\dot{n}\end{array}$ & $\stackrel{m}{m}$ & $\stackrel{R}{2}$ & $\stackrel{n}{-}$ & {$\left[\begin{array}{l}\infty \\
\stackrel{\infty}{-}\end{array}\right.$} & $\stackrel{\infty}{\infty}$ & \begin{tabular}{c|c}
0 \\
\\
\end{tabular} & $\begin{array}{l}\text { 导 } \\
\text { i }\end{array}$ & $\begin{array}{l} \pm \\
\dot{m}\end{array}$ & $\begin{array}{l}\vec{b} \\
\text { i }\end{array}$ & $\stackrel{?}{\stackrel{0}{+}}$ \\
\hline & & 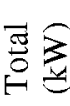 & 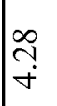 & $\tilde{i}$ & 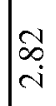 & 究 & $\mid \begin{array}{l}\breve{c} \\
\tilde{m}\end{array}$ & & $\begin{array}{l}\vec{f} \\
\dot{r}\end{array}$ & $\begin{array}{l}\infty \\
\infty \\
\dot{\gamma}\end{array}$ & $\vec{a}$ & $\stackrel{m}{\sim}$ & 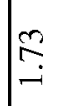 & ర్ర & $\stackrel{\Omega}{-}$ & $\Omega$ & 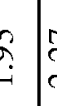 & तु & $\begin{array}{l}\mathscr{1} \\
\dot{r} \\
\dot{r}\end{array}$ & $\begin{array}{l}\mathscr{D} \\
m \\
i\end{array}$ & $\begin{array}{l}\tilde{\sigma} \\
\infty \\
\dot{c}\end{array}$ \\
\hline & 表 & 预 & $\hat{\overbrace{}}$ & f. & $\vec{\infty}$ & . & 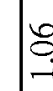 & & 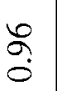 & $\stackrel{ \pm}{\Xi}$ & $\stackrel{ }{\leftrightarrows}$ & $\stackrel{0}{\circ}$ & $\stackrel{2}{0}$ & त̂ & $\vec{\jmath}$ & กิ & vִ & & & 1 & 1 \\
\hline & & 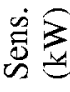 & $\vec{\sigma}$ & $\begin{array}{l}g \\
\dot{r}\end{array}$ & $\underset{c}{8}$ & $\begin{array}{l}\text { î } \\
\text { in }\end{array}$ & $\begin{array}{l}\curvearrowright \\
\text { ri }\end{array}$ & & 尔 & $\frac{r}{i j}$ & $\mid \begin{array}{l}\vec{\infty} \\
\text { i }\end{array}$ & بִ & $\ddot{n}$ & $\vec{\nabla}$ & 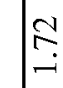 & $\S$ & 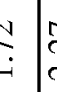 & $\stackrel{\substack{c \\
c i}}{c}$ & $\begin{array}{l}\qquad 0 \\
\dot{r} \\
\dot{m}\end{array}$ & ri & $\begin{array}{l}\approx \\
\infty \\
\dot{\infty}\end{array}$ \\
\hline \multirow{4}{*}{ 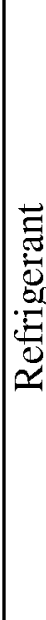 } & $\frac{\alpha}{\sum}$ & $\frac{\infty}{b}$ & बì & $\begin{array}{l}a \\
\infty \\
\infty\end{array}$ & 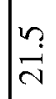 & ㄱ. & $\begin{array}{l}m \\
\sim \\
n\end{array}$ & & 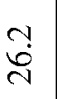 & $\overrightarrow{\dot{\theta}}$ & $\begin{array}{l}a \\
\infty \\
\infty\end{array}$ & $\stackrel{m}{\sharp}$ & $\begin{array}{l}n \\
\infty \\
-1\end{array}$ & $\begin{array}{l}\forall \\
\infty \\
=\end{array}$ & $\stackrel{+}{\partial}$ & $\stackrel{+}{2}$ & 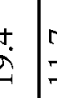 & $\Xi$ & $\stackrel{\infty}{\stackrel{\infty}{=}}$ & $\begin{array}{l}m \\
0 \\
0 \\
i\end{array}$ & $\stackrel{\circ}{\circ}$ \\
\hline & 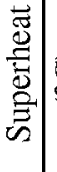 & $\begin{array}{l}0 \\
0\end{array}$ & $\underset{\infty}{\infty}$ & $\mid \begin{array}{l}\infty \\
\infty \\
\infty\end{array}$ & $\begin{array}{l}0 \\
\dot{1}\end{array}$ & $\vec{v}$ & $\underset{\sim}{\infty}$ & & $\begin{array}{l}n \\
n \\
n\end{array}$ & $\underset{v}{+}$ & m & ชె. & ?n & 8 & $\begin{array}{l}0 \\
\text { ir }\end{array}$ & $\vec{r}$ & $\dot{6}$ & $\vec{\nabla}$ & $\stackrel{n}{i}$ & 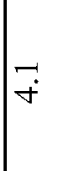 & $\underset{\infty}{-1}$ \\
\hline & $\begin{array}{c}\vec{E} \\
\vec{n} \\
\Leftrightarrow\end{array}$ & 0 & $\stackrel{r}{r}$ & $\stackrel{\sim}{\sim}$ & $\stackrel{n}{r}$ & ? & $\frac{N}{2}$ & & $\underset{\sim}{\checkmark}$ & 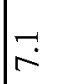 & $\underset{r}{r}$ & בֶ. & \begin{tabular}{l}
$\infty$ \\
\hdashline \\
\end{tabular} & $\ddot{q}$ & $\begin{array}{l}\infty \\
c \\
c\end{array}$ & $\underset{c}{\infty}$ & $\stackrel{0}{j}$ & $\vec{d}$ & $\vec{a}$ & $\begin{array}{l}+ \\
\ddot{3} \\
\end{array}$ & 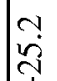 \\
\hline & $x^{\frac{5}{4}}$ & & 疋 & के & 年 & | & $\stackrel{5}{8}$ & 8 & $\stackrel{\square}{\checkmark}$ & $\stackrel{m}{\stackrel{9}{\circ}}$ & $\stackrel{m}{\stackrel{0}{0}}$ & $\stackrel{8}{8}$ & 年 & 吉 & ?ִ & ? & 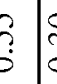 & @̊ & ân & 富 & 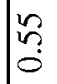 \\
\hline \multirow{6}{*}{$: \exists$} & $\vec{\partial}$ & $\tilde{\sigma}$ & $\stackrel{6}{0}$ & ه & F & F & $\vec{\gamma}$ & $\dot{f}$ & $\vec{r}$ & 8 & ?ֶ. & $\mathscr{f}$ & ? & in & m. & $\stackrel{+}{0}$ & $\dot{0}$ & ְֶ. & $\frac{⿱}{i}$ & 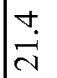 & 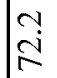 \\
\hline & $\frac{2}{4}$ & $\stackrel{\text { }}{\nexists}$ & $\hat{N}$ & $\vec{r}$ & $\begin{array}{l}3 \\
0\end{array}$ & $\bar{b}$ & in & $\frac{d}{6}$ & $\underset{\forall}{\forall}$ & बे & $\stackrel{2}{R}$ & $\frac{N}{i n}$ & $\stackrel{\infty}{\mathscr{\sigma}}$ & $\begin{array}{l}\infty \\
8 \\
8\end{array}$ & $\stackrel{r}{7}$ & $\stackrel{g}{2}$ & $\tilde{f}$ & 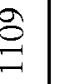 & 茎 & $\underset{\exists}{\sigma}$ & \begin{tabular}{l}
0 \\
đa \\
\multirow{2}{*}{}
\end{tabular} \\
\hline & \multirow{2}{*}{$\mid$} & 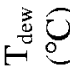 & $\hat{c}$ & בֶ. & $\begin{array}{l}+ \\
\ddot{\theta}\end{array}$ & $\begin{array}{r}0 \\
\dot{r}\end{array}$ & a & 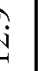 & $\begin{array}{l}m \\
\ddot{g}\end{array}$ & $\overline{c i}$ & $\begin{array}{l}\infty \\
\underset{\sim}{c}\end{array}$ & 둥. & $\mid \begin{array}{l}\infty \\
\ddot{n}\end{array}$ & $\begin{array}{l}\infty \\
\dot{\omega} \\
\sim\end{array}$ & {$\left[\begin{array}{l}\ddot{\varphi} \\
\ddot{n}\end{array}\right.$} & s. & $\dot{0}$ & & & 1 & 1 \\
\hline & & $\begin{array}{l}30 \\
10\end{array}$ & In & $\begin{array}{l}6 \\
\dot{J}\end{array}$ & 6 & 它. & in & ?ִ & 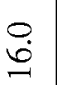 & $\ddot{n}$ & $\vec{n}$ & iे & $\underline{a}$ & ? & $\stackrel{\circ}{\stackrel{i}{0}}$ & : & Pُ & \begin{tabular}{l}
0 \\
\multicolumn{1}{c}{}
\end{tabular} & 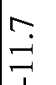 & $\stackrel{m}{m}$ & $\infty$ \\
\hline & \multirow{2}{*}{ 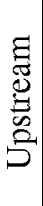 } & 亲 0 & $\begin{array}{l}\infty \\
\ddot{-} \\
-\end{array}$ & ar & $\underline{a}$ & 음 & 2 & !ִ & $\begin{array}{l}\hat{\theta} \\
\dot{\theta}\end{array}$ & 吕 & n & 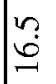 & ○ِ & ชֶ. & 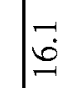 & 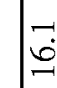 & - & & \begin{tabular}{|l|l}
1 \\
\end{tabular} & ' & 1 \\
\hline & & $\begin{array}{l}30 \\
H 0\end{array}$ & 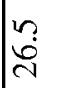 & 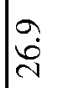 & 奋 & $\begin{array}{l}a \\
0 \\
0\end{array}$ & $\begin{array}{l}6 \\
6 \\
c\end{array}$ & : & 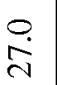 & $\begin{array}{l}\infty \\
\stackrel{\sim}{0} \\
\stackrel{\sim}{0}\end{array}$ & 令 & $\begin{array}{l}\infty \\
\stackrel{\infty}{0} \\
\stackrel{0}{0}\end{array}$ & 我 & $\begin{array}{l}\infty \\
\infty \\
\dot{\phi}\end{array}$ & aे & 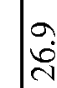 & o. & $\begin{array}{l}m \\
\infty \\
\infty\end{array}$ & $\frac{9}{1}$ & $\frac{9}{1}$ & 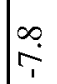 \\
\hline \multicolumn{3}{|c|}{ 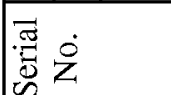 } & 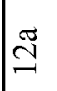 & ิㅡㅁ & $\stackrel{\vec{m}}{=}$ & $\ddot{m}$ & ल & 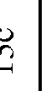 & \pm & $\stackrel{\circledast}{\check{2}}$ & $\ddot{n}$ & 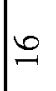 & $\stackrel{\pi}{\check{\sigma}}$ & $\stackrel{0}{\underline{N}}$ & $\infty$ & $\stackrel{0}{\infty}$ & 8 & 2 & i̊ & $\vec{\sim}$ & तี \\
\hline
\end{tabular}




\subsection{Data Reduction and Discussion}

Energy balances were checked for all reported experimental data and found to be within $\pm 3 \%$ except for test series $19-22$, where the refrigerant saturation temperature was around $-23{ }^{\circ} \mathrm{C}$. Since a saturation temperature of $-23{ }^{\circ} \mathrm{C}$ is beyond the normal operating conditions of the present experimental setup, it was difficult for the system to become stabilized. Also, the air stream might still contain a very small amount of moisture and thus influence the energy balance results. Figure 4.1 shows that the energy balance for test series $1-18$ is within $\pm 3 \%$.

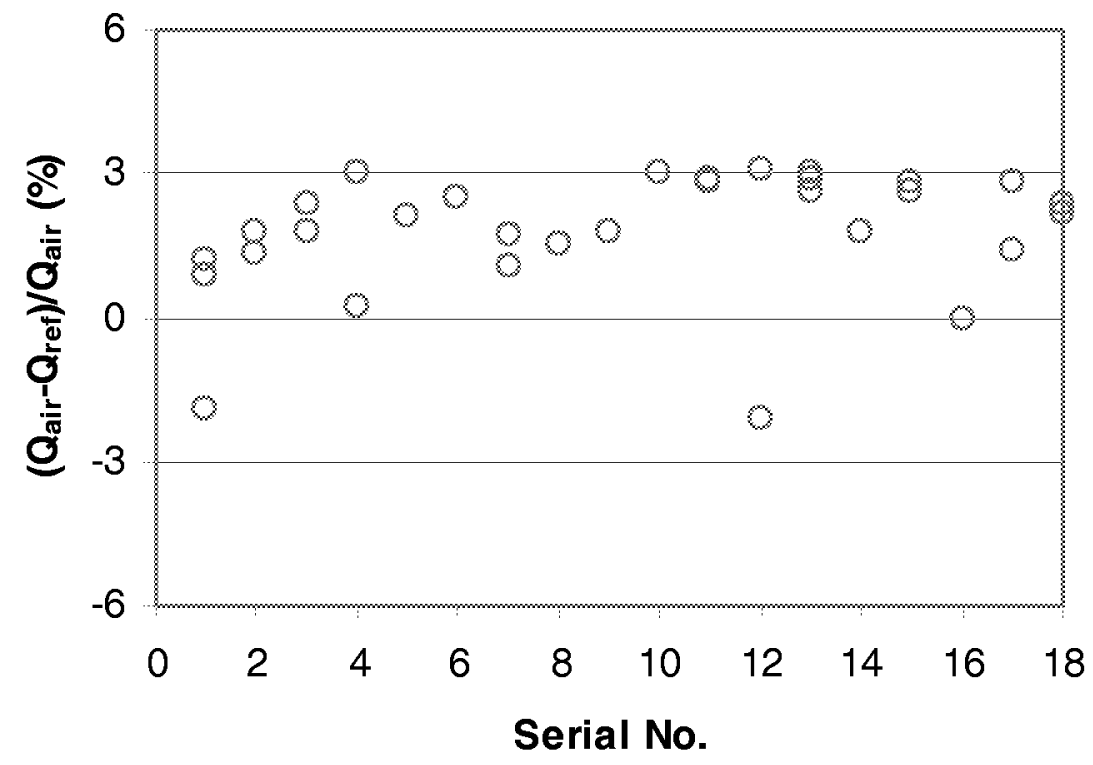

Figure 4.1 Energy balance for evaporation test results

Figure 4.2 depicts the cooling capacity of the evaporator vs. refrigerant mass flow rate for refrigerant inlet vapor qualities of $20 \%$ and $50 \%$ and certain specified outlet superheats. It is clearly shown that the cooling capacity of the evaporator is proportional to the refrigerant mass flow rate when the refrigerant outlet superheats are maintained. Increasing the inlet vapor quality shifts the curve to the right. 
Ordinarily, air side conditions dominate the overall heat transfer coefficient of an evaporator since the air side thermal resistance is much larger than the refrigerant side when the refrigerant experiences phase changes. However, the capacity of an evaporator depends not only on the overall heat transfer coefficient, but also on the temperature difference between the air and refrigerant. This means that the two-phase region in an evaporator influences the capacity of the evaporator significantly by affecting the temperature difference. The capacity of an evaporator increases if the two-phase region occupies a larger area of the evaporator. However, it should be noted that this is only true when the refrigerant is superheated at the outlet of the evaporator.

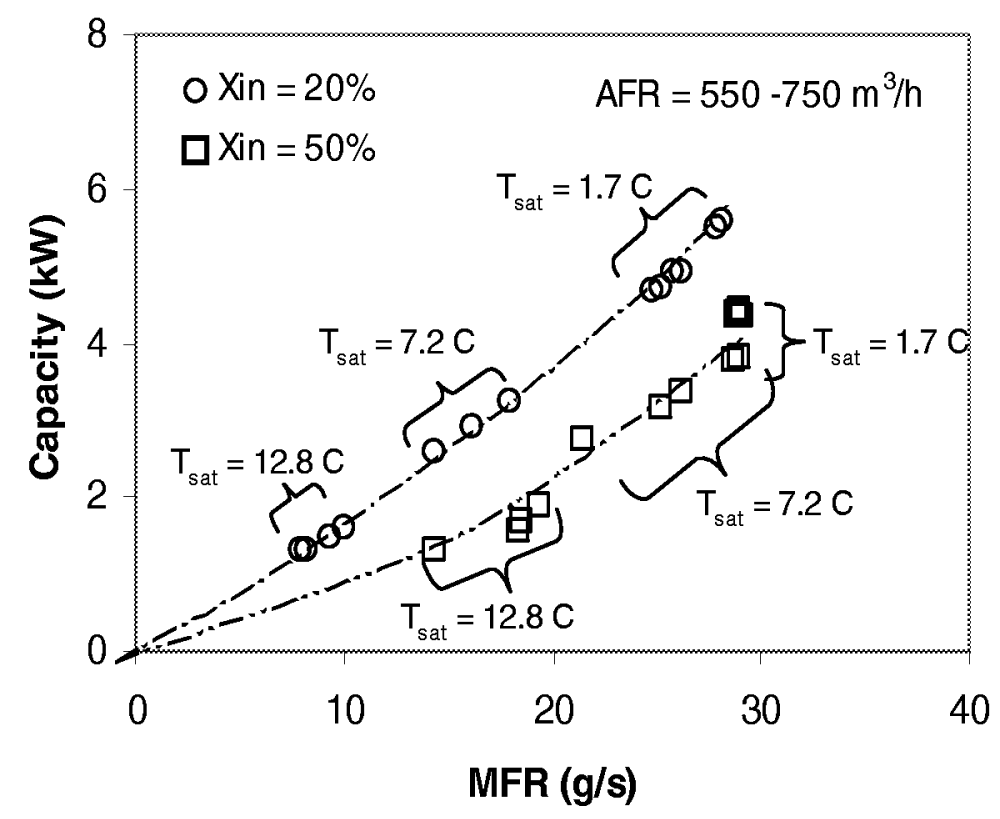

Figure 4.2 Capacity of the evaporator vs. $\mathrm{CO}_{2}$ mass flow rate (MFR)

To better understand the heat transfer process through the evaporator, overall heat transfer coefficients were calculated. The overall heat transfer coefficient is defined as $\mathrm{U}$ 
$=\mathrm{q}$ "/DT, where q" refers to the mean heat flux and DT refers to the temperature difference between the average air temperature (the mean value of upstream and downstream temperatures) and the refrigerant saturation temperature. Since pressure drops of refrigerant side are very small (less than $20 \mathrm{kPa}$, with the corresponding temperature change less than $0.2{ }^{\circ} \mathrm{C}$ ) in the present tests, inlet saturation temperature was selected to represent the refrigerant saturation temperature.

Figure 4.3 depicts the influence of the airflow rate and saturation temperature on the overall heat transfer coefficient for an inlet quality of $20 \%$. Saturation temperature strongly affects the overall heat transfer coefficient. A lower saturation temperature results in a higher overall heat transfer coefficient. This is because the moisture is condensed on the outer surface of the heat exchanger. It is well known that the overall heat transfer coefficient of an evaporator strongly depends on the air-side heat transfer coefficient. The air-side heat transfer is always very weak if the air is dry. However, if the moisture condenses or evaporation takes place, the heat transfer of the air-side will be enhanced significantly since latent heat is much more efficient than sensible heat in a heat transfer process. This will improve the air-side heat transfer coefficient significantly. The lower the saturation temperature, the higher the moisture condensate rate, and thus, higher enhancement on the air-side heat transfer. To verify the explanation experimentally, the ratio of the latent heat to total air-side heat transfer rate is depicted in Figure 4.4. These results clearly show that a lower saturation temperature is associated with a larger percentage of latent heat. 


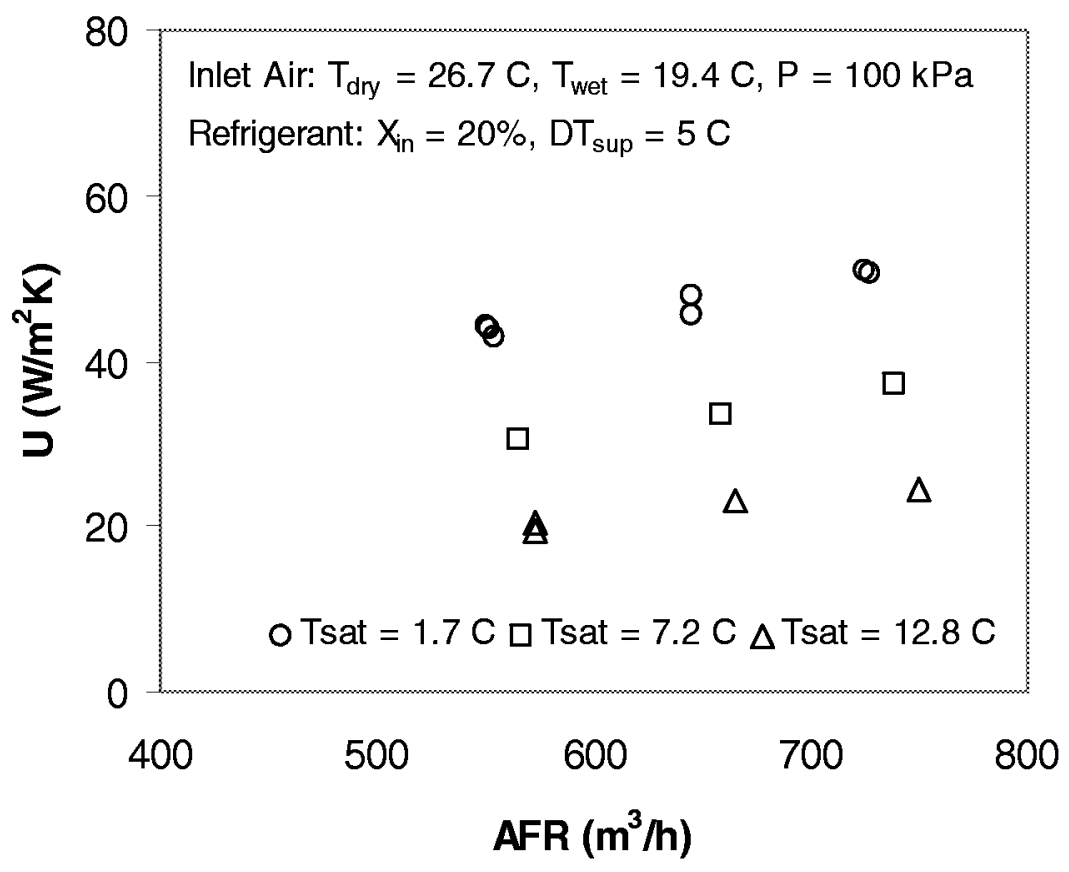

Figure 4.3 Overall heat transfer coefficient vs. air flow rate (AFR)

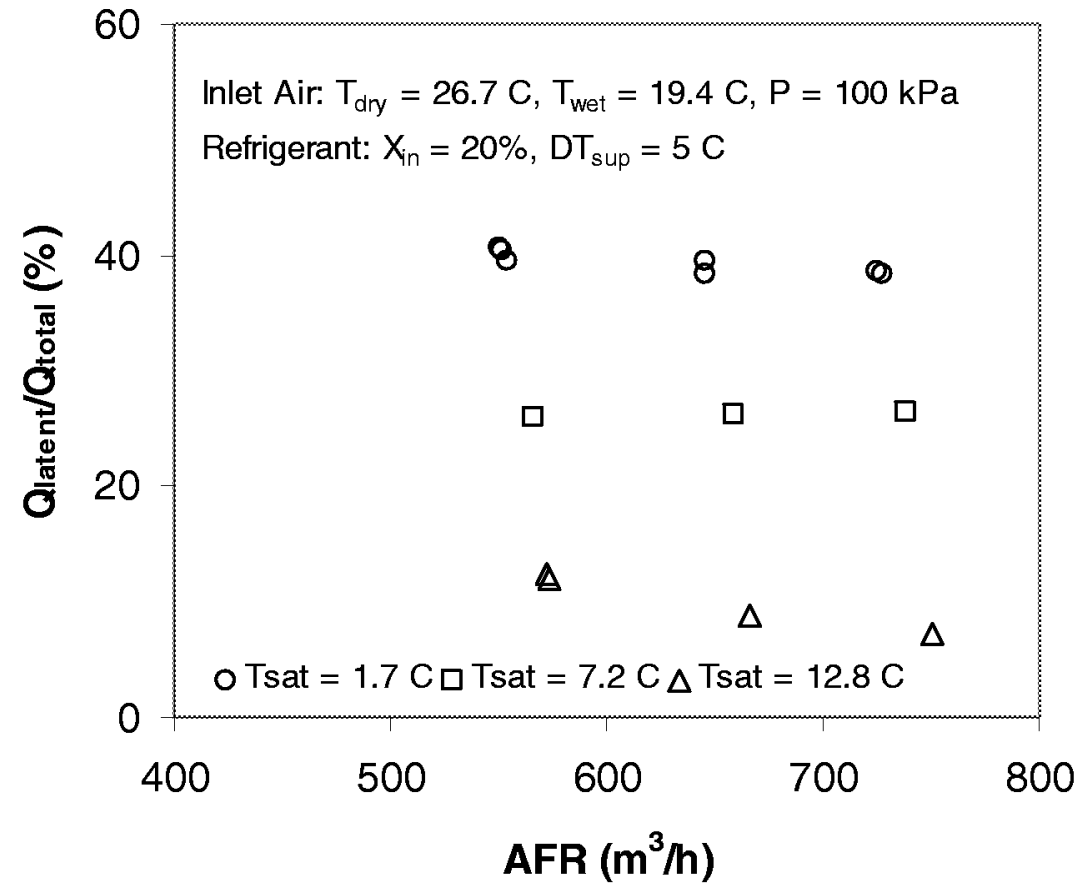

Figure 4.4 Ratio of latent heat to total heat of air side vs. air flow rate (AFR) 
Figures 4.5 and 4.6 present the overall heat transfer coefficient and ratio of the latent heat to the total heat exchange of the air-side for a refrigerant inlet vapor quality of $50 \%$, respectively. In Figure 4.5, the overall heat transfer coefficient for $\mathrm{T}_{\text {sat }}=1.7{ }^{\circ} \mathrm{C}$ is comparable to that of $\mathrm{T}_{\text {sat }}=7.2^{\circ} \mathrm{C}$. This is due to the fact that, during the experiments, it was very difficult to precisely maintain the superheat at certain values. The experimental results for $\mathrm{T}_{\text {sat }}=1.7^{\circ} \mathrm{C}$ have larger outlet superheat $\left(>8{ }^{\circ} \mathrm{C}\right)$ than the other two test serials (around $5^{\circ} \mathrm{C}$ ). Since larger superheats means larger heat transfer surface area occupied by superheated vapor, the overall heat transfer coefficient reduces.

Figures 4.7 and 4.8 present the air-side pressure drop as a function of air flow rate at different saturation temperatures for an inlet vapor quality of $20 \%$ and $50 \%$, respectively. The air-side pressure drop is expected to increase with an increasing air flow rate. The pressure drop is slightly higher for lower saturation temperatures. This can be explained by the fact that more water condenses on the outer surface of the evaporator, retarding the air flow to a greater extent.

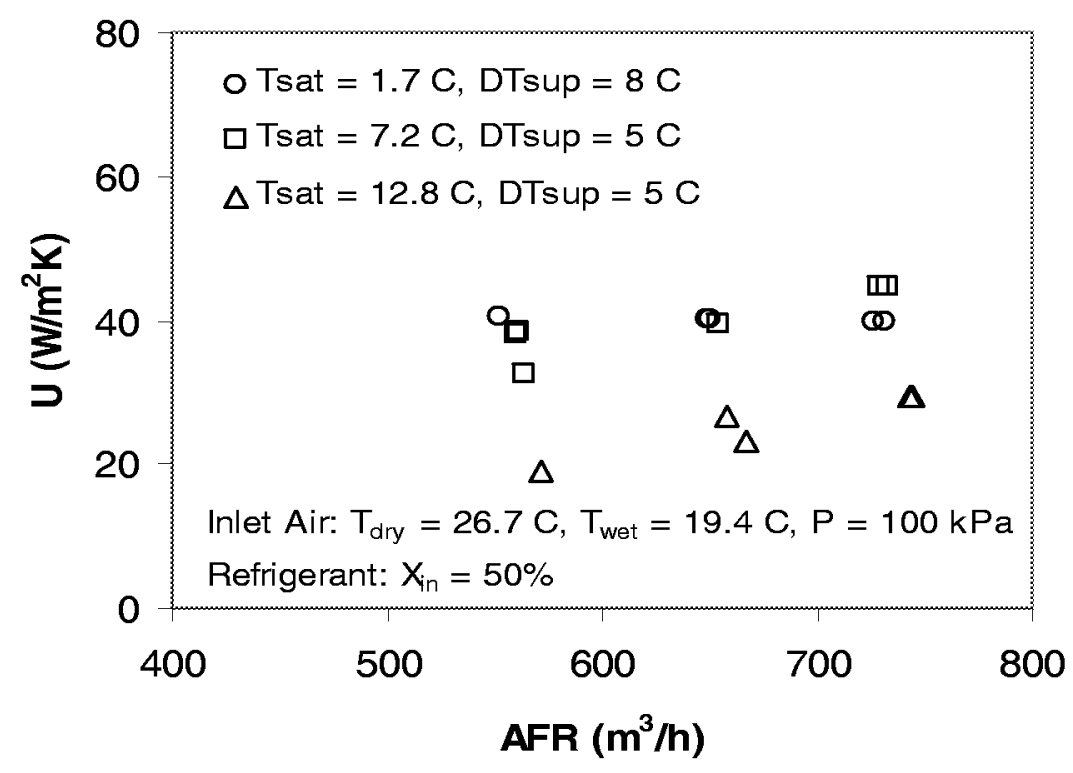

Figure 4.5 Overall heat transfer coefficient vs. air flow rate (AFR) 


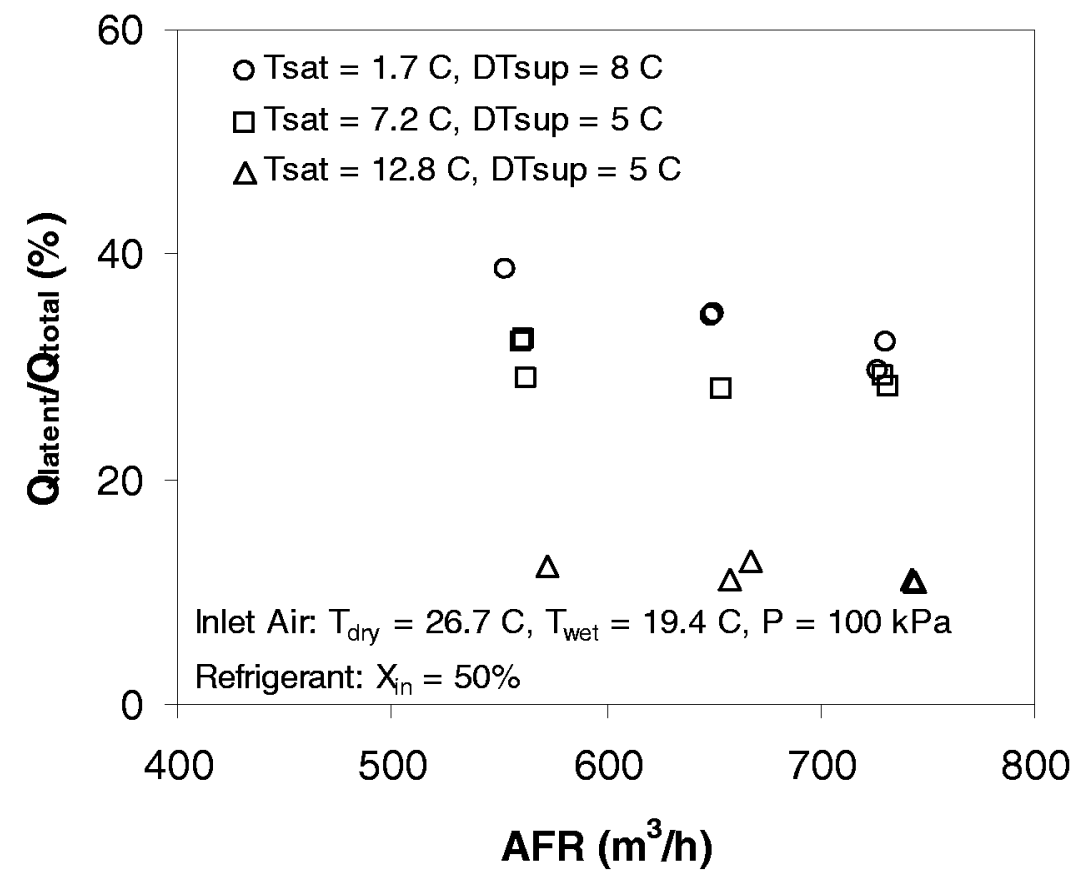

Figure 4.6 Ratio of latent heat to total heat of air side vs. air flow rate (AFR)

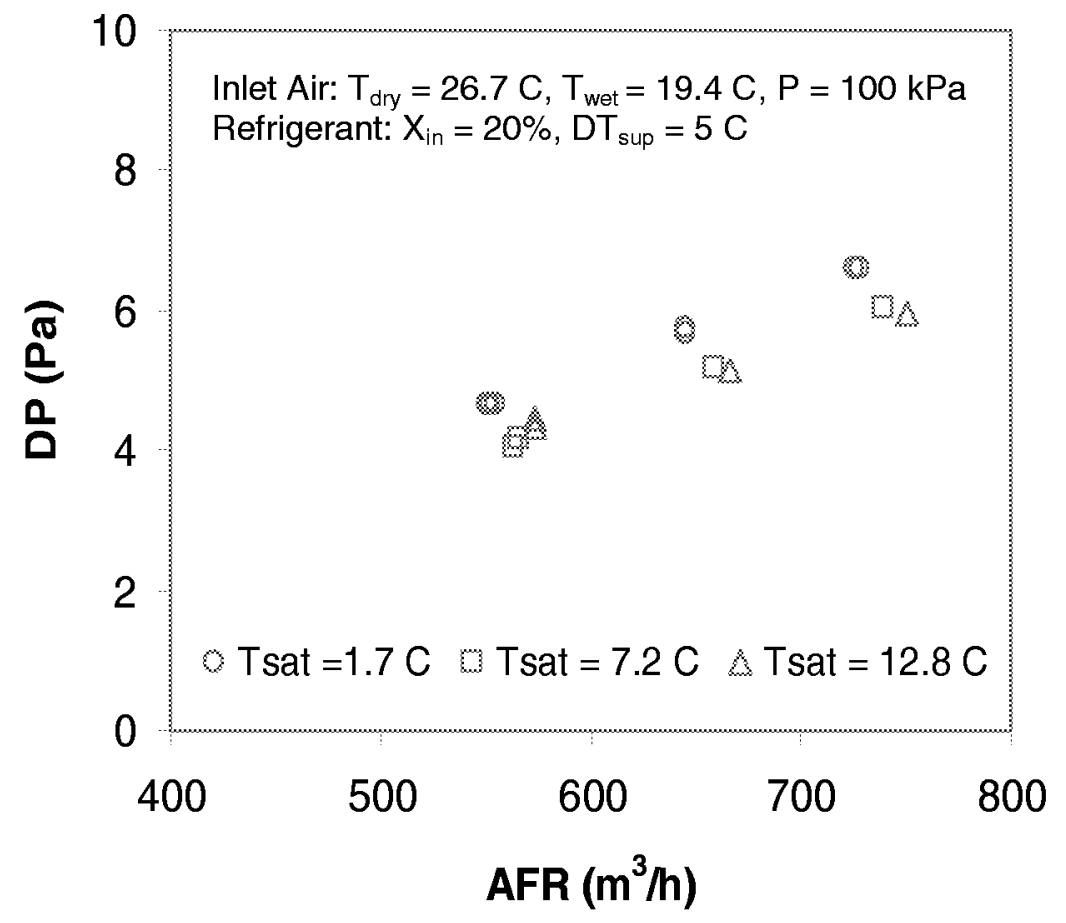

Figure 4.7 Pressure drop of air vs. air flow rate 


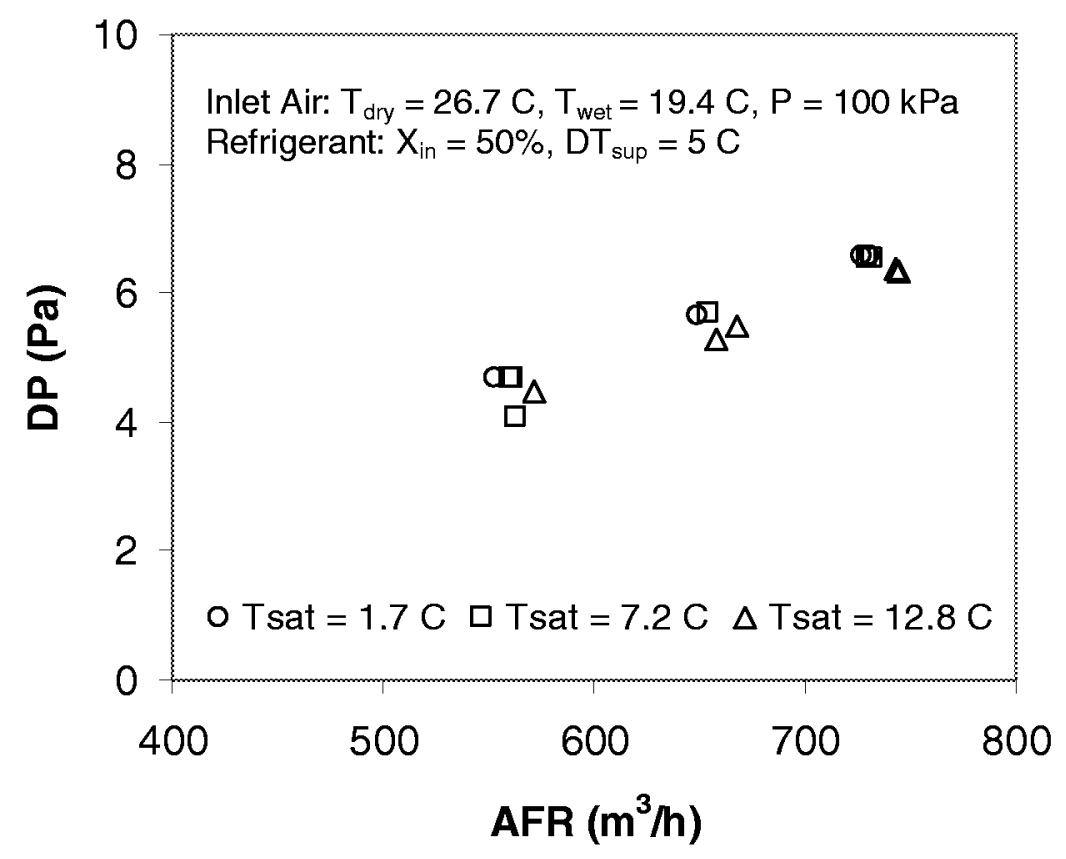

Figure 4.8 Pressure drop of air vs. air flow rate

\subsection{Capacity Predictive Model for Microchannel Evaporators}

The present experiments provide extensive data under different test conditions. The data can be used as a platform to develop prediction models for the evaporator capacity.

The capacity of an evaporator can be expressed as:

$$
Q=U \cdot A \cdot D T
$$

From Figs 4.3 - 4.6, it is clear that overall heat transfer coefficient $U$ depends on many factors such as moisture condensation, refrigerant outlet superheat, air flow rate, fin geometry, etc.

The experimental results show that a larger amount of moisture condensation will improve air side heat transfer coefficient and thus resulting in higher overall heat transfer 
coefficient. To reflect the moisture condensate effect, a new factor, Cta, is defined as follows:

$$
\begin{array}{ll}
\text { For } \mathrm{T}_{\text {air-in-dew }} \geq \mathrm{T}_{\text {ref-sat }}, & \text { Cta }=\frac{T_{\text {air-in-dew }}-T_{\text {ref-sat }}}{T_{\text {air-in-dry }}-T_{\text {ref-sat }}} \\
\text { For } \mathrm{T}_{\text {air-in-dew }}<\mathrm{T}_{\text {ref-sat }}, & \text { Cta }=0
\end{array}
$$

Figure 4.9 shows the overall heat transfer coefficient versus Cta. Generally, the overall heat transfer coefficient increases with increasing Cta. However, there is some data scatter as shown in Figure 4.9. This is due to the effects of some other factors. To develop a successful model, those effects also need to be addressed.

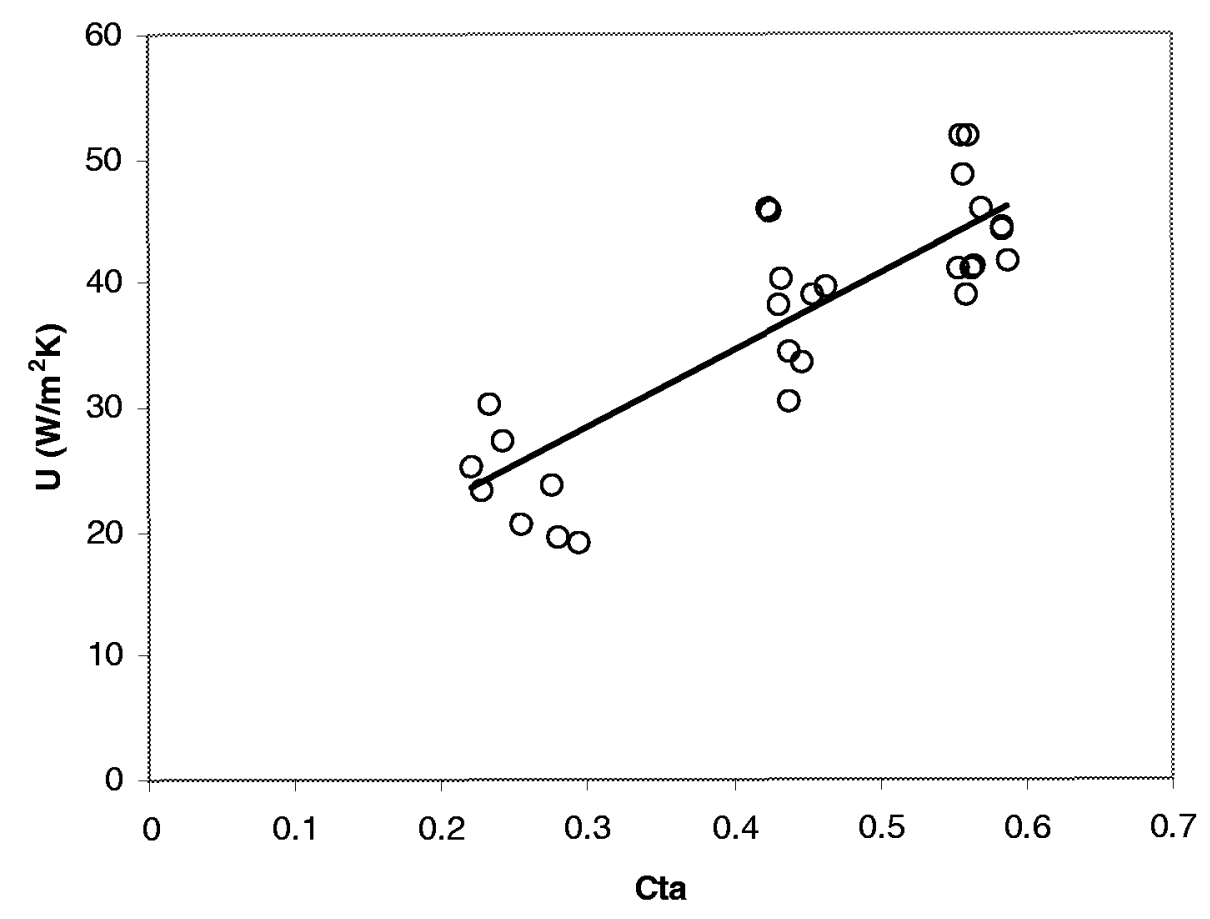

Figure 4.9 Overall heat transfer coefficient vs. Cta

To reflect the effects of refrigerant superheat at the outlet of evaporator, another factor Bta is defined as: 


$$
B t a=\frac{T_{r e f-o u t}-T_{r e f-s a t}}{T_{\text {air-in-dry }}-T_{\text {ref-sat }}}
$$

As shown in Figure 4.10, the overall heat transfer coefficient generally decreases with increasing Bta. It reflects the fact that, in a typical evaporator, the heat transfer performance decreases with increasing the refrigerant outlet superheat.

Figures 4.9 and 4.10 reflect the effects of moisture condensate and refrigerant superheat on the heat transfer performance of the evaporator.

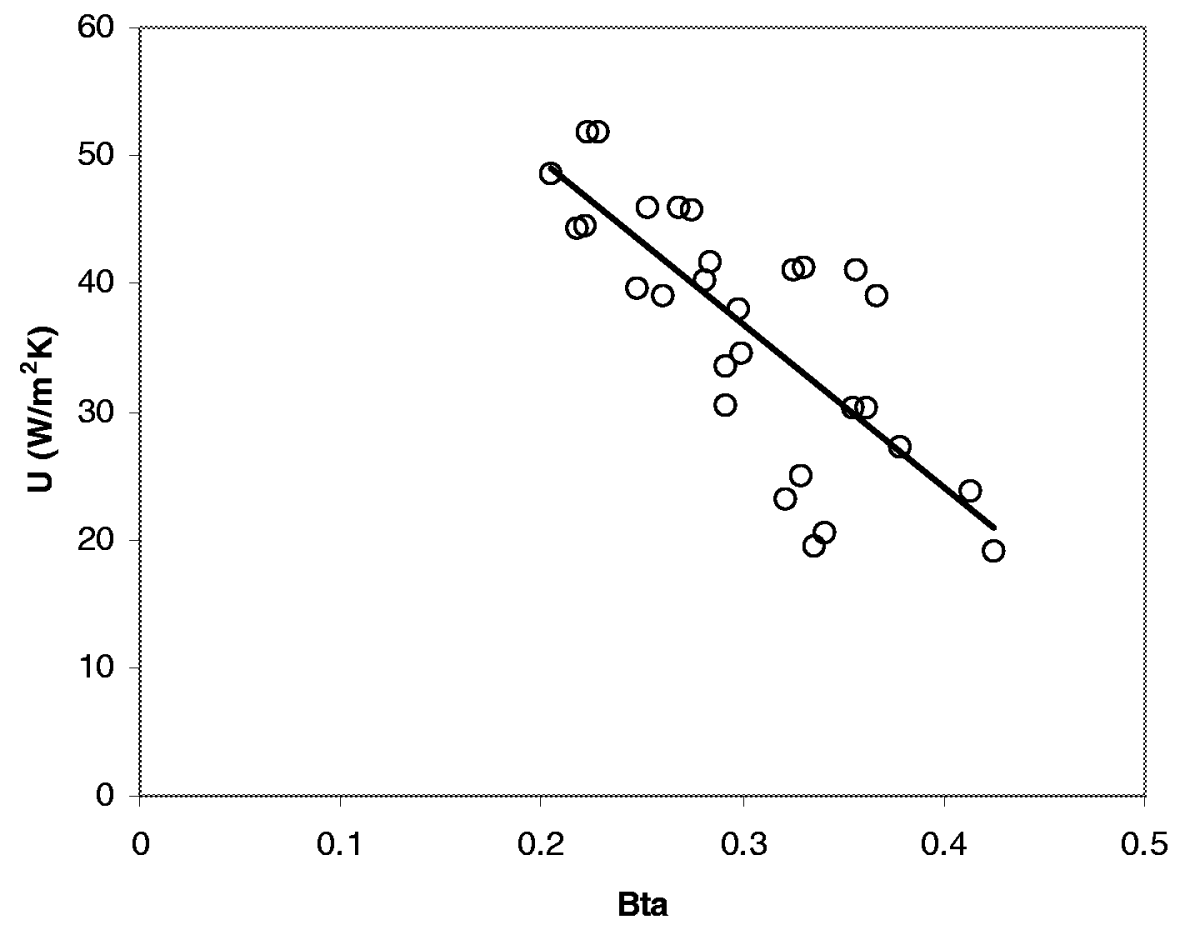

Figure 4.10 Overall heat transfer coefficient vs. Bta

Therefore, a new model is proposed for predicting the capacity of the microchannel evaporator that accounts for the above-mentioned factors. It is as follows:

$$
Q=A \cdot D T \cdot \frac{G_{a i r} \cdot C_{p}}{\operatorname{Pr}_{a i r}^{2 / 3}}\left(0.0185-3.467 \times 10^{-5} \mathrm{Re}_{a i r}\right)(1+6.343 C t a)^{0.8}(1-0.75 B t a)^{0.65}
$$




$$
\begin{gathered}
\operatorname{Re}_{a i r}=\frac{G_{a i r} \delta}{\mu_{a i r}} \\
G_{a i r}=\frac{\dot{m}_{a i r}}{A_{\text {air }- \text { face }}}
\end{gathered}
$$

$A_{\text {air-face }}$ is face area of the evaporator regardless of the microchannel tubes and fins. $\delta$ refers to the fin spacing. DT is the difference between the average temperature of air upstream and downstream and refrigerant saturation temperature.

Figure 4.11 presents comparison of the predicted capacity with the experimental results. The proposed empirical model can predict experimental results within $\pm 13 \%$ (for $\mathrm{Cta}<0.6$ and $\mathrm{Bta}<0.45)$.

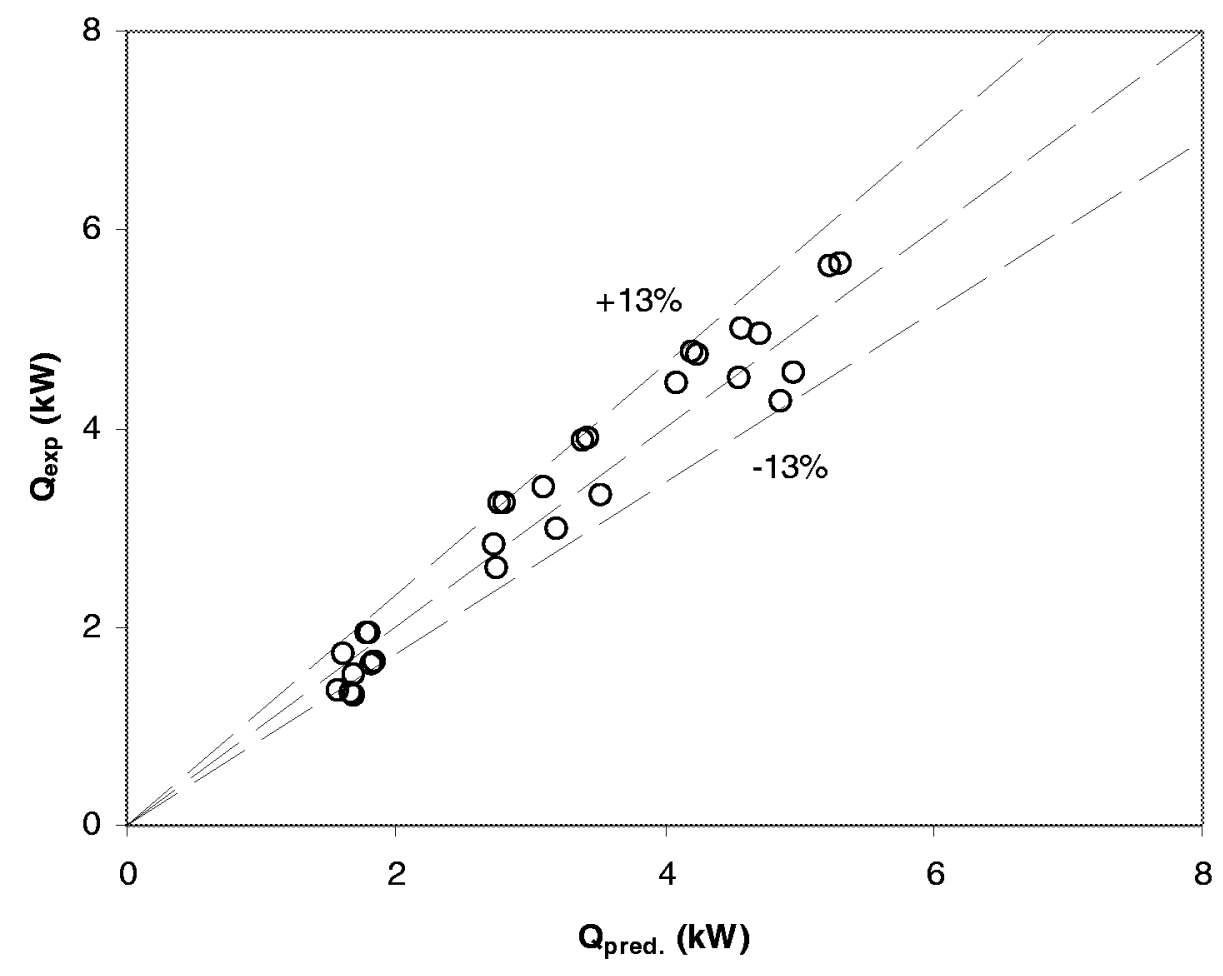

Figure 4.11 Compresion between the model predictions and experimental results 


\section{CHAPTER 5 EXPERIMENTAL TESTS FOR MICROCHANNEL GAS COOLER}

In this chapter, the experimental data for the gas cooler test conditions will be presented. Then, data analysis and prediction models will be discussed.

\subsection{Experimental Test Conditions}

Experimental tests for the microchannel gas cooler were conducted in an outdoor chamber. The system was allowed about two hours to reach a steady-state condition for any specific test conditions. Data was taken once the steady-state conditions were achieved and remained constant for 30 minutes. Data was recorded for 40 minutes for each test condition and averaged over time.

Experimental test conditions for the gas cooler, as specified in the proposal of Microchannel Heat Exchangers with Carbon Dioxide (Ohadi, et al., 1999) are tabulated

in Table 5.1. In the proposal, all parameters are given in SI Units. Table 5.2 lists the proposed test conditions in SI units.

The test conditions of $\mathrm{P}_{\text {in }}=13.79 \mathrm{MPa}$ (test series $15-21$ ) were beyond the capacity of the current test facilities. In the present test setup, the Dorin compressor could only permit a high-side pressure of $12.5 \mathrm{MPa}$. Therefore, during the experiments, the refrigerant pressure at the inlet of the gas cooler for test serial No. $15-21$ was set at around 12.5 MPa.

In Chapter 5, all properties related to air were based on dry air properties. 


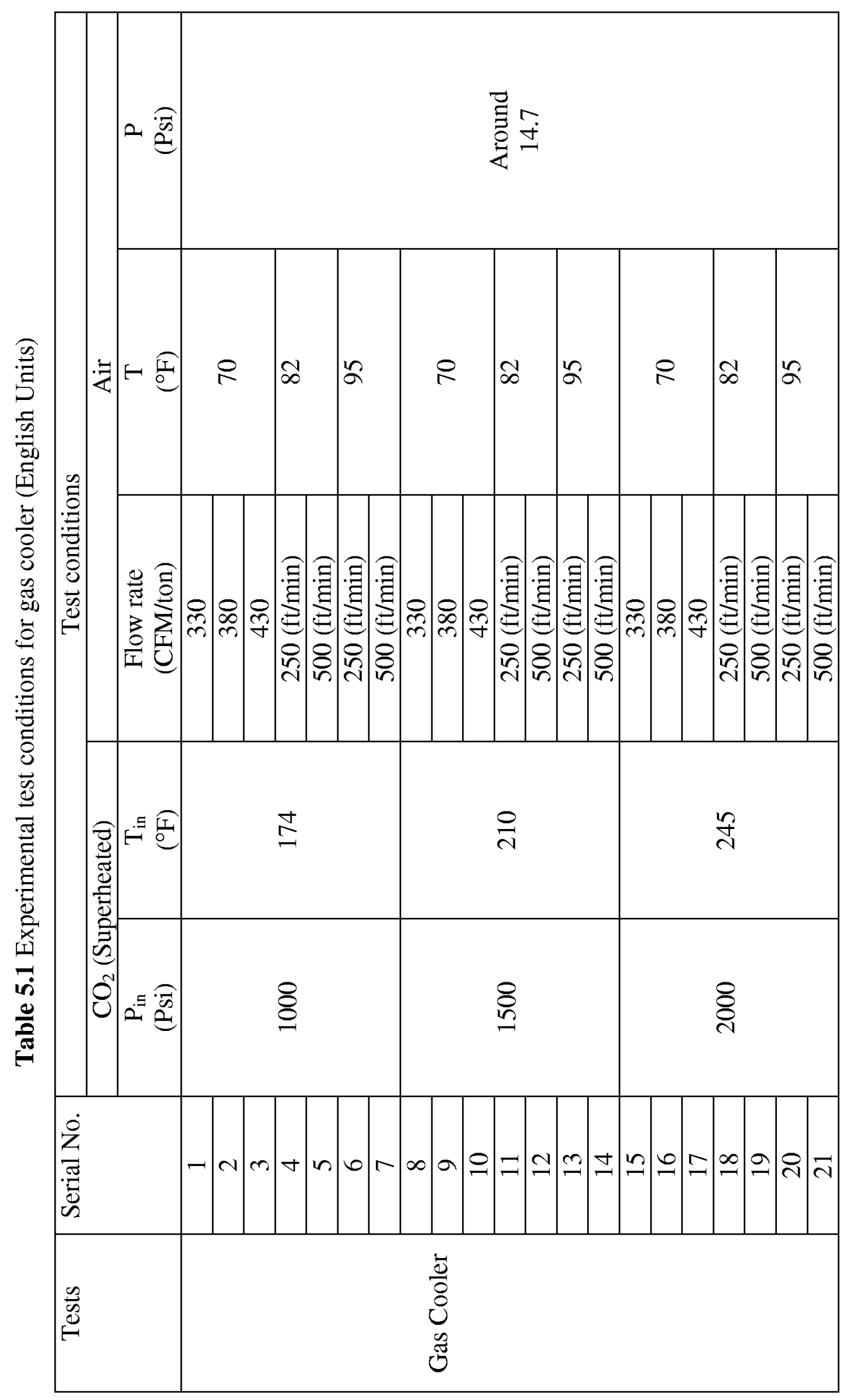




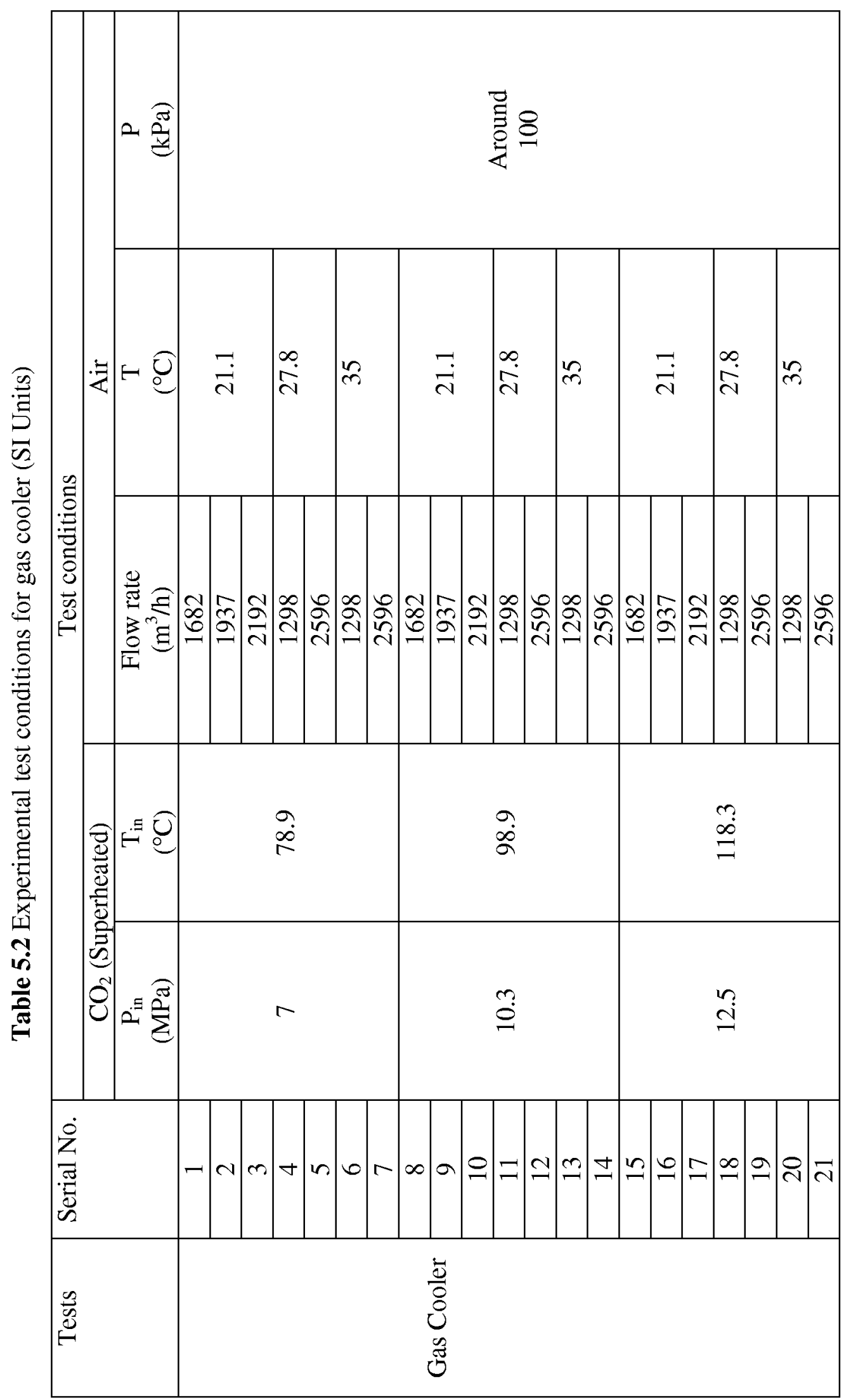




\subsection{Experimental Test Results}

Table 5.3 lists all raw experimental data for the gas cooler test conditions. The first column in the table indicates the test serial number. Because refrigerant mass flow rates are not specified in the proposal, some test series were repeated at the same proposed conditions, but at a different refrigerant mass flow rate. This can help us to better understand the effect of refrigerant mass flow rate.

Since the inlet conditions (pressure and temperature) of the refrigerant at the gas cooler strongly depend on the discharge conditions of the compressor, pressure and temperature of the refrigerant at the gas cooler inlet are related to each other to some extent. Therefore, the refrigerant inlet pressure and temperature are very difficult to set perfectly simultaneously. This means that each experimental data point might have a very accurate match (normally within $0.5{ }^{\circ} \mathrm{C}$ for temperature, $5 \%$ for pressure) on either the proposed pressure or the temperature, but have a less accurate match on the other. Experimental tests showed that the pressure of the refrigerant has a stronger effect on the heat transfer process of the gas cooler than temperature. 


\begin{tabular}{|c|c|c|c|c|c|c|c|c|c|c|c|c|c|c|c|c|c|c|}
\hline \multirow{2}{*}{ 离 } & $\sigma^{\circ}$ & 盗 & 冓 & $\underset{f}{F}$ & 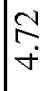 & $\underset{r}{ }$ & 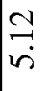 & ?ִ & $\underset{\infty}{9}$ & $\underset{\infty}{\stackrel{f}{+}}$ & $\stackrel{+}{\leftrightarrows}$ & ma & $\begin{array}{l}n \\
m \\
i n\end{array}$ & $\stackrel{m}{\infty}$ & $\stackrel{2}{2}$ & $\begin{array}{l}0 \\
2 \\
2\end{array}$ & $\frac{d}{\stackrel{\Delta}{r}}$ & 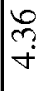 \\
\hline & $\ddot{\mathscr{g}}$ & 登 & $\stackrel{?}{r}$ & $\stackrel{\hat{\infty}}{\dot{\gamma}}$ & 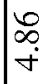 & $\stackrel{m}{r}$ & in & r & $\begin{array}{l}m \\
\infty \\
\infty\end{array}$ & $\begin{array}{l}\vec{m} \\
m \\
\infty\end{array}$ & $\begin{array}{l}0 \\
\text { in }\end{array}$ & $\begin{array}{l}\text { in } \\
\text { in }\end{array}$ & $\begin{array}{l}m \\
\text { in }\end{array}$ & $\begin{array}{l}\delta \\
\infty \\
\infty\end{array}$ & $\stackrel{2}{2}$ & $\frac{2}{2}$ & $\begin{array}{l}\infty \\
\infty \\
\dot{r}\end{array}$ & 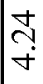 \\
\hline \multirow{14}{*}{ 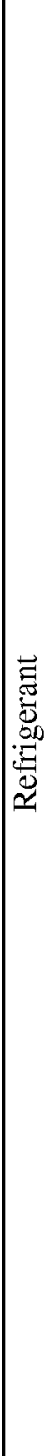 } & $\Xi$ & 0 & $\mid \frac{0}{\dot{N}}$ & $\begin{array}{l}0 \\
\ddot{\gamma} \\
\tilde{\Omega}\end{array}$ & $\begin{array}{l}0 \\
\tilde{N}\end{array}$ & $\frac{\text { I }}{3}$ & $\frac{n}{2}$ & $\stackrel{\infty}{i}$ & 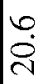 & 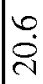 & 오․ & $\vec{\lambda}$ & $\exists$ & à & $\begin{array}{l}\infty \\
\infty \\
\infty \\
i\end{array}$ & $\mid \begin{array}{l}a \\
\infty \\
\infty\end{array}$ & $\frac{m}{m}$ & 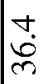 \\
\hline & $\underset{\Leftrightarrow}{\stackrel{ }{F}}$ & $\int_{0}^{0}$ & $\begin{array}{l}\dot{\Delta} \\
\text { ì }\end{array}$ & $\stackrel{-}{\Delta}$ & i & 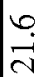 & $\begin{array}{l}0 \\
\dot{\vec{i}}\end{array}$ & $\overrightarrow{\mathrm{N}}$ & $\hat{\vec{s}}$ & $\hat{\mathrm{s}}$ & $\frac{\pi}{\sim}$ & $\frac{\vec{\Delta}}{\overrightarrow{\mathrm{d}}}$ & 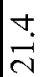 & $\stackrel{m}{m}$ & g. & $\vec{d}$ & $\begin{array}{l}+ \\
\infty \\
\infty\end{array}$ & 离 \\
\hline & $\hat{\theta}$ & $0_{0}^{0}$ & $\begin{array}{l}0 \\
\dot{n} \\
\ddot{n}\end{array}$ & $\begin{array}{l}0 \\
\stackrel{a}{a}\end{array}$ & $\frac{n}{\sim}$ & तָ & $\begin{array}{l}m \\
\ddot{n} \\
\ddot{a}\end{array}$ & त̂̀ & 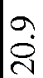 & 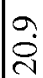 & $\mid \begin{array}{l}\infty \\
\dot{\sim}\end{array}$ & 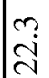 & ત̇ & m. & $\stackrel{\sim}{a}$ & $\begin{array}{l}0 \\
\stackrel{0}{2}\end{array}$ & ㅇ. & $\frac{n}{n}$ \\
\hline & $\infty$ & $\bigcup_{0}^{0}$ & $\vec{d}$ & $\begin{array}{l}0 \\
\infty \\
\infty\end{array}$ & $\begin{array}{l}0 \\
\infty \\
0\end{array}$ & $\begin{array}{l}\Delta \\
\ddot{d}\end{array}$ & $\mid \begin{array}{r}0 \\
i \\
i\end{array}$ & $\ddot{\Omega}$ & $\exists$ & $\stackrel{-}{\vec{\sigma}}$ & $\begin{array}{l}n \\
\text { sin }\end{array}$ & $\begin{array}{l}\sim \\
\ddot{z}\end{array}$ & $\vec{\partial}$ & $\frac{9}{3}$ & O্̊日) & ت্ & a & $\frac{9}{\Omega}$ \\
\hline & $\hat{F}$ & ${ }_{0}^{0}$ & $\begin{array}{l}\forall \\
\infty \\
0 \\
d\end{array}$ & 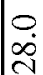 & $\begin{array}{l}0 \\
\infty \\
0 \\
0\end{array}$ & 苂 & 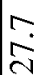 & s. & ì & $\stackrel{r}{\Omega}$ & $\begin{array}{l}n \\
2 \\
2\end{array}$ & $\begin{array}{l}\infty \\
\ddot{n} \\
\end{array}$ & 今. & 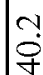 & $\stackrel{\infty}{-}$ & $\stackrel{9}{-1}$ & $\stackrel{+}{\dot{\theta}}$ & $\begin{array}{l}m \\
\infty \\
\infty\end{array}$ \\
\hline & $\stackrel{\odot}{\bullet}$ & $\bigcup_{0}^{0}$ & $\mid \begin{array}{l}\infty \\
\dot{m} \\
\text { m. }\end{array}$ & r. & - & å & $\stackrel{i}{i}$ & $\mid \begin{array}{c}r \\
\infty \\
0\end{array}$ & $\begin{array}{l}\infty \\
\ddot{2}\end{array}$ & $\begin{array}{l}n \\
\tilde{a}\end{array}$ & $\begin{array}{l}\text { cy } \\
\infty \\
\text { d. }\end{array}$ & $\mid \begin{array}{l}\dot{v} \\
\dot{0} \\
a\end{array}$ & $\begin{array}{l}\checkmark \\
\dot{0} \\
i\end{array}$ & ঙ্ণ & $\begin{array}{l}\ddot{m} \\
\ddot{m}\end{array}$ & $\begin{array}{l}0 \\
\ddot{m}\end{array}$ & 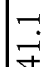 & $\infty$ \\
\hline & $\tilde{\varphi}$ & O & $\vec{m}$ & $\begin{array}{l}n \\
\infty \\
\infty \\
c\end{array}$ & $\begin{array}{l}n \\
\infty \\
0\end{array}$ & $\exists$ & $\mid \infty$ & @্ & $\begin{array}{l}\text { N } \\
\infty \\
\infty \\
d\end{array}$ & $\infty$ & $\begin{array}{l}m \\
\infty \\
0\end{array}$ & $\begin{array}{l}\Delta \\
\infty \\
\infty\end{array}$ & 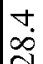 & $\stackrel{+}{\dot{J}}$ & $\ddot{0}$ & $\ddot{0}$ & 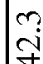 & $\vec{\sigma}$ \\
\hline & $\stackrel{ \pm}{ \pm}$ & ${ }_{0}^{0}$ & $\begin{array}{l}b \\
\infty \\
m\end{array}$ & g. & 옹 & $\begin{array}{l}\infty \\
\infty \\
i \\
r\end{array}$ & $\frac{a}{2}$ & $\begin{array}{l}\infty \\
m \\
m\end{array}$ & ris & 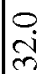 & $\mid \begin{array}{l}0 \\
\infty \\
0\end{array}$ & $\mid \begin{array}{l}n \\
\infty \\
\infty\end{array}$ & $\begin{array}{l}n \\
\infty \\
0 \\
d\end{array}$ & $\begin{array}{l}+ \\
\dot{0}\end{array}$ & $\begin{array}{l}+ \\
\infty \\
\infty \\
\infty\end{array}$ & 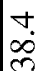 & $\begin{array}{l}+ \\
\dot{g}\end{array}$ & $\ddot{q}$ \\
\hline & $\hat{\theta}$ & O & 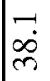 & 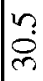 & : & $\begin{array}{l}0 \\
\dot{m} \\
\dot{m}\end{array}$ & बें & $\begin{array}{c}m \\
\ddot{m} \\
m\end{array}$ & & $\begin{array}{l}\infty \\
\infty \\
\infty \\
\infty\end{array}$ & $\frac{\pi}{8}$ & $\mid \begin{array}{l}0 \\
\dot{i}\end{array}$ & i̊. & 政 & $\underset{\forall}{\stackrel{8}{q}}$ & $\underset{\forall}{\rightleftarrows}$ & $\begin{array}{l}m \\
b \\
0\end{array}$ & $\begin{array}{l}\infty \\
\stackrel{\sim}{\sim}\end{array}$ \\
\hline & $\tilde{N}$ & O & $\vec{m}$ & $\begin{array}{l}\text { ra } \\
\ddot{n}\end{array}$ & $\vec{n}$ & ra & $\ddot{m}$ & 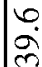 & 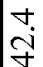 & 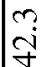 & $\begin{array}{l}0 \\
m \\
m\end{array}$ & $\begin{array}{l}\dot{\sigma} \\
\dot{m}\end{array}$ & $m$ & 议 & 离 & 离 & a & 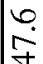 \\
\hline & $\bar{E}$ & ${ }_{0}^{0}$ & $\underset{\infty}{\infty}$ & 2 & 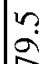 & $\underset{\infty}{+}$ & ? & 3 & gे & $\mid \begin{array}{l}\infty \\
2\end{array}$ & 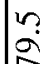 & $\underset{\infty}{\sim}$ & 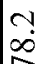 & $\mid \begin{array}{l}\infty \\
\Omega \\
\Omega\end{array}$ & $=$ & $\begin{array}{l}\sim \\
\infty \\
\infty\end{array}$ & $\mid \begin{array}{l}0 \\
i \\
\infty\end{array}$ & $F$ \\
\hline & $\frac{\alpha}{x_{i}^{\prime}}$ & $\frac{\infty}{\infty \infty}$ & $\begin{array}{l}\infty \\
\text { i } \\
\text { in }\end{array}$ & $\ddot{n}$ & $\stackrel{+}{\stackrel{\Delta}{8}}$ & $\ddot{n}$ & $\underset{\text { a }}{\nexists}$ & $\frac{\sim}{m}$ & 离 & in & $\stackrel{g}{8}$ & $\mid \begin{array}{l}\infty \\
\stackrel{d}{d}\end{array}$ & 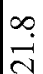 & ন্. & & & $\begin{array}{l}\hat{\lambda} \\
\hat{z}\end{array}$ & : \\
\hline & $2^{\bar{O}}$ & 芉 & 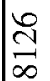 & do & f & $\stackrel{2}{2}$ & 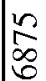 & $\begin{array}{l}\infty \\
\infty \\
\infty \\
\infty\end{array}$ & స్ & $\frac{\infty}{2}$ & $\frac{2}{8}$ & 2 & $\frac{2}{8}$ & కా & $\mid \begin{array}{l}2 \\
\infty \\
\infty \\
\infty\end{array}$ & 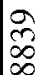 & $\begin{array}{l}\frac{a}{2} \\
\frac{1}{\infty}\end{array}$ & $\underset{\infty}{\infty}$ \\
\hline & $a^{\circ}$ & 音 & $\frac{⿱ 亠}{\infty}$ & 我 & f & $\stackrel{m}{2}$ & {$\left[\begin{array}{l}\infty \\
\infty \\
\infty\end{array}\right.$} & $\stackrel{0}{\infty}$ & 2 & $\mid \begin{array}{l}\not \\
\infty \\
\infty\end{array}$ & 文 & 8 & gे & $\frac{2}{9}$ & $\mid \begin{array}{l}0 \\
\infty \\
\infty \\
\infty\end{array}$ & $\mid \begin{array}{r}\not \\
\infty \\
\infty \\
\infty\end{array}$ & $\underset{\infty}{\stackrel{2}{\infty}}$ & $\underset{\sim}{\Xi}$ \\
\hline \multirow{4}{*}{ 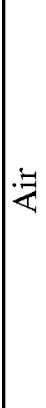 } & $\hat{\mathrm{a}}$ & $\approx$ & $n$ & $g$ & 夺 & ip & t & $\infty$ & $亠_{\infty}$ & $\infty$ & 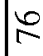 & $\cong$ & $\stackrel{2}{2}$ & $m$ & $\stackrel{m}{=}$ & 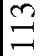 & 웅 & $\underset{త}{-N}$ \\
\hline & $\mid \frac{x}{\frac{x}{r}}$ & 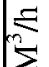 & $\mathscr{0}$ & 8 & $\overline{8}$ & $\widehat{\Omega}$ & $\stackrel{\sim}{\sigma}$ & शे & $\hat{\sigma}$ & $\stackrel{2}{8}$ & 今 & 过 & 5 & 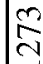 & 点 & $\frac{0}{2}$ & 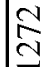 & ir \\
\hline & $H^{\overline{3}}$ & 0 & $\begin{array}{l}r \\
\sim \\
n \\
m\end{array}$ & $\begin{array}{l}\infty \\
g \\
g\end{array}$ & 㐫 & ì & $\mid \begin{array}{l}\infty \\
\infty \\
\infty \\
\infty\end{array}$ & 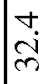 & $\underset{\text { in }}{\text { in }}$ & 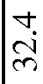 & $\begin{array}{l}\sim \\
\infty \\
\infty \\
i\end{array}$ & $\mid \begin{array}{l}n \\
\infty \\
\infty\end{array}$ & $\mid \begin{array}{l}0 \\
\infty \\
\infty \\
i\end{array}$ & $\frac{3}{8}$ & $\underset{\infty}{-1}$ & 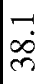 & 年 & $\ddot{q}$ \\
\hline & $\stackrel{\Xi}{\mapsto}$ & U & $\frac{\widetilde{y}}{\mathrm{~N}}$ & $\stackrel{m}{\stackrel{2}{2}}$ & $\stackrel{+}{\stackrel{\sim}{\sim}}$ & 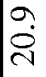 & 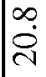 & $\stackrel{n}{\sim}$ & $\stackrel{m}{3}$ & $\stackrel{m}{8}$ & $\stackrel{\infty}{\infty}$ & $\hat{\imath}$ & 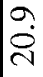 & & 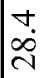 & $\mid \begin{array}{l}0 \\
\infty \\
0 \\
c\end{array}$ & $\vec{m}$ & $\stackrel{\vec{m}}{m}$ \\
\hline \multicolumn{3}{|c|}{ 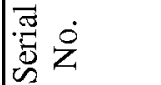 } & $\Xi$ & 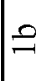 & 0 & तూ & $\bar{\nu}$ & m. & লি & 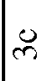 & m & $\ddot{m}$ & $m$ & $\forall$ & $\ddot{n}$ & $n$ & 6 & $r$ \\
\hline
\end{tabular}




\begin{tabular}{|c|c|c|c|c|c|c|c|c|c|c|c|c|c|c|c|c|c|c|c|c|c|c|c|c|c|c|}
\hline \multirow{2}{*}{$\begin{array}{l}\overrightarrow{\widetilde{\Xi}} \\
\text { I }\end{array}$} & $\stackrel{\circ}{\sigma}$ & 童 & $\vec{b}$ & $\mid \begin{array}{l}\mathscr{n} \\
\infty \\
\infty\end{array}$ & $\begin{array}{l}\sigma \\
\sigma \\
\infty \\
\infty\end{array}$ & $\mid \begin{array}{l}\infty \\
\infty \\
1\end{array}$ & & $\hat{\sigma}$ & $\stackrel{\alpha}{\Omega}$ & $\underset{\sigma}{\sigma}$ & $\begin{array}{l}\tilde{\infty} \\
\infty \\
n\end{array}$ & & $\begin{array}{l} \pm \\
\stackrel{0}{0}\end{array}$ & 寺 & $\begin{array}{l}\hat{\theta} \\
\dot{\varphi}\end{array}$ & 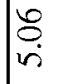 & $\begin{array}{l}\hat{b} \\
\dot{\theta}\end{array}$ & ir & $\begin{array}{l}8 \\
\text { ir }\end{array}$ & $\begin{array}{l}r \\
u \\
v\end{array}$ & & త్రి & ڤூ & $\begin{array}{l}\mathscr{\infty} \\
\stackrel{+}{+}\end{array}$ & 守 & 官 \\
\hline & $\partial$ & 竞 & $\mid \begin{array}{l}\hat{n} \\
\infty \\
\infty\end{array}$ & $\underset{\infty}{\infty}$ & 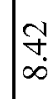 & 象 & & $\begin{array}{l}\stackrel{0}{-1} \\
6\end{array}$ & $\stackrel{0}{\stackrel{0}{r}}$ & $\stackrel{2}{2}$ & $\frac{7}{n}$ & & $\begin{array}{l}\infty \\
\vdots \\
i \\
i\end{array}$ & $\vec{n}$ & $\begin{array}{l}\hat{\sigma} \\
\text { is }\end{array}$ & 虫 & $\begin{array}{l}\hat{g} \\
\text { in }\end{array}$ & $\mid \begin{array}{c}a \\
\dot{b} \\
\dot{n}\end{array}$ & $\mid \begin{array}{l}\infty \\
\sim \\
i\end{array}$ & $\mid \begin{array}{l}8 \\
i n\end{array}$ & & $\begin{array}{c}\tilde{n} \\
\tilde{\sigma} \\
\sigma\end{array}$ & ஜn & $\stackrel{\partial}{\stackrel{f}{f}}$ & \begin{tabular}{|l}
$\vec{m}$ \\
$i$
\end{tabular} & $\underset{f}{+}$ \\
\hline \multirow{14}{*}{ 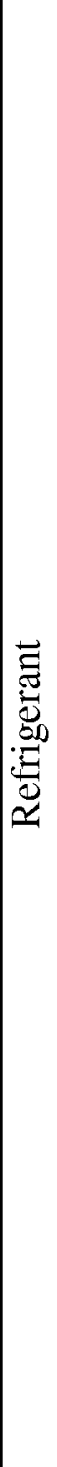 } & 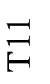 & O & $\stackrel{\infty}{\infty}$ & $\frac{\pi}{4}$ & $\frac{\infty}{\mathrm{N}}$ & $\hat{\gamma}$ & & $\begin{array}{l}\text { ra } \\
\text { d) }\end{array}$ & 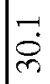 & 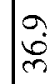 & $\begin{array}{l}b \\
n \\
m \\
m\end{array}$ & & $\begin{array}{l}\infty \\
\dot{n} \\
m\end{array}$ & 엄 & $\begin{array}{l}0 \\
\text { in } \\
\text { d }\end{array}$ & 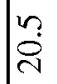 & $\underset{\mathrm{N}}{0}$ & $\frac{\nabla}{c}$ & $\stackrel{\infty}{\sim}$ & $\frac{\sigma}{\sigma}$ & & $\begin{array}{l}m \\
\infty \\
\infty \\
c\end{array}$ & 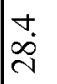 & - & 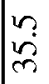 & $\underset{\sim}{\stackrel{\nabla}{~}}$ \\
\hline & $\stackrel{\ominus}{F}$ & ${ }_{0}^{0}$ & $\stackrel{\Omega}{2}$ & $\frac{\pi}{4}$ & 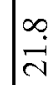 & 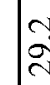 & & 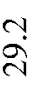 & - & $\underset{m}{\stackrel{\circ}{m}}$ & $\begin{array}{l}n \\
n \\
m\end{array}$ & & $\begin{array}{l}\infty \\
\stackrel{n}{m}\end{array}$ & $\vec{a}$ & $\frac{\Omega}{\pi}$ & m: & $\frac{\Omega}{\sim}$ & $\frac{n}{c}$ & ה & $\mid \frac{\infty}{\sim}$ & & $\vec{c}$ & $\begin{array}{l}\text { N } \\
\text { s } \\
\text { ind }\end{array}$ & $\vec{\sigma}$ & $\begin{array}{l}\forall \\
\text { r. }\end{array}$ & $\ddot{m}$ \\
\hline & $\stackrel{\rho}{\theta}$ & U & $\overrightarrow{\dot{\ominus}}$ & $\begin{array}{l}0 \\
\stackrel{\sim}{\sim}\end{array}$ & $\stackrel{\partial}{\vec{\lambda}}$ & $\begin{array}{l}\infty \\
\infty \\
\infty\end{array}$ & & gे & ت. & ले & ñ & & $\begin{array}{l}\dot{g} \\
\dot{m}\end{array}$ & $\overrightarrow{\vec{\sim}}$ & $\begin{array}{l}0 \\
\text { in }\end{array}$ & ma & $\begin{array}{l}O \\
\text { I }\end{array}$ & $\frac{m}{n}$ & $\vec{\sim}$ & $\mid \infty$ & & $\begin{array}{l}m \\
\infty \\
d \\
d\end{array}$ & $\begin{array}{l}\text { ry } \\
\infty \\
\text { d }\end{array}$ & $\begin{array}{l}0 \\
\stackrel{0}{0} \\
m\end{array}$ & $\begin{array}{l}\forall \\
\stackrel{d}{m}\end{array}$ & 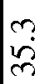 \\
\hline & $\stackrel{\infty}{\bullet}$ & 0 & ?ִ & $\overrightarrow{\vec{\lambda}}$ & $\begin{array}{l}\stackrel{0}{\text { inj }} \\
\text { in }\end{array}$ & rn & & $\stackrel{n}{n}$ & مִ & $\begin{array}{l}0 \\
\dot{8}\end{array}$ & $\begin{array}{l}\infty \\
\infty \\
m\end{array}$ & & $\vec{b}$ & $\overrightarrow{\vec{\lambda}}$ & $\begin{array}{l}0 \\
\text { ij }\end{array}$ & m: & $\begin{array}{l}0 \\
\text { I }\end{array}$ & $\frac{m}{n}$ & $\bar{\sim}$ & $\mid \infty$ & & 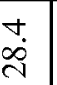 & 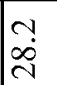 & $\overrightarrow{0}$ & $\begin{array}{l}\dot{v} \\
\dot{m}\end{array}$ & $\begin{array}{l}m \\
m \\
m\end{array}$ \\
\hline & $E$ & ${ }_{0}^{0}$ & $\frac{m}{\mathrm{~N}}$ & $\begin{array}{l}\mathscr{n} \\
\mathrm{N}\end{array}$ & $\mid \begin{array}{l}0 \\
\dot{N} \\
\text { in }\end{array}$ & $\begin{array}{l}\text { in } \\
\text { man }\end{array}$ & & $\begin{array}{l}n \\
i \\
n \\
m\end{array}$ & $\dot{0}$ & $\stackrel{m}{q}$ & $\begin{array}{l}n \\
m \\
m\end{array}$ & & $\begin{array}{l}\infty \\
\dot{0} \\
\stackrel{\infty}{0}\end{array}$ & $\frac{m}{2}$ & $\overrightarrow{\vec{d}}$ & 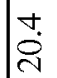 & $\overrightarrow{\mathrm{N}}$ & $\frac{\pi}{\mathrm{s}}$ & $\mid \frac{\infty}{\Delta}$ & $\infty$ & & iे & $\mid \begin{array}{l}\Delta \\
\infty \\
\infty\end{array}$ & $\begin{array}{l}\hat{b} \\
\dot{m}\end{array}$ & $\mid \begin{array}{l}0 \\
\infty \\
\infty \\
\end{array}$ & $\begin{array}{l}m \\
\ddot{m} \\
m\end{array}$ \\
\hline & 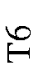 & O & ì & $\begin{array}{l}\tilde{y} \\
\ddot{n}\end{array}$ & $\ddot{\ddot{r}}$ & $\frac{n}{m}$ & & $\frac{n}{m}$ & $\frac{\sim}{m}$ & 官 & $\begin{array}{l}\vec{b} \\
\text { ch }\end{array}$ & & $\frac{n}{m}$ & $\frac{n}{\grave{N}}$ & $\overrightarrow{\widetilde{N}}$ & 苍 & $\overrightarrow{\tilde{N}}$ & $\frac{ \pm}{\mathrm{s}}$ & $\underset{\vec{\sim}}{\infty}$ & $\frac{\infty}{\sim}$ & & $\hat{\text { ते }}$ & 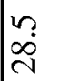 & 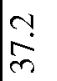 & $\vec{r}$ & $\stackrel{m}{m}$ \\
\hline & $\stackrel{\curvearrowleft}{\ominus}$ & O & $\begin{array}{l}\infty \\
\dot{\varphi} \\
\sim\end{array}$ & $\dot{\sim}$ & $\vec{b}$ & $\begin{array}{l}0 \\
\infty \\
\infty \\
m\end{array}$ & & $\begin{array}{l}0 \\
\infty \\
\infty \\
m\end{array}$ & $\begin{array}{l}\infty \\
\dot{r} \\
m\end{array}$ & $\begin{array}{l}0 \\
\stackrel{0}{q}\end{array}$ & $\begin{array}{l}0 \\
\text { ले }\end{array}$ & & $\begin{array}{l}\infty \\
\stackrel{m}{m}\end{array}$ & $\begin{array}{l}\infty \\
\text { ì } \\
\text { and }\end{array}$ & $\begin{array}{l}\infty \\
\text { N } \\
\text { and }\end{array}$ & $\dot{\tilde{\theta}}$ & $\begin{array}{l}\infty \\
\stackrel{N}{~}\end{array}$ & $\frac{\infty}{\mathrm{N}}$ & 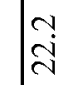 & 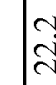 & & $\begin{array}{l}0 \\
i \\
r \\
r\end{array}$ & 奋 & $\begin{array}{l}n \\
\ddot{m} \\
\ddot{m}\end{array}$ & $\begin{array}{l}0 \\
0 \\
\infty\end{array}$ & $\begin{array}{l}\infty \\
\ddot{\infty} \\
\ddot{\infty}\end{array}$ \\
\hline & 声 & 0 & $\frac{\sim}{m}$ & $\ddot{n}$ & $\overrightarrow{\mathrm{s}}$ & $\vec{j}$ & & $\overrightarrow{\dot{y}}$ & 苟 & $\begin{array}{l}\text { ry } \\
\text { in }\end{array}$ & $\frac{\gamma}{7}$ & & $\begin{array}{c}\underset{j}{\mathrm{j}} \\
\underset{f}{2}\end{array}$ & $\vec{d}$ & $\underset{\sim}{\dot{\sim}}$ & $\underset{\overrightarrow{\mathrm{N}}}{\stackrel{0}{\mathrm{~N}}}$ & $\begin{array}{l}\dot{\vec{v}} \\
\ddot{\sim}\end{array}$ & 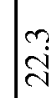 & $\mid \begin{array}{l}0 \\
\text { i }\end{array}$ & $1 \sim$ & & $\begin{array}{l}n \\
n \\
n\end{array}$ & 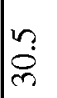 & $\underset{\dot{g}}{\infty}$ & $\frac{n}{n}$ & 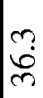 \\
\hline & $\hat{\epsilon}$ & ${ }_{0}^{u}$ & $\overrightarrow{\stackrel{i}{q}}$ & 芦 & $\begin{array}{l}\infty \\
\infty \\
\infty \\
\infty\end{array}$ & $\begin{array}{l}b \\
\infty \\
d \\
d\end{array}$ & & $\begin{array}{l}b \\
\infty \\
\infty \\
+\infty\end{array}$ & $\begin{array}{l}\mathscr{n} \\
\dot{y}\end{array}$ & กั & $\begin{array}{l}n \\
y \\
y\end{array}$ & & 鸟 & $\begin{array}{l}\tilde{y} \\
\ddot{m}\end{array}$ & \begin{tabular}{l}
0 \\
0 \\
$\infty$ \\
\hdashline
\end{tabular} & m & $\begin{array}{l}0 \\
\infty \\
\infty \\
\end{array}$ & نֶ. & : & $\begin{array}{l}\sigma \\
\sim \\
r\end{array}$ & & $\begin{array}{l}0 \\
\dot{0} \\
\text { of }\end{array}$ & 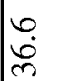 & $\stackrel{m}{n}_{0}$ & 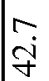 & 官 \\
\hline & $\stackrel{N}{\ominus}$ & $0_{0}^{0}$ & $\begin{array}{l}r \\
\dot{\infty}\end{array}$ & $\begin{array}{l}m \\
\infty \\
\dot{\alpha}\end{array}$ & $\mid \begin{array}{l}\infty \\
\dot{\varphi} \\
\dot{q}\end{array}$ & $\begin{array}{l}\infty \\
\text { in }\end{array}$ & & $\begin{array}{l}\infty \\
\dot{\vec{n}}\end{array}$ & $\underset{\dot{n}}{0}$ & $\stackrel{8}{8}$ & in & & $\begin{array}{l}\text { ra } \\
\text { ñ }\end{array}$ & $\overrightarrow{\dot{\gamma}}$ & 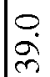 & $\frac{\sim}{\sim}$ & $\begin{array}{l}0 \\
\dot{\rho}\end{array}$ & 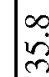 & 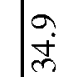 & ${ }_{m}^{m}$ & & $\begin{array}{l}\infty \\
\dot{n} \\
\ddot{n}\end{array}$ & 学 & $\frac{a}{i n}$ & $\frac{0}{\vec{n}}$ & $\begin{array}{l}r \\
\infty \\
\infty \\
\infty\end{array}$ \\
\hline & $\bar{F}$ & ${ }_{0}^{0}$ & $\begin{array}{l}m \\
\infty \\
\infty\end{array}$ & $\hat{a}$ & $\begin{array}{l}\stackrel{0}{\infty} \\
\infty\end{array}$ & $\begin{array}{l}n \\
\infty \\
\infty\end{array}$ & & $\begin{array}{l}0 \\
\infty \\
\infty\end{array}$ & $\begin{array}{l}a \\
\infty \\
\infty\end{array}$ & ֻேं & $\begin{array}{l}\text { ra } \\
\text { s}\end{array}$ & & $\stackrel{n}{\infty}$ & $\begin{array}{l}\infty \\
\stackrel{\infty}{\Xi} \\
=\end{array}$ & 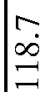 & : & $\begin{array}{l}\infty \\
\infty \\
=\end{array}$ & $\mid \begin{array}{l}\simeq \\
\infty \\
\approx\end{array}$ & {$\left[\begin{array}{l}n \\
\infty \\
=\end{array}\right.$} & $\left(\begin{array}{l}\infty \\
0\end{array}\right.$ & & $\begin{array}{c}0 \\
\mathrm{i} \\
\mathrm{J}\end{array}$ & 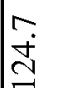 & ت্் & $\ddot{a}$ & $\vec{m}$ \\
\hline & $\frac{\frac{\alpha}{y}}{\sum_{y}^{2}}$ & $\frac{\infty}{20}$ & ra & $\begin{array}{l}\dot{\sigma} \\
\dot{m}\end{array}$ & $\dot{m}$ & J゙ & & 芯 & $\begin{array}{l}0 \\
\dot{m} \\
\dot{m}\end{array}$ & $\stackrel{\circ}{\stackrel{\circ}{m}}$ & $\begin{array}{l}\infty \\
\vdots \\
d\end{array}$ & & $\begin{array}{l}\infty \\
\infty \\
\infty \\
\end{array}$ & 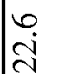 & $\frac{n}{\pi}$ & $\frac{1}{2}$ & $\frac{n}{2}$ & $\frac{\pi}{c}$ & $\overrightarrow{3}$ & 8 & & r & 旾 & $=$ & $\mid \begin{array}{l}\dot{v} \\
\dot{i}\end{array}$ & 2 \\
\hline & $2^{\bar{z}}$ & $\frac{\tilde{2}}{\underline{y}}$ & 吾 & 守 & \begin{tabular}{l}
$\infty$ \\
$\infty$ \\
$\infty$ \\
\hdashline \\
0
\end{tabular} & है & & ले & $\stackrel{\infty}{\infty}$ & $\begin{array}{l}0 \\
\infty \\
\infty \\
\Xi \\
\Xi\end{array}$ & $\hat{\mathscr{\alpha}}$ & & 疋 & $\begin{array}{l}\infty \\
\Xi \\
\exists\end{array}$ & 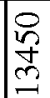 & 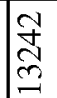 & 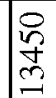 & 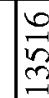 & 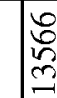 & ב্ & & 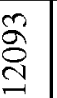 & $\overrightarrow{\vec{\sigma}}$ & $\underset{\Xi}{\leftrightarrows}$ & 离 & $\mid \begin{array}{l}\stackrel{\rho}{\infty} \\
\mathcal{I}\end{array}$ \\
\hline & $\stackrel{=}{=}$ & $\frac{\pi}{\underline{z}}$ & 守 & 흉 & 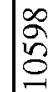 & $\stackrel{f}{\tilde{g}}$ & & 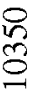 & 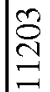 & $\stackrel{\substack{f \\
=}}{=}$ & $\begin{array}{l}n \\
\infty \\
0 \\
0\end{array}$ & & $\stackrel{8}{8}$ & $\begin{array}{l}\infty \\
\stackrel{\infty}{\Xi} \\
\Xi\end{array}$ & $\stackrel{0}{9}$ & $\begin{array}{l}\infty \\
0 \\
\\
\end{array}$ & 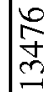 & m & $\mid \begin{array}{l}\sigma \\
\tilde{n} \\
n\end{array}$ & 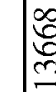 & & $\stackrel{\Xi}{\vec{\Xi}}$ & $\underset{9}{9}$ & $\underset{\Xi}{\stackrel{f}{J}}$ & $\overrightarrow{\tilde{\delta}}$ & 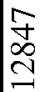 \\
\hline \multirow{4}{*}{ 文 } & $\overrightarrow{\hat{\sigma}}$ & $\widetilde{2}$ & $\ddot{n}$ & $\stackrel{2}{2}$ & $\infty$ & $\lambda$ & & तิ & $\stackrel{0}{=}$ & $\stackrel{\infty}{m}$ & $\bar{z}$ & & $\Xi$ & 8 & $\ddot{n}$ & $\because$ & $\hat{n}$ & $\approx$ & $\stackrel{\infty}{\sim}$ & $\stackrel{\infty}{\sim}$ & & ले & $\vec{\beth}$ & f & $\underset{\mathrm{I}}{\mathbf{U}}$ & $\stackrel{\text { I }}{\mathrm{I}}$ \\
\hline & 愛 & $\sum_{\Sigma}$ & $\frac{2}{6}$ & $\hat{\sigma}$ & $\begin{array}{l}\infty \\
\infty \\
\vec{N}\end{array}$ & है & & $\begin{array}{c}\text { Oे } \\
\text { d }\end{array}$ & 志 & $\stackrel{\infty}{m}$ & ה & & 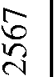 & $\underset{\sigma}{\sigma}$ & $\underset{0}{2}$ & $\underset{⿱ 乛}{\mathbb{6}}$ & $\frac{2}{6}$ & ๙઼ & $\mid \begin{array}{c}0 \\
\infty \\
0 \\
0\end{array}$ & 18 & & $\overline{\mathrm{े}}$ & $\begin{array}{l}\stackrel{0}{i} \\
\text { in } \\
\text { an }\end{array}$ & $\begin{array}{l}\infty \\
\infty \\
\vdots \\
=1\end{array}$ & $\mid \begin{array}{l}0 \\
\infty \\
\sim \\
\end{array}$ & $\sqrt{\hat{\imath}}$ \\
\hline & $\stackrel{\bar{z}}{\bullet}$ & 0 & $\begin{array}{l}n \\
n \\
n\end{array}$ & $\mid \begin{array}{l}\dot{0} \\
\dot{m}\end{array}$ & 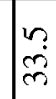 & $\tilde{r}$ & & $\ddot{q}$ & $\frac{m}{2}$ & $\stackrel{\nabla}{\sim}$ & $\underset{f}{f}$ & & $\begin{array}{l}\stackrel{0}{\dot{f}} \\
\dot{y}\end{array}$ & $\begin{array}{l}n \\
\tilde{n} \\
n\end{array}$ & $\frac{\vec{m}}{m}$ & $\overrightarrow{\mathrm{d}}$ & $\frac{\hat{m}}{m}$ & $\vec{\lambda}$ & $\tilde{\Omega}$ & $1+$ & & $\vec{P}$ & $\begin{array}{l}\ddot{0} \\
\dot{b}\end{array}$ & $\begin{array}{l}\infty \\
\dot{\sigma}\end{array}$ & $\frac{9}{\dot{y}}$ & 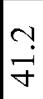 \\
\hline & $\stackrel{\Xi}{ت}$ & 0 & $\stackrel{\infty}{\infty}$ & 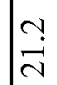 & $\frac{n}{\sim}$ & $\begin{array}{l}\infty \\
\infty \\
\infty \\
\end{array}$ & & 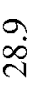 & $\begin{array}{l}\infty \\
\stackrel{\gamma}{ }\end{array}$ & $\begin{array}{l}\infty \\
\ddot{m} \\
m\end{array}$ & $\begin{array}{l}n \\
n\end{array}$ & & $\begin{array}{l}n \\
m \\
m\end{array}$ & 赵 & $\frac{0}{\sim}$ & $\ddot{\text { ¿ }}$ & $\begin{array}{l}0 \\
\vec{\lambda} \\
\text { a }\end{array}$ & a & $\vec{\sim}$ & $\frac{r}{r}$ & & $\frac{9}{N}$ & 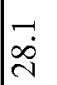 & $\begin{array}{r}r \\
\ddot{r}\end{array}$ & $\begin{array}{l}m \\
m \\
m\end{array}$ & $\vec{m}$ \\
\hline \multicolumn{3}{|c|}{ 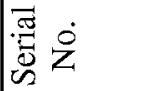 } & $\infty$ & $1 a$ & $\stackrel{\rho}{9}$ & 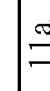 & & $\vec{\exists}$ & 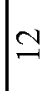 & 2 & J & & 导 & صొ & $\stackrel{n}{n}$ & $\check{~}$ & ஜூ & $\simeq$ & 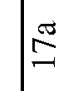 & $\underline{\Sigma}$ & & $\infty$ & 2 & (ి) & $\frac{\pi}{\sim}$ & $\vec{\sim}$ \\
\hline
\end{tabular}




\subsection{Data Reduction and Discussion}

The inlet and outlet air-side and refrigerant-side pressures and temperatures were measured during the gas cooler tests. The measured data were used to determine the capacity and pressure drop. The air-side capacity was calculated from air enthalpy change and mass flow rate. The air enthalpy change was determined by the temperature difference multiplied by air specific heat. Air specific heat was based on dry air properties. The values are listed in Table 5.3.

$$
Q_{\text {air }}=\dot{m}_{\text {air }} \cdot C_{p} \cdot\left(T_{\text {air-out }}-T_{\text {air-in }}\right)
$$

The refrigerant-side capacity was determined by the mass flow rate and enthalpy difference between the inlet and outlet of the gas cooler, as shown in Equation 5.2. The refrigerant side capacity is also listed in Table 5.3.

$$
Q_{\text {ref }}=\dot{m}_{r e f} \cdot\left(h_{r e f-\text { in }}-h_{\text {ref-out }}\right)
$$

Energy balances were checked for all reported experimental data using Equation 5.3:

$$
E B=\frac{Q_{r e f}-Q_{a i r}}{Q_{r e f}}
$$

Figure 5.1 depicts the energy balance results for all reported experimental results, clearly indicating that energy balances for all reported data were within $\pm 3 \%$. 


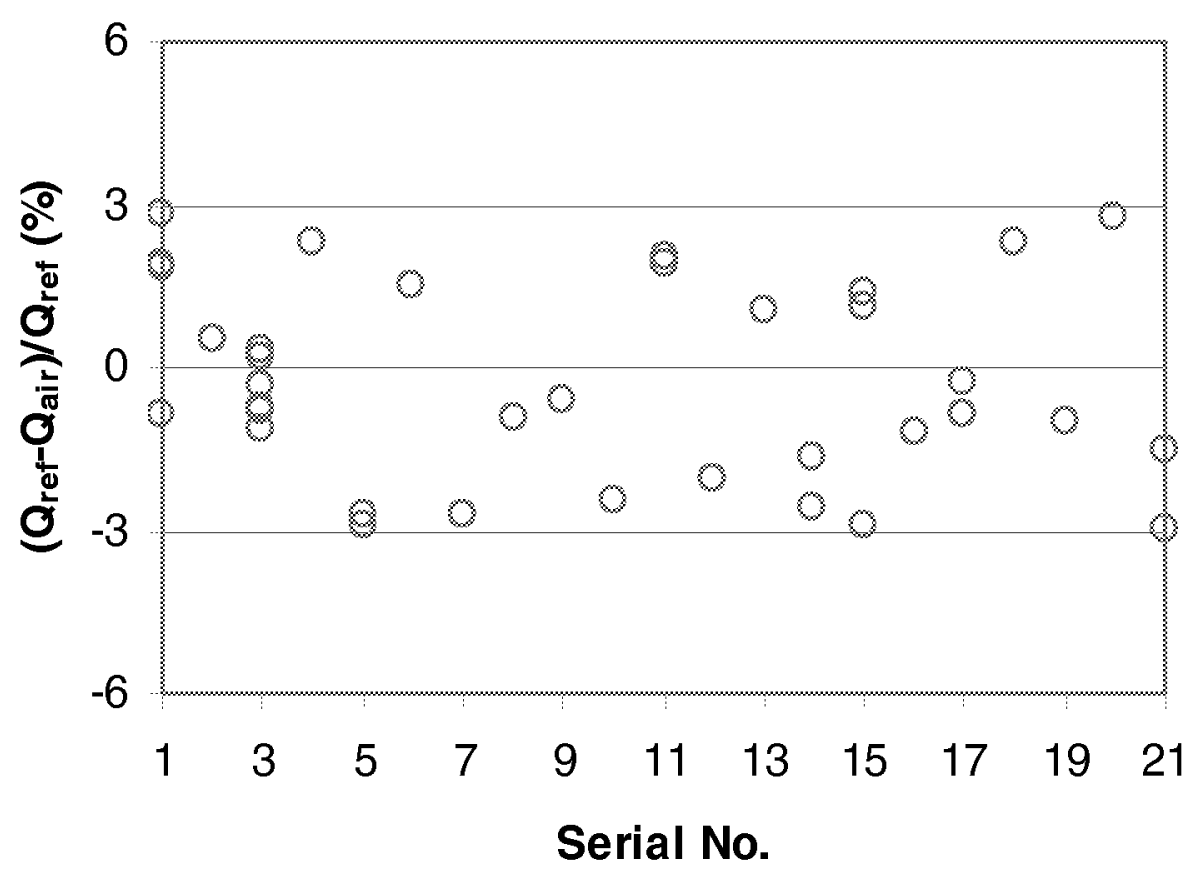

Figure 5.1 Energy balance for gas cooler test results

Figure 5.2 shows the gas cooler capacity vs. mass flow rate of the refrigerant for an air inlet temperature of $21{ }^{\circ} \mathrm{C}$. The refrigerant-side inlet pressure was varied $\left(\mathrm{P}_{\text {in }}\right)$ from 6.9 $\mathrm{MPa}$ to 12.5 $\mathrm{MPa}$. As seen there, the mass flow rate of the refrigerant has a significant effect on the capacity of the gas cooler. This is expected because the refrigerant capacity rate $\left(\dot{m}_{r f} \cdot C_{p}\right)$ is much smaller than that of the air-side $\left(\dot{m}_{a i r} \cdot C_{p}\right)$. Increasing refrigerant mass flow rate results in the augmentation of the capacity of the heat exchanger. These results also show that refrigerant mass flow rate plays a more important role than those of the inlet pressure and temperature of the refrigerant. Thus, the mass flow rate is the one of the primary factors that affects the capacity of a gas cooler. 


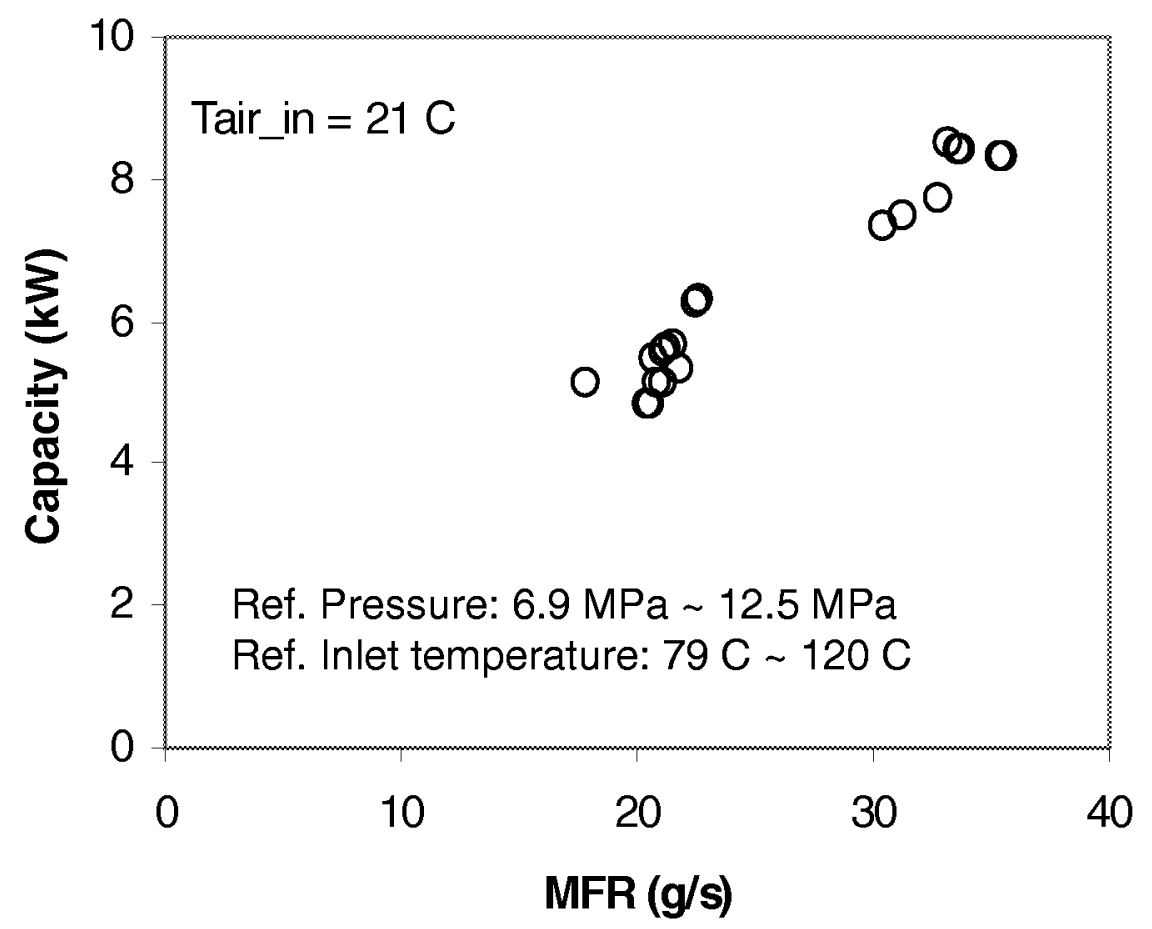

Figure 5.2 Capacity vs. refrigerant mass flow rate

Figure 5.3 shows typical temperature profiles for the air and refrigerant streams in the gas cooler. The two arrows indicate the flow directions of refrigerant and air. A schematic of the gas cooler layout is shown in Figure 3.10. The flow pattern is a cross counter flow. Eleven thermocouples were installed in the refrigerant path to precisely measure and monitor the temperature of the refrigerant. The abscises in Figure 5.3 indicate the thermocouple locations. The air stream temperatures were determined by applying an energy balance to specific heat exchanger units. The temperature difference between the refrigerant and air reaches a maximum at the refrigerant inlet while the difference approaches zero at the air inlet. This is because the air capacity rate $\left(\dot{m}_{a i r} \cdot C_{p}\right)$ is much larger than the refrigerant capacity rate $\left(\dot{m}_{r e f} \cdot C_{p}\right)$. The temperature profiles also 
suggest that most of the heat transfer occurs at the heat exchanger units that are near the refrigerant inlet side. The last three slabs do not transfer any heat since there is no temperature difference.

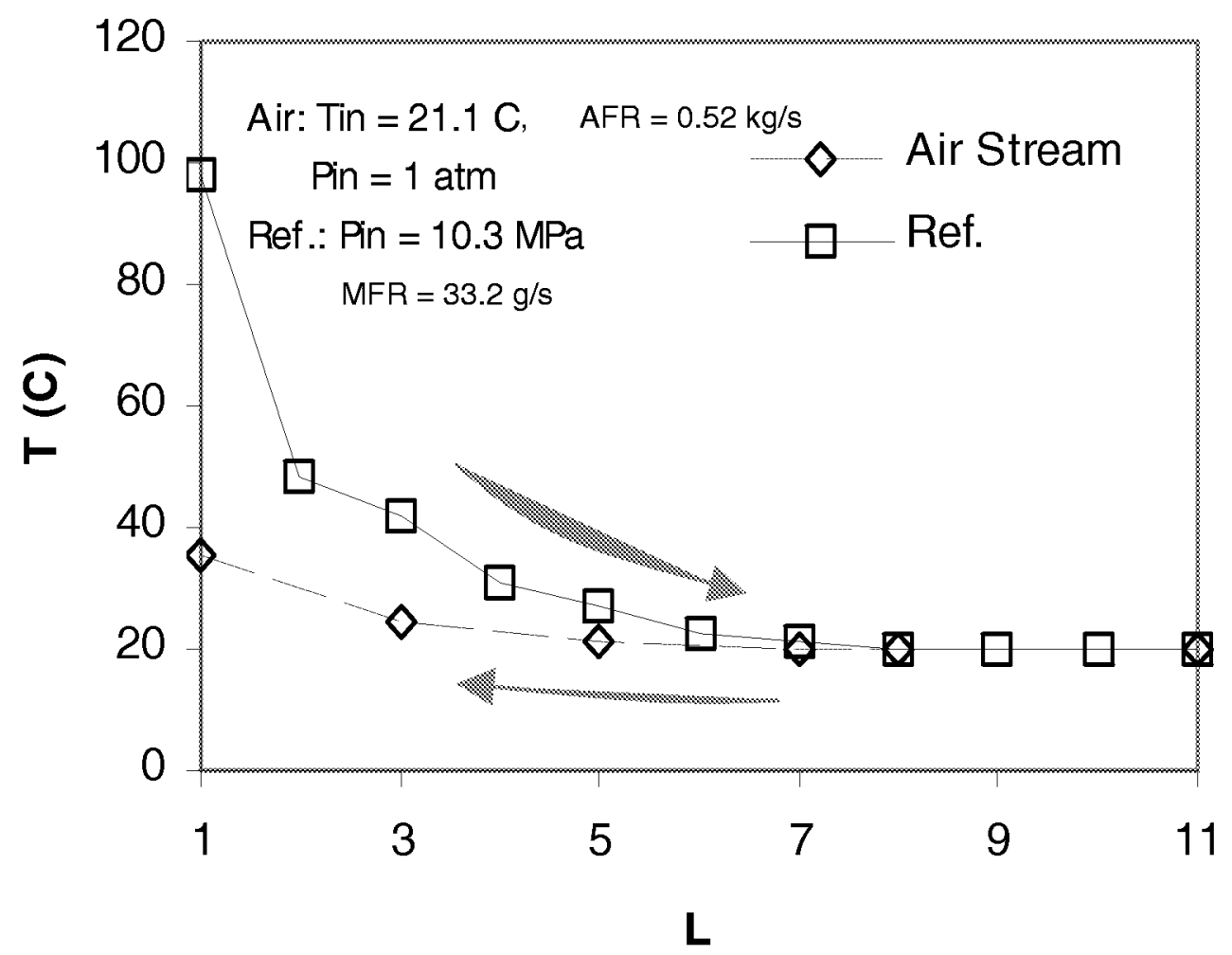

Figure 5.3 Typical temperature profiles of air stream and refrigerant

Based on the temperature profile of the refrigerant, heat transfer rates for each $\mathrm{HX}$ unit can be determined. Figure 5.4 shows typical heat transfer rate profiles at various refrigerant pressures and temperatures. The results show that a large portion of the total heat transfer takes place in the heat exchanger no. 1 (HX1) that is located at the refrigerant inlet side with the higher refrigerant inlet pressure and temperature. In other words, the slope of $\mathrm{Q}_{\mathrm{i}} / \mathrm{Q}_{\text {total }}$ is steeper at the refrigerant inlet side for higher refrigerant inlet temperature and pressure. 


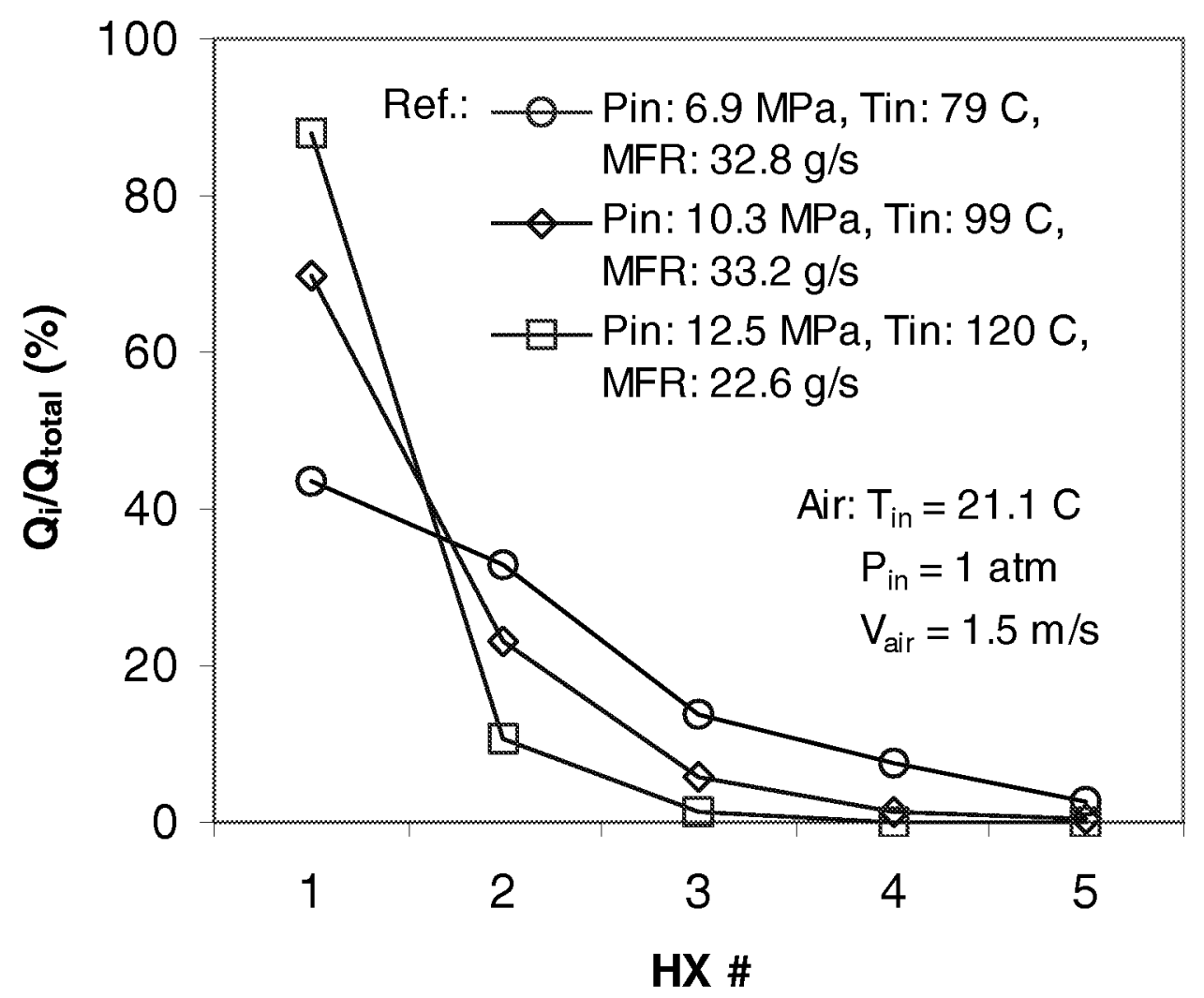

Figure 5.4 Typical heat transfer rate profile for each HX unit

Figure 5.5 depicts the percentage of heat $\left(\mathrm{Q}_{\mathrm{i}} / \mathrm{Q}_{\text {total }}\right)$ transferred by each $\mathrm{HX}$ as a function of refrigerant inlet pressure for all gas cooler test results. It should be noted that higher refrigerant inlet pressures are associated with higher refrigerant inlet temperatures. The percentage of heat transferred by HX1 increases with increasing refrigerant inlet pressures. The HX5 does not transfer any heat, thus it did not appear in the figure. This indicates that over-sizing a gas cooler does not improve its capacity. It was found that no significant improvement in the capacity was obtained when more than four HXs were used in the current experiments (i.e., the number of HXs was oversized). Four HXs have a total surface area of $24 \mathrm{~m}^{2}$. For high refrigerant inlet pressures (>10 MPa), the first 
three HXs transfer up to $95 \%$ of the heat. One benefit associated with this characteristic is that the size of the gas cooler can be reduced if it operates at high gas cooling pressures.

Another observation from Figure 5.5 is that for low refrigerant inlet pressures, the HXs that are near the outlet of refrigerant also play a significant role in the heat transfer process. This may be explained by the fact that the specific heat of $\mathrm{CO}_{2}$ increases rapidly in the temperature range of $30-50{ }^{\circ} \mathrm{C}$ for low refrigerant inlet pressures, as shown in Figure 5.6. Since refrigerant capacity rate $\left(\dot{m}_{r f} \cdot C_{p}\right)$ is proportional to specific heat, the heat transfer amount for low refrigerant inlet pressures is still significant for the temperature range of $30-50^{\circ} \mathrm{C}$.

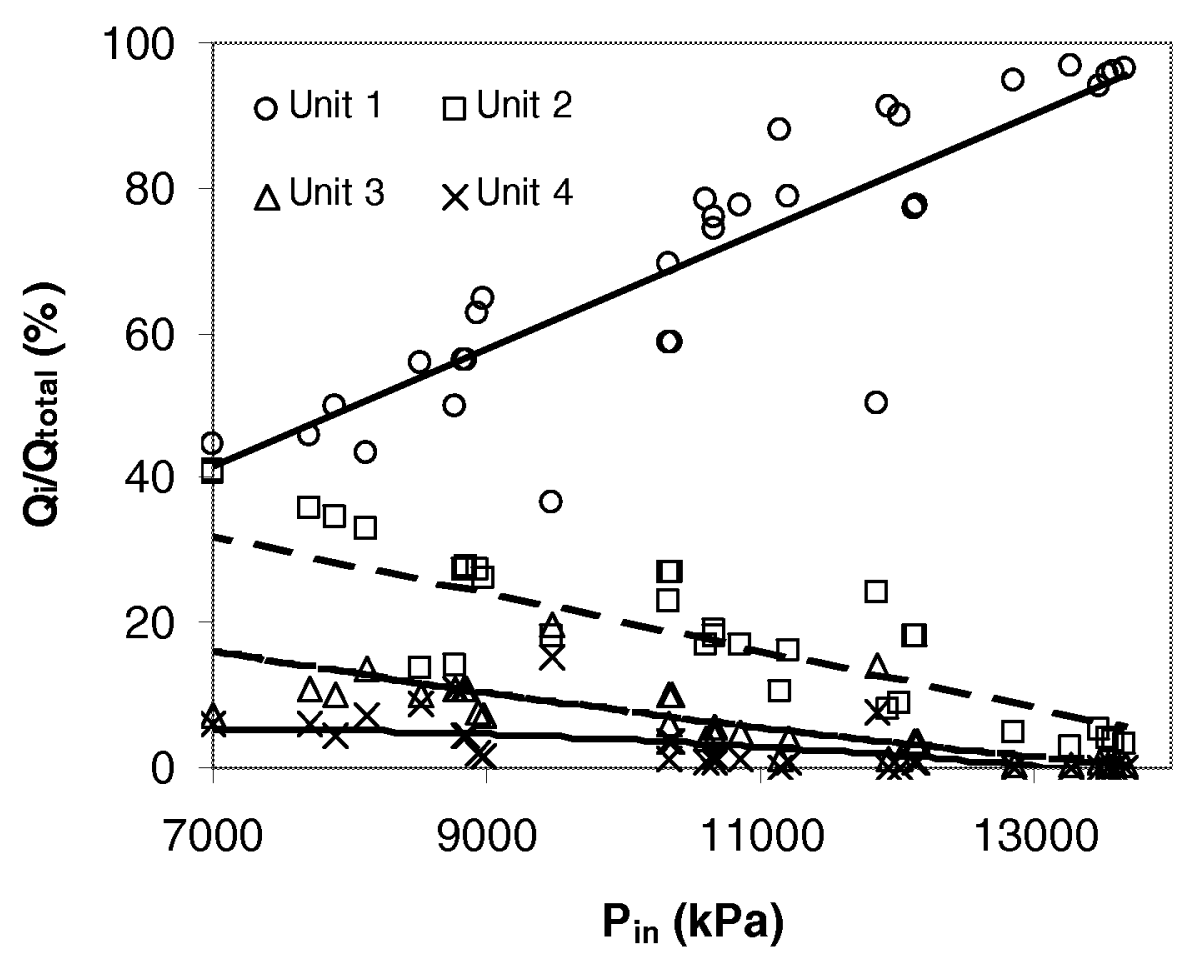

Figure 5.5 Percentage of heat transferred by each HX vs. refrigerant inlet pressure 


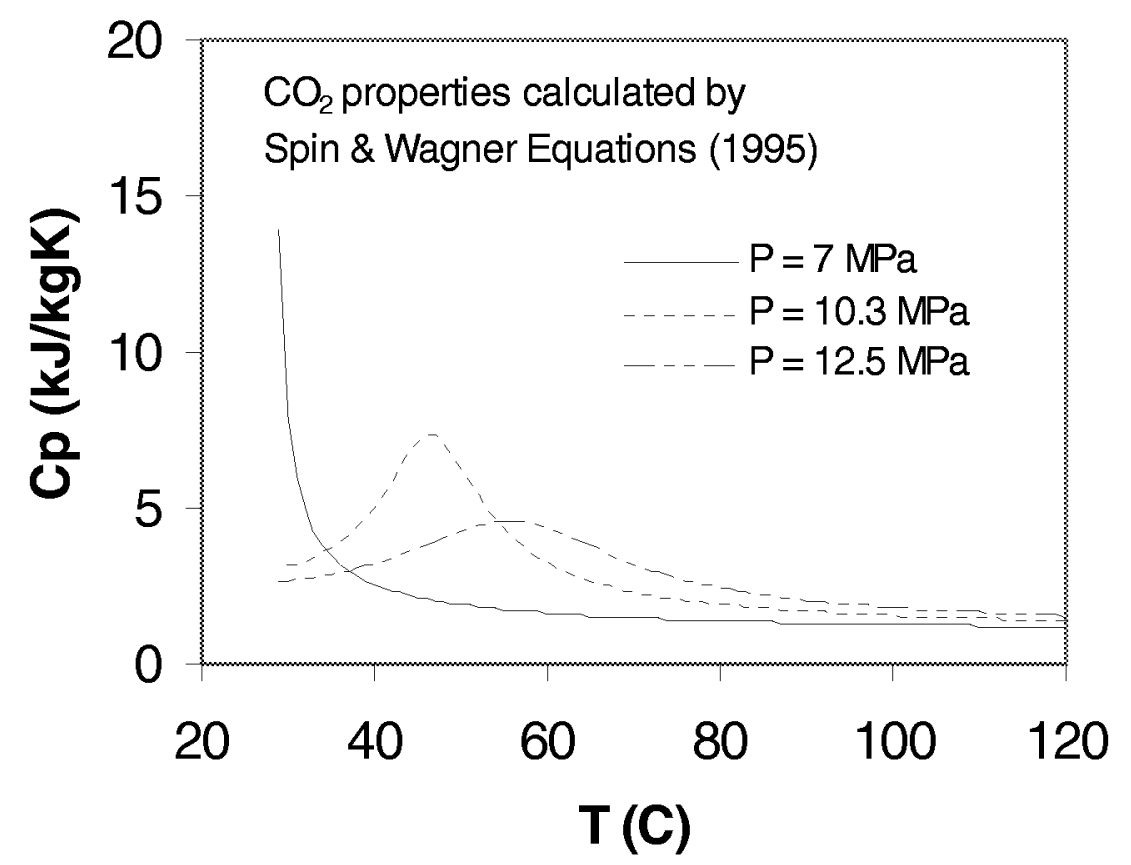

Figure 5.6 Specific heat of $\mathrm{CO}_{2}$ vs. temperature

Because the specific heat of $\mathrm{CO}_{2}$ changes significantly with variations in temperature, logarithmic mean temperature difference (LMTD defined in Equation 5.4) cannot be applied.

$$
L M T D=\frac{\Delta T_{1}-\Delta T_{2}}{\ln \left(\Delta T_{1} / \Delta T_{2}\right)}
$$

where $\Delta \mathrm{T}_{1}$ and $\Delta \mathrm{T}_{2}$ refer to the temperature differences between refrigerant and air at the inlet and outlet of the gas cooler, respectively.

LMTD is based on the assumptions that the overall heat transfer coefficient is constant, that the specific heat of refrigerant is constant through the heat exchanger, and that no heat losses occur. Also, as shown in Figure 5.2, the temperature profiles of air and refrigerant are not linear. Therefore, the average temperature difference is not helpful in defining the overall heat transfer coefficient. In fact, it is nearly impossible to calculate 
the overall heat transfer coefficient such that it can reflect the performance of the heat exchanger. In the present experiments, our trial-and-error attempts to determine the overall heat transfer coefficient were unsuccessful since the results do not have any significance in studying the performance of the heat exchanger.

Another important parameter that reflects the performance of a heat exchanger is the heat transfer effectiveness eff, which is defined as:

$$
\text { eff }=\frac{h_{r, \text { in }}-h_{r, \text { out }}}{h_{r, \text { in }}-h_{r, \text { ideal }}}
$$

where $h_{r, \text { ideal }}$ refers to the enthalpy of the refrigerant at the air inlet temperature. The term $h_{r, \text { in }}-h_{r, \text { ideal }}$ indicates the capacity potential of the refrigerant side.

Figure 5.7 shows the heat transfer effectiveness as a function of the heat exchanger size for all test conditions except those of $\mathrm{P}_{\text {ref }}=7 \mathrm{MPa}$. Since there are 11 thermocouples installed along the refrigerant path as shown in Figure 3.10, it is convenient to calculate the heat transfer effectiveness for the gas coolers made from a different number of HXs (such as HX1, HX1+HX2, HX1+HX2+HX3, $\mathrm{HX} 1+\mathrm{HX} 2+\mathrm{HX} 3+\mathrm{HX} 4$, and the entire five HXs, respectively). The $\mathrm{x}$-axis represents the size of the heat exchanger. For each curve depicted in the figure, the heat transfer effectiveness increases in a very similar pattern with an increase in the size of the heat exchanger. This figure is important and very helpful in developing empirical models to predict the capacity of a heat exchanger. 


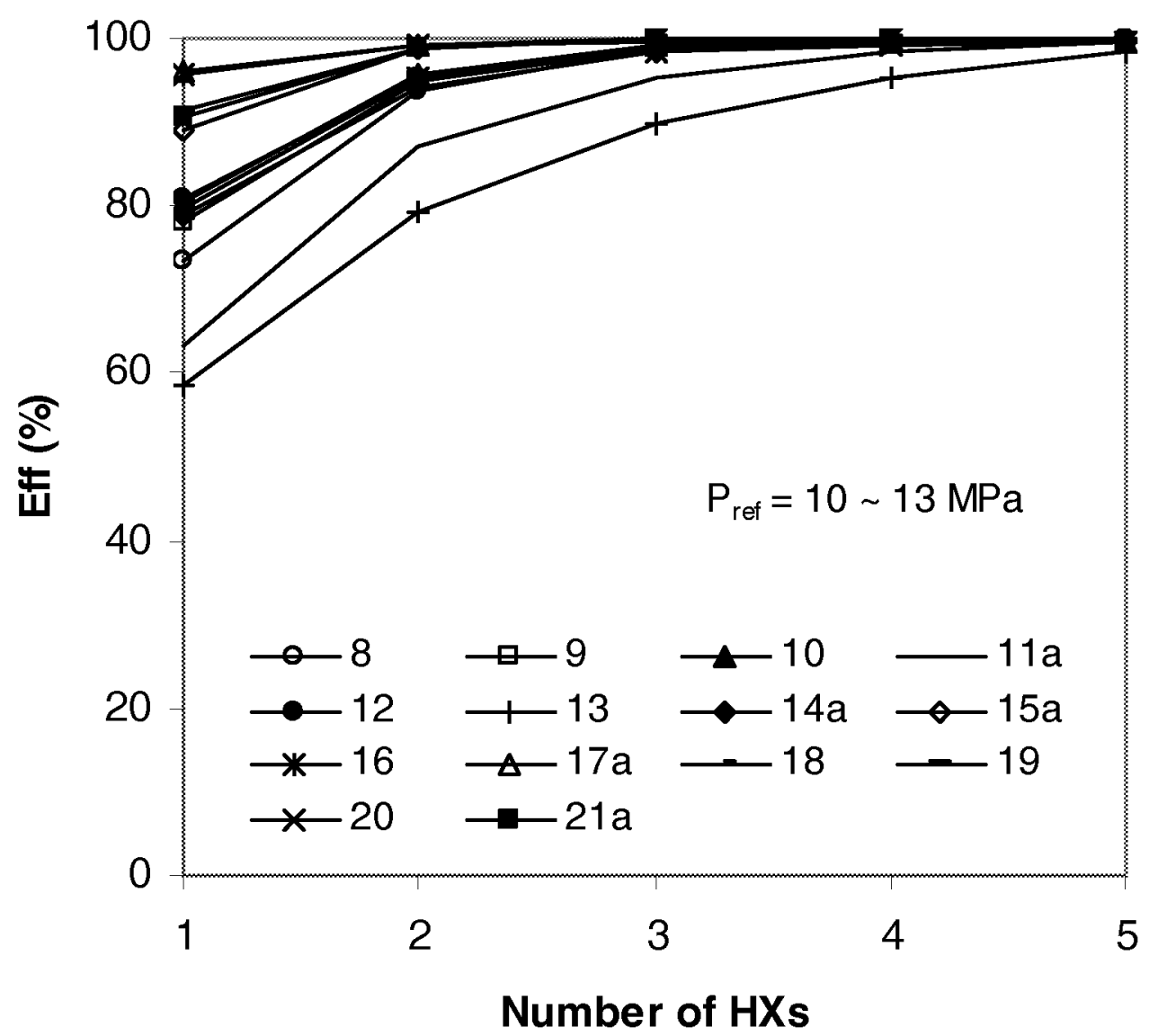

Figure 5.7 Heat transfer effectiveness vs. number of HXs

Figure 5.8 shows the heat transfer effectiveness vs. number of HXs for test conditions of $\mathrm{P}_{\text {ref }}=7 \mathrm{MPa}$. The data shown in Figure 5.8 shows a similar trend to those of Figure 5.7. However, when compared to Figure 5.7, two curves in Figure 5.8 do not show a similar trend. This can be explained by the fact that the specific heat of $\mathrm{CO}_{2}$ changes rapidly in the temperature range of $30-40{ }^{\circ} \mathrm{C}$, as shown in Figure 5.6. At $\mathrm{P}_{\text {ref }}=7 \mathrm{MPa}$, which is close to the critical pressure of $\mathrm{CO}_{2}\left(\mathrm{P}_{\mathrm{cri}}=7.3 \mathrm{MPa}\right)$, the temperature of $\mathrm{CO}_{2}$ is typically in the range of $30-40{ }^{\circ} \mathrm{C}\left(\mathrm{T}_{\mathrm{cri}}=31^{\circ} \mathrm{C}\right)$ at later $\mathrm{HX}$ units such as $\mathrm{HX} 3, \mathrm{HX} 4$, or HX5. Since the capacity of $\mathrm{CO}_{2}$ in this temperature range increase rapidly, even a small 
temperature variation corresponds to a significant amount of heat. In fact, at this section, the local refrigerant capacity rate $\left(\dot{m}_{a i r} \cdot C_{p}\right)$ becomes very large, thus enhancing the heat transfer. In addition, the heat transfer process becomes more complicated when the test conditions of $\mathrm{CO}_{2}$ approach its critical point. Therefore, to some extent, inconsistent trends are expected since the refrigerant properties change drastically.

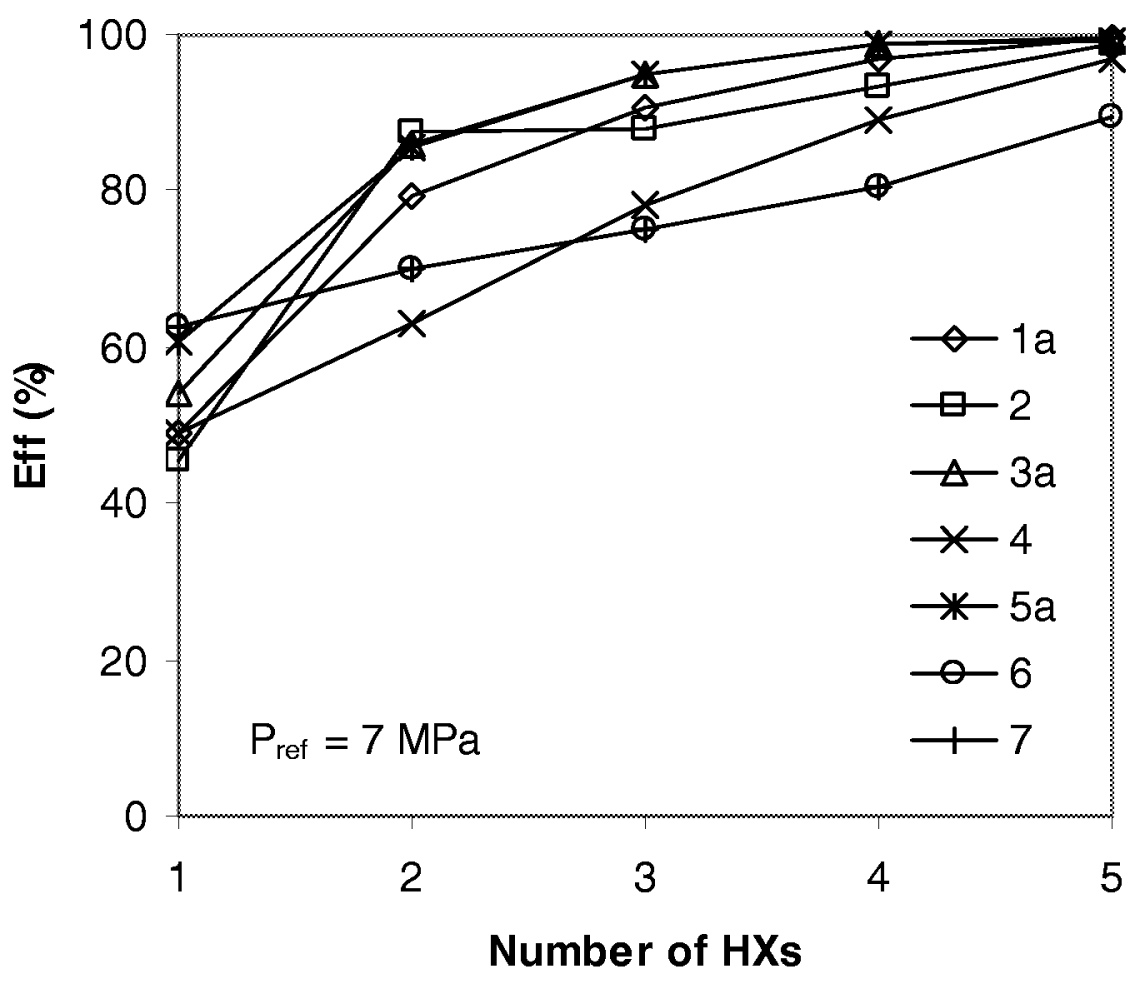

Figure 5.8 Heat transfer effectiveness vs. number of $\mathrm{HXs}$ for a $\mathrm{CO}_{2}$ pressure of $7 \mathrm{MPa}$ Figure 5.9 shows the effect of the refrigerant mass flow rate on the heat transfer effectiveness. It shows that refrigerant mass flow rate plays an important role in determining the performance of microchannel heat exchangers with $\mathrm{CO}_{2}$. 


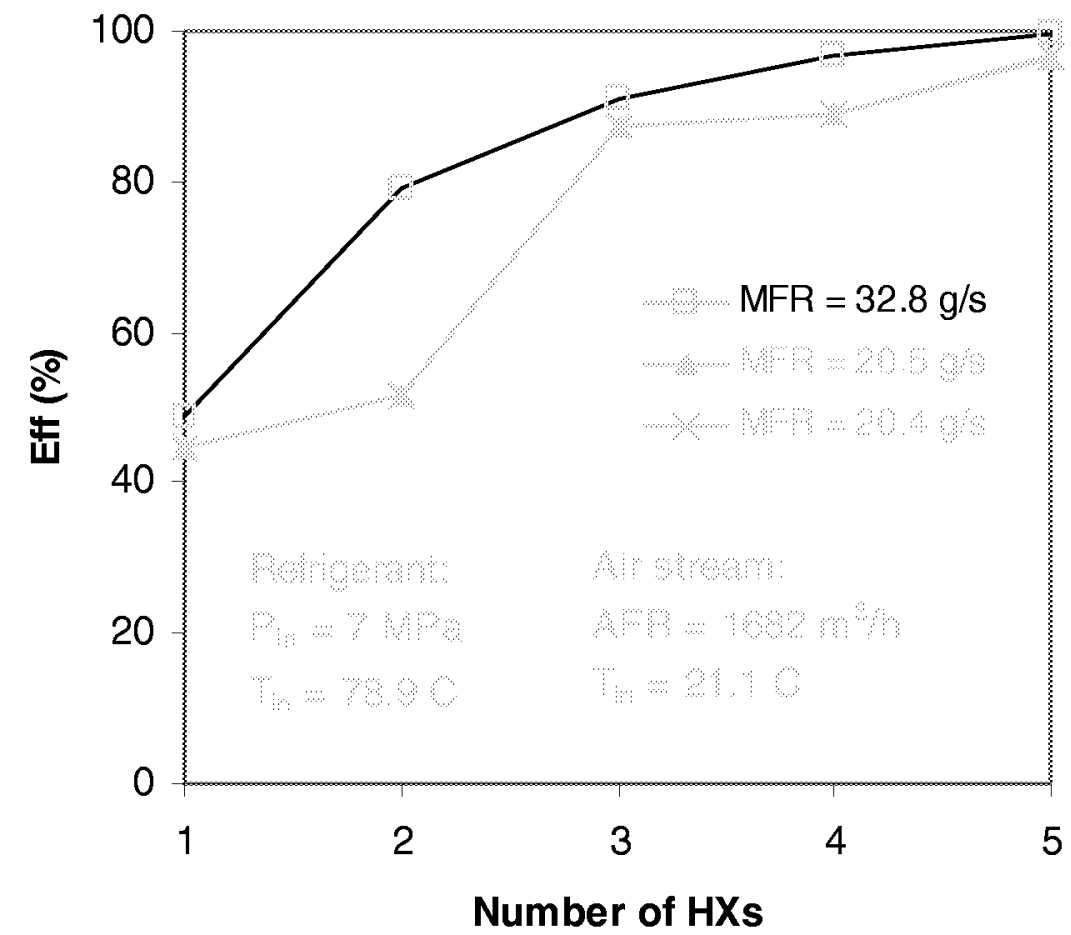

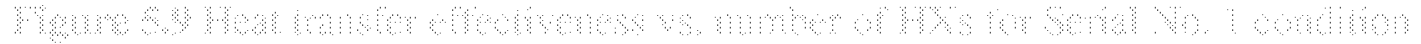

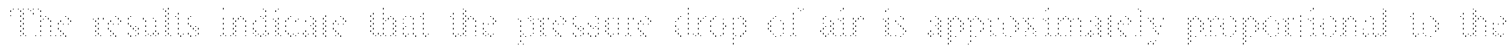

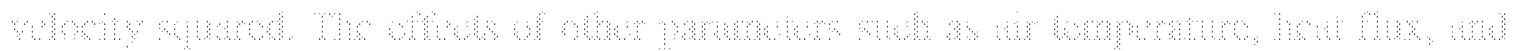

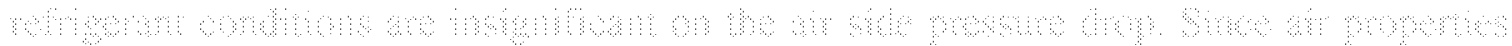

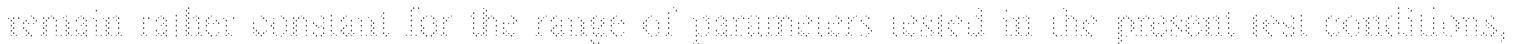

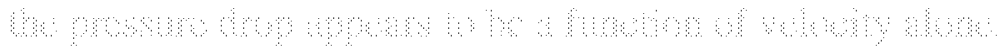




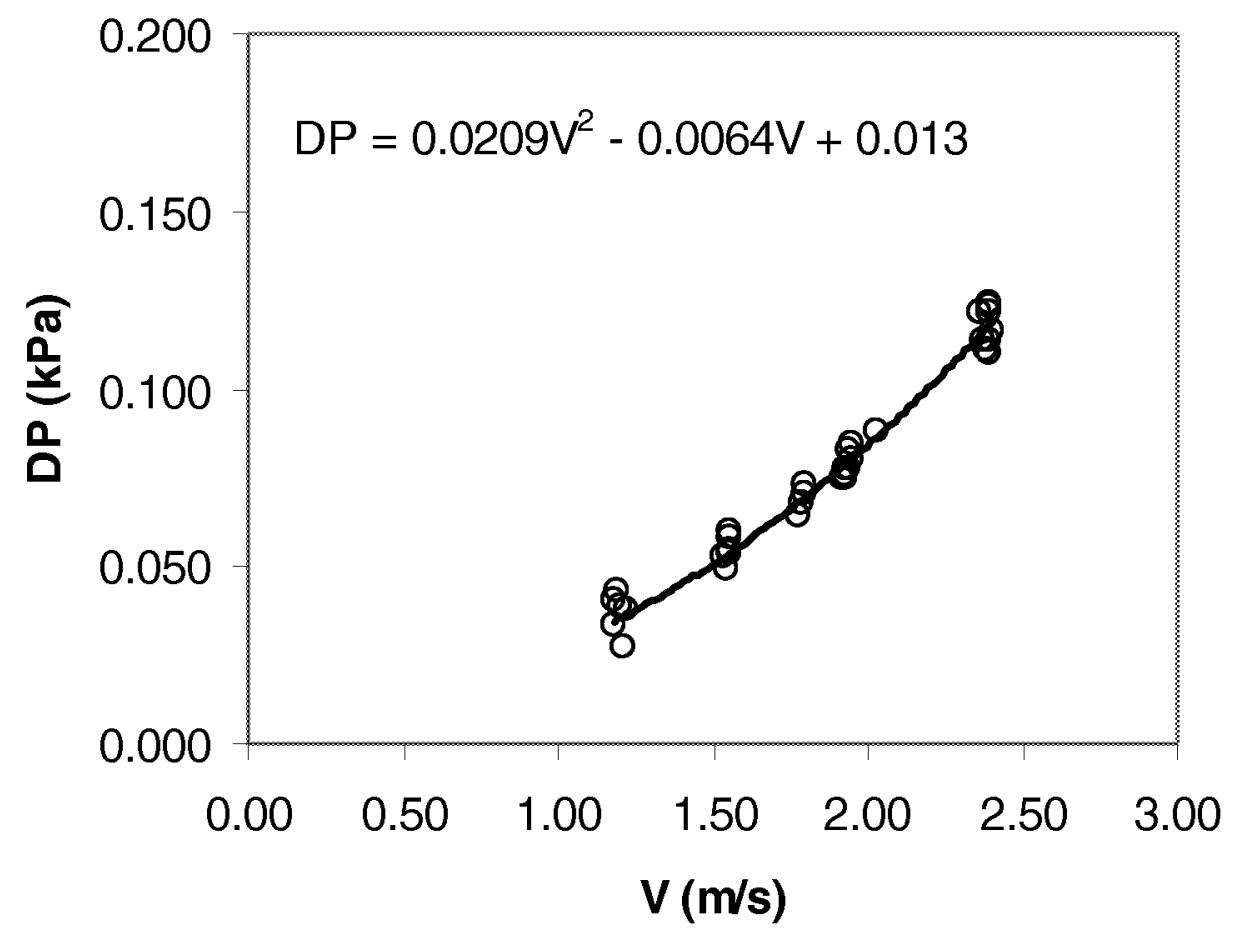

Figure 5.10 Air side pressure drop as a function of air velocity

Refrigerant pressure drop is much more complicated due to the rapid changes in the properties of $\mathrm{CO}_{2}$ with temperature. Basically, for a certain heat exchanger, refrigerant pressure drop is related to the refrigerant viscosity and velocity. Figure 5.11 depicts the viscosity of $\mathrm{CO}_{2}$ as a function of temperature at different pressures. During gas cooler tests, the temperature of the refrigerant changes as it flows through each heat exchanger unit. The range of operating temperatures of the refrigerant for the present study corresponds with the temperature range in which the viscosity is changing rapidly, as shown in Figure 5.11. Moreover, refrigerant velocity depends on the refrigerant mass flux and refrigerant density. Figure 5.12 shows the density of $\mathrm{CO}_{2}$ as a function of temperature for different refrigerant pressures. As shown, the density of $\mathrm{CO}_{2}$ strongly 
depends on the refrigerant temperature. Therefore, refrigerant temperature is expected to be one of the dominant factors in refrigerant pressure drop.

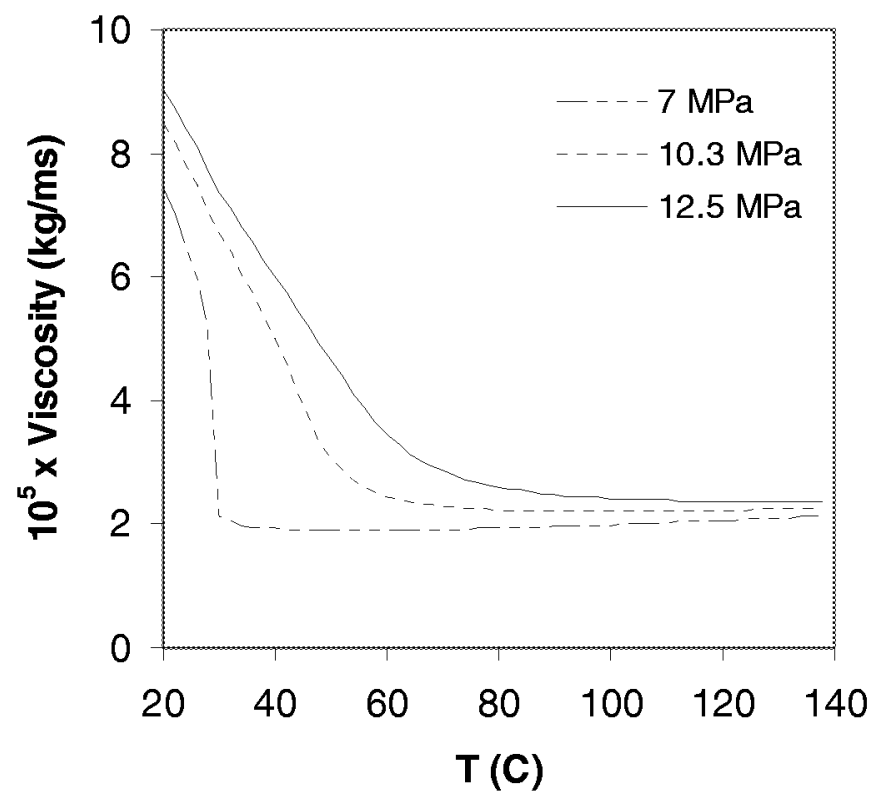

Figure 5.11 Viscosity of $\mathrm{CO}_{2}$ vs. temperature

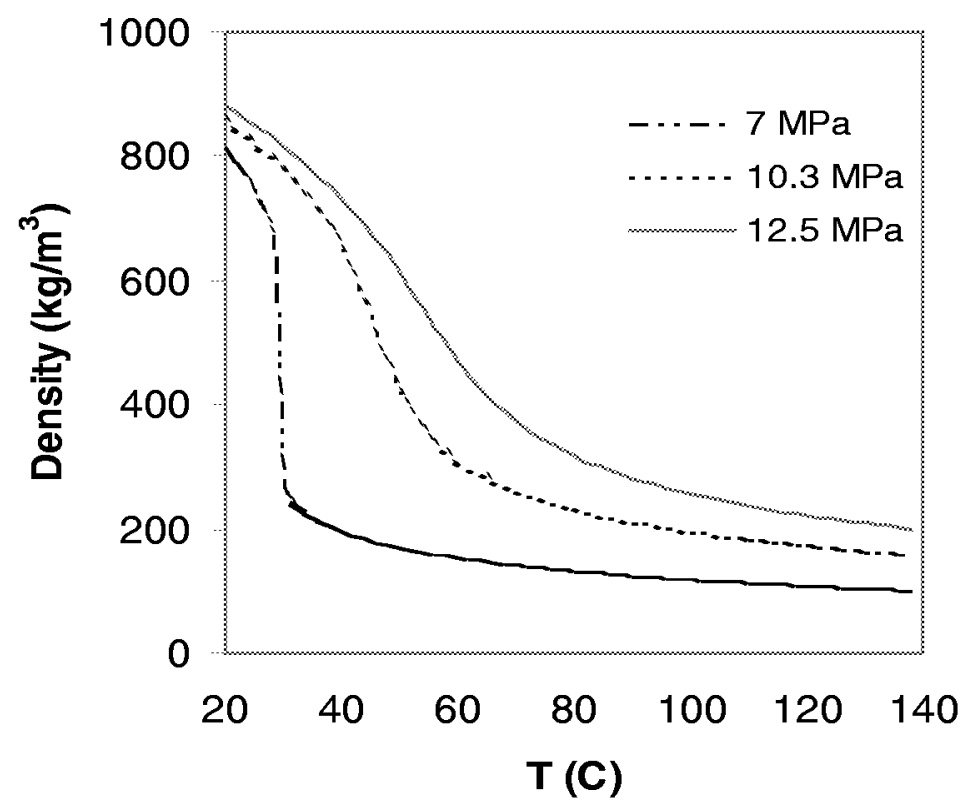

Figure 5.12 Density of $\mathrm{CO}_{2}$ vs. temperature 


\subsection{A Model for Predicting the Capacity of a Gas Cooler}

As discussed in the previous sections, it is difficult to determine the overall heat transfer coefficient for a $\mathrm{CO}_{2}$ gas cooler since the properties of $\mathrm{CO}_{2}$ change significantly with temperature. Particularly, the specific heat of $\mathrm{CO}_{2}$ changes tremendously in the present experimental temperature range. To overcome this problem, the concept of heat exchanger effectiveness was introduced to develop an empirical correlation for predicting a $\mathrm{CO}_{2}$ gas cooler capacity.

The capacity of a gas cooler can be expressed as:

$$
Q=Q_{\text {ref }}=\dot{m}_{r e f} \cdot\left(h_{\text {ref-in }}-h_{\text {ref-out }}\right)
$$

The heat transfer effectiveness (eff) is defined as:

$$
\text { eff }=\frac{h_{\text {ref-in }}-h_{\text {ref-out }}}{h_{\text {ref-in }}-h_{\text {ref-ideal }}}
$$

where $h_{\text {refideal }}$ refers to the enthalpy of refrigerant at the air inlet temperature. eff represents the performance of a heat exchanger. Then, we have

$$
Q=\dot{m}_{r e f} \cdot\left(h_{r e f-i n}-h_{r e f-i d e a l}\right) \cdot e f f
$$

In the above equation, $\dot{m}_{r e f}, h_{r e f-i n}$, and $h_{\text {ref-ideal }}$ are normally available when designing a gas cooler. If we can find eff, the capacity of the gas cooler can be predicted.

Theoretically, for a heat exchanger,

$$
\text { eff }=f(N T U, Z, \text { flowarrangement })
$$

where $Z$ refers to the ratio of capacity rate between the two fluids, and $N T U$ is a function of $\int U d A . U$ refers to the local overall heat transfer coefficient.

The effectiveness for counterflow heat exchangers can be expressed as: 


$$
e f f=\frac{1-\exp (-N T U \cdot(1-Z))}{1-Z \cdot \exp (-N T U \cdot(1-Z))}=1-\frac{(1-Z) \cdot \exp (-N T U \cdot(1-Z))}{1-Z \cdot \exp (-N T U \cdot(1-Z))}
$$

The present gas cooler is a counter-cross flow type. Recall from the previous section that the effectiveness of the present heat exchanger can be orderly plotted as a function of the number of HXs.

For the present type of gas cooler, we assume the effectiveness has the form:

$$
e f f=1-\frac{1}{f\left(U_{\text {local }}\right) \cdot \exp \left(a_{1} \cdot(L / D)^{a_{2}}\right)}
$$

where $f\left(U_{\text {local }}\right)$ is expected to depend on the air-side and refrigerant heat transfer coefficients. Or,

$$
f\left(U_{\text {local }}\right)=f\left(S t_{\text {air }}, N u_{\text {ref }}\right)
$$

The present experiment provides extensive data for various test conditions. Since the refrigerant temperature was measured for each exchanger slab, the amount of heat transfer from each $\mathrm{HX}$ unit can be determined. Thus, the present experiment also enables us to study a $\mathrm{CO}_{2}$ gas cooler of different sizes (HX1 alone, $\mathrm{HX} 1+\mathrm{HX} 2$, $\mathrm{HX} 1+\mathrm{HX} 2+\mathrm{HX} 3$, $\mathrm{HX} 1+\mathrm{HX} 2+\mathrm{HX} 3+\mathrm{HX} 4$, and HX1+HX2+HX3+HX4+HX5).

An empirical model is developed as follows:

$$
Q=\dot{m}_{r e f} \cdot\left(h_{r e f-i n}-h_{r e f-i d e a l}\right) \cdot e f f
$$

where eff depends only on non-dimensional parameters.

$$
\begin{gathered}
\text { eff }=1-\frac{1}{\left(1+1.254 \times 10^{-8} S t_{\text {air }}^{-4.493} N u_{\text {ref }}^{-2.958}\right) \cdot \exp \left(0.5829 \cdot\left(2.325581 \times 10^{-4} \frac{L}{D}\right)^{1.269}\right)} \\
S t_{\text {air }}=\frac{j}{\operatorname{Pr}^{0.677}}
\end{gathered}
$$




$$
\begin{array}{r}
N u=\frac{(\operatorname{Re}-1000) \operatorname{Pr} \zeta / 8}{1+12.7 \sqrt{\zeta / 8}\left(\operatorname{Pr}^{2 / 3}-1\right)} \\
\zeta=(0.79 \ln (\operatorname{Re})-1.64)^{-2}
\end{array}
$$

where $L$ refers to the length of the refrigerant flow path while $D$ is the hydraulic diameter of the microchannels.

Figures 5.13 and 5.14 present the predicted effectiveness as a function of number of HXs. Compared with Figures 5.8 and 5.9, it shows that the model can predict the test results of higher refrigerant pressure $(10 \sim 13 \mathrm{MPa})$ with higher accuracy. Figure 5.15 compared the predicted effectiveness with experimental results. The empirical model can predict experimental results within $\pm 20 \%$ except for the tests that are very close to the critical point of $\mathrm{CO}_{2}$.

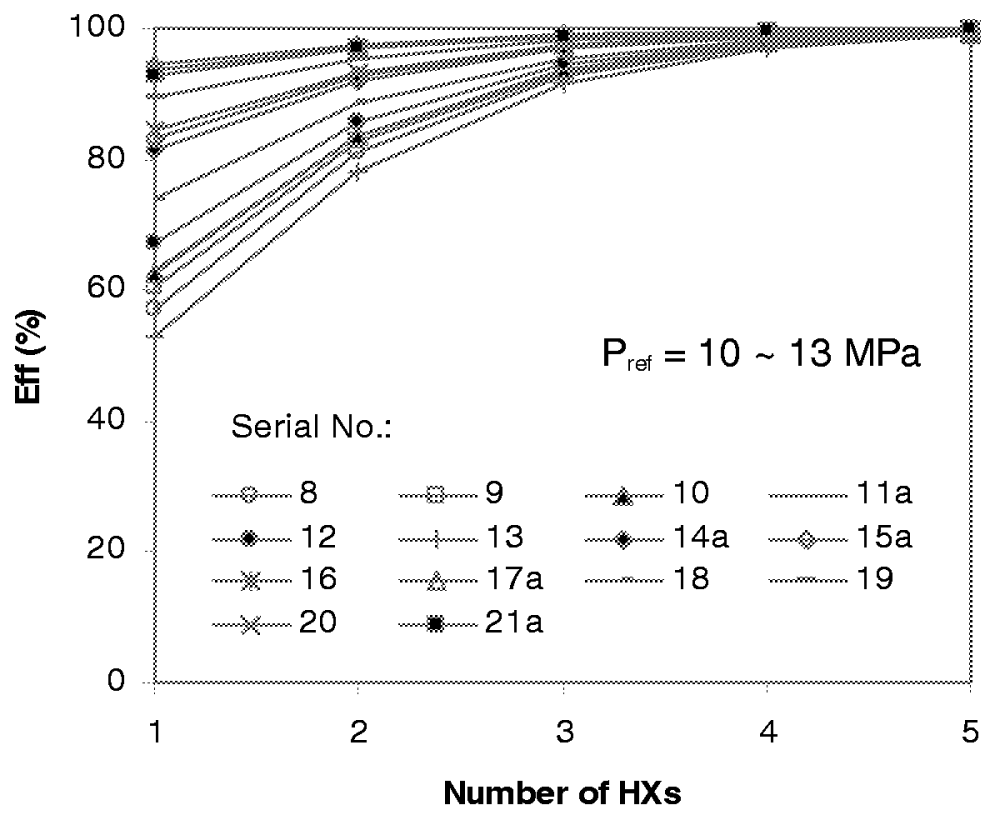

Figure 5.13 Predicted effectiveness vs. number of HXs 


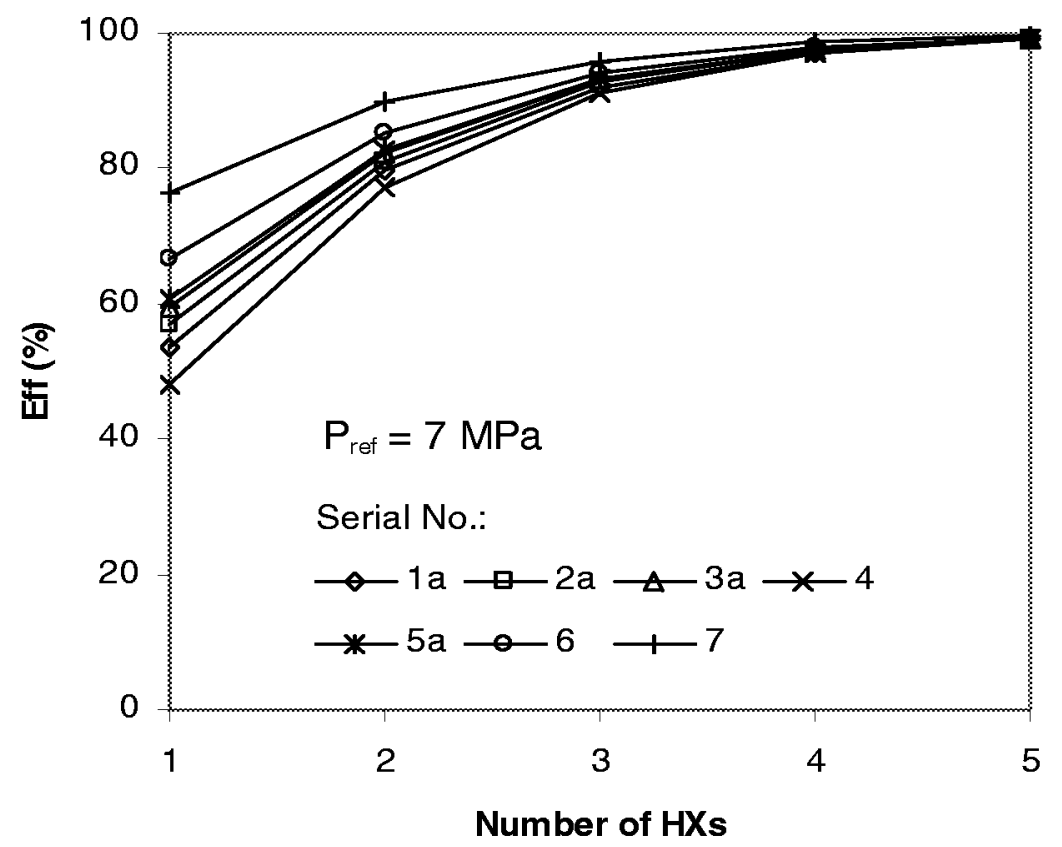

Figure 5.14 Predicted effectiveness vs. number of HXs

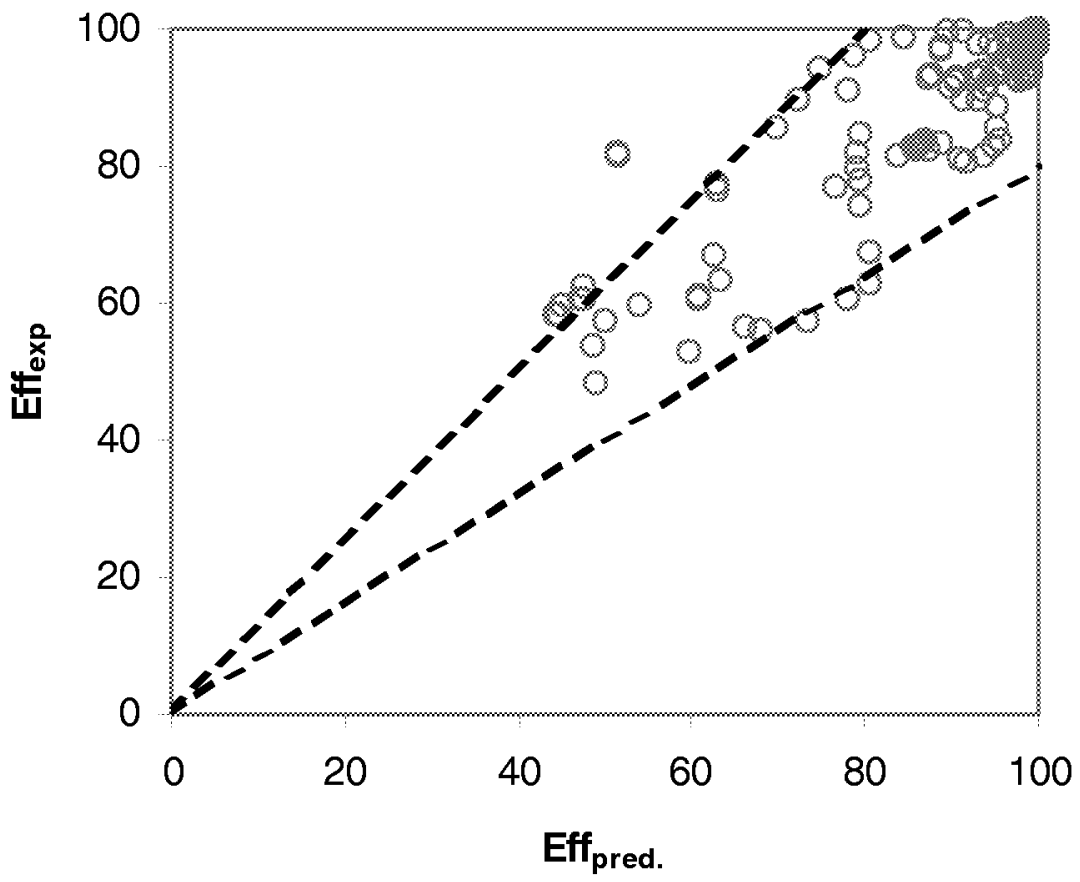

Figure 5.15 Comparison between the model predictions and experimental results 


\section{CHAPTER 6. CONCLUSIONS AND FUTURE WORK}

\subsection{CONCLUSIONS}

An experimental and computer simulation study was conducted to characterize the performance of $\mathrm{CO}_{2}$ microchannel evaporators and gas coolers over a range of operating conditions found in residential heat pumps. An extensive review of the literature failed to indicate any previous systematic study in this area, suggesting a lack of fundamental understanding of the phenomena and a lack of comprehensive data that would quantify the performance potential of $\mathrm{CO}_{2}$ microchannel heat exchangers for the application at hand.

In the present study, experiments were conducted to evaluate capacities and pressure drops for sub-critical $\mathrm{CO}_{2}$ flow boiling and transcritical $\mathrm{CO}_{2}$ gas cooling in microchannel heat exchangers. All experimental tests were successfully conducted with an energy balance within $\pm 3 \%$. The only exceptions to this were experiments at very low saturation temperatures $\left(-23^{\circ} \mathrm{C}\right)$, where heat balances were as high as $10 \%$.

In the case of evaporators, it was found that a lower saturation temperature (especially when moisture condensation occurs) improves the overall heat transfer coefficient significantly. However, under such conditions, air-side pressure drop also increases when moisture condensation occurs. An increase in airflow rate also increases the overall heat transfer coefficient. However, this in turn is associated with higher pressure drops at higher air flow rates. A semi-empirical model was developed for prediction of $\mathrm{CO}_{2}$ evaporator system capacity by introducing two new factors (Cta and Bta). The model agrees within $\pm 13 \%$ with the experimental test results. 
For the gas cooler, a significant portion of the heat transfer occurred in the first heat exchanger module on the refrigerant inlet side. For example, over $80 \%$ of the heat transfer occurred in the first heat exchanger module for the refrigerant with $\mathrm{T}_{\text {in }}$ of $120^{\circ} \mathrm{C}$ and $\mathrm{P}_{\text {in }}$ of $12.5 \mathrm{MPa}$, and nearly $50 \%$ occurred in the first module for $\mathrm{T}_{\text {in }}$ of $79^{\circ} \mathrm{C}$ and $\mathrm{P}_{\text {in }}$ of $7 \mathrm{MPa}$. The temperature and pressure of $\mathrm{CO}_{2}$ significantly affect the heat transfer and fluid flow characteristics due to some important properties (such as specific heat, density, viscosity). In the transcritical region, heat transfer of $\mathrm{CO}_{2}$ strongly depends on temperature and pressure. A semi-empirical model was developed based on nondimensional parameters for the prediction of $\mathrm{CO}_{2}$ gas cooler system capacity. The model successfully predicted the experimental results within $\pm 20 \%$. Recommendations for future work on this project are listed at the end of this report.

\subsection{Future Work}

During the course of this project, many questions, ideas, and opportunities have become apparent and are included here. The work includes recalling and discussing important phenomena of $\mathrm{CO}_{2}$ and microchannel heat exchangers, proposing problems for future study, and including some guidelines for designing microchannel heat exchangers.

\subsubsection{Two-Phase Flow Mal-distribution for a Microchannel Evaporator}

Flow mal-distribution is one of the major concerns in designing heat exchangers. Moreover, when heat exchangers experience phase change, such as condensation and evaporation, flow mal-distribution becomes even more important, especially for microchannel heat exchangers, which normally have to distribute the fluid of a two-phase 
mixture into many parallel microchannels. Since the entrance of each microchannel is very small, and two-phase fluid typically exists as a non-homogenous pattern, the entrances of some microchannels may come into contact with the refrigerant only in vapor phase, while others may meet pure liquid all the time. The channels that meet only pure vapor will have a very poor heat transfer coefficient, which will reduce the total heat transfer performance of the heat exchanger. Therefore, header design is a key issue in designing microchannel heat exchangers that experience phase change. Two-phase flow mal-distribution is a research topic in our advanced heat exchangers laboratory. Zhao et al. (2000) has conducted some preliminary tests focused on two-phase flow maldistribution in microchannels. The tests indicated that two-phase mal-distribution was caused by the phase separation in the inlet header. To suppress two-phase flow maldistribution, some flow mixers could be introduced into the inlet header.

\subsubsection{Defrosting Techniques}

The present experimental conditions cover some tests at a saturation temperature of $-23{ }^{\circ} \mathrm{C}$, which is significantly below the freezing temperature of water. In such cases, icing may occur if the air stream has a certain level of moisture. Moisture frozen on the outer surface of a heat exchanger may block airflow, thus reducing the gas cooler performance significantly. For a typical heat pump in winter, the system requires periodic system operation of the defrost cycle. Defrost techniques are currently being researched in our laboratory. 


\subsubsection{Model Developments and Improvements}

The present study developed two models for predicting the capacity of an evaporator and a gas cooler with $\mathrm{CO}_{2}$. The evaporator model results agree with experimental results within $\pm 13 \%$ when coefficients are introduced to account for the effects of moisture condensate and superheat. The gas cooler model implements nondimensional parameters and can predict the experimental data within $\pm 20 \%$. More accurate model can be developed after a better understanding of the heat transfer process of $\mathrm{CO}_{2}$ gas coolers is gained and a detailed investigation of the gas cooler is initiated. Furthermore, since the properties of supercritical $\mathrm{CO}_{2}$ change significantly with temperature, a numerical model that accounts for that will better represent the practical situation.

As discussed above, flow mal-distribution is a key factor in the performance of a microchannel evaporator. In order to develop a more accurate model for predicting the performance of an evaporator, the flow mal-distribution problem needs to be investigated thoroughly. In addition, experimental tests need to be done on the air-side heat transfer coefficient, specifically when moisture condensation or freezing occurs.

\subsubsection{Recommendations for Heat Exchanger Design}

Based on the present experimental study, some recommendations for the microchannel heat exchanger design are listed as follows:

1. Since the flow pattern for two-phase flow is always heterogeneous, the flow maldistribution problem needs to be considered. Using an elbow to replace the 90 degree sharp turn may improve this problem. 
2. Considering the velocity profile of the air stream, the central area of the heat exchanger normally has higher air velocity, and thus has higher cooling potential. Therefore, the heat exchanger should be designed so that the refrigerant can be fed at the middle, as shown in Figure 6.1.

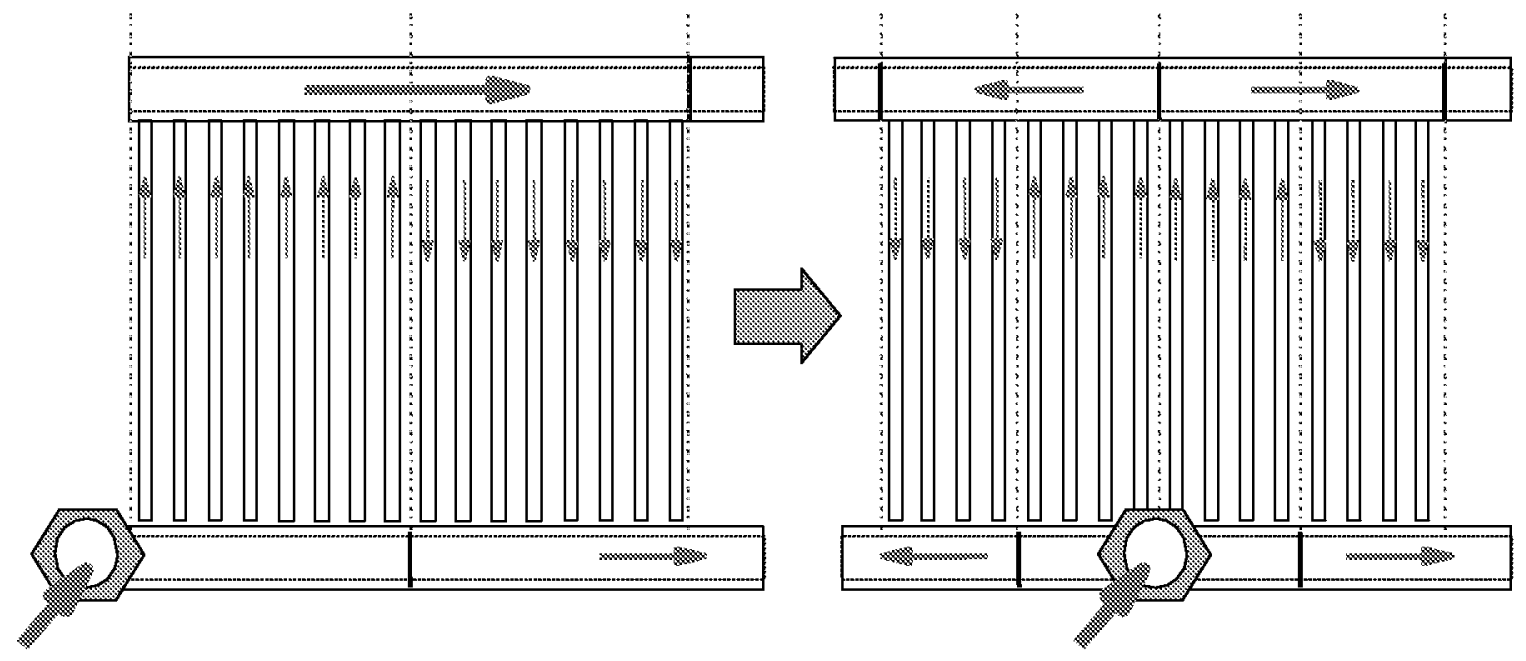

Figure 6.1 Schematic diagram of the proposed header design

3. To decrease the mal-distribution effect, limit the length of each pass.

4. Other important issues on heat exchanger design:

- Cross section optimization (oval vs. square or round)

- Header Design (minimization of mal-distribution and pressure drops)

- Heat exchanger circuitry

- Air-side enhancement 


\section{APPENDIX A. DESIGN OF AN OBSTRUCTION FLOW METER}

\section{A.1 Introduction}

To test a microchannel heat exchanger as a gas cooler, an outdoor air duct was built. The duct was $1.22 \mathrm{~mm}$ wide, $0.91 \mathrm{~m}$ high, and $2.74 \mathrm{~m}$ long. It consisted of an obstruction meter, an air mixer, a speed-variable fan, two thermocouple grids (one upstream, the other downstream), two screens, and a heat exchanger as shown in Fig. A.1. The duct was sealed carefully with silicone and insulated with a $25 \mathrm{~mm}$ thick thermal insulation material $(\mathrm{k}=0.04 \mathrm{~W} / \mathrm{mK})$. Since the cross sectional area of the duct is very large $(1.22 \mathrm{~m}$ by $0.91 \mathrm{~m})$, a large air flow rate was needed to provide the specified air velocity as required by the project.

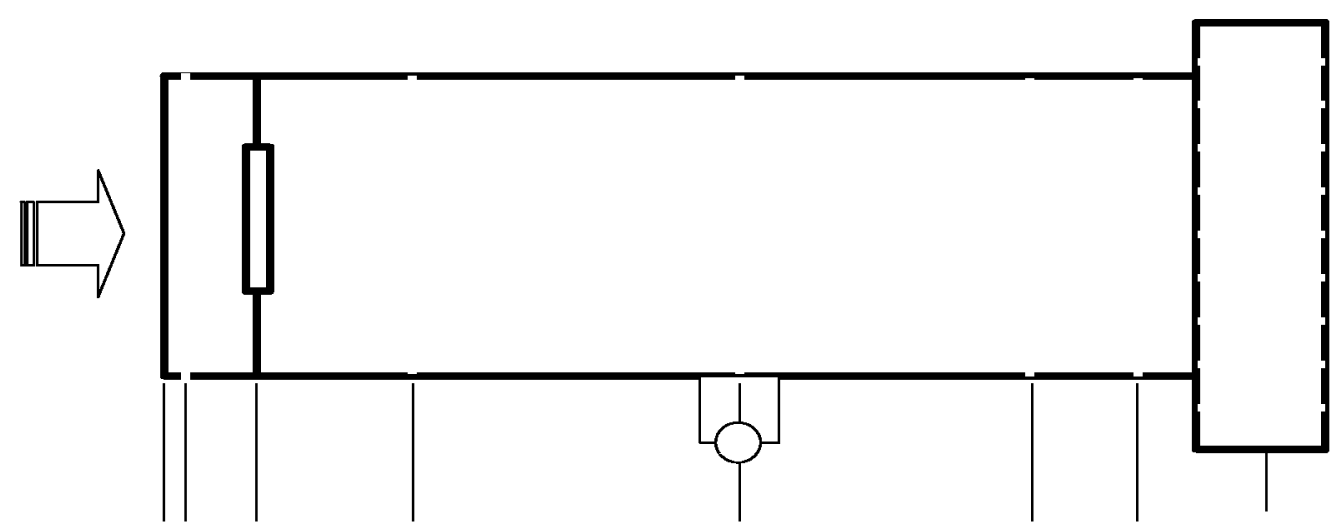


1. Primary or quantity methods such as weight or volume tanks, burettes, positivedisplacement meters;

2. Flowmeters including obstruction meters, variable-area meters, vortex-shedding meters, turbine and propeller meters, magnetic flowmeters;

3. Velocity probes such as Pitot-static tubes, hot-wire and hot-film anemometers, Laser-Doppler anemometer, Ultrasonic anemometer;

4. Flow-visualization techniques including smoke trails, dye injection, laser-induced fluorescence, and refractive-index change.

The above outline does not exhaust the list of flow-measuring methods, but it includes those of primary interest to the mechanical engineer. Among those methods, primary methods capture and record the volume or mass that flows during a fixed time interval. The primary methods, especially weight tanks, are typically used for steady-state calibration of liquid flow-meters. They are not suitable for on-line measurement applications. For on-line measurements, flowmeters and velocity probes are the most commonly used devices. Flowmeters determine volume or mass flow rates through tubes and ducts, whereas velocity-sensing probes measure fluid speed at a point in the flow. Although velocity-sensing probes can be used as building blocks for flowmeters, the converse is rarely true. Flow-visualization techniques sometimes can be employed to obtain an image of the overall flow field; however, these methods usually have special requirements on the experimental test section.

As flow meters, obstruction meters are the most often used flow measurement devices in industrial practice. Compared with other measurement methods such as 
velocity probes, obstruction meters are the most convenient methods for on-line volume/mass measurement, and they can also provide very high accuracy.

\section{A.2 Obstruction Meters}

There are three basic types of obstruction meters, such as the venturi, the flow nozzle, and the orifice. An obstruction meter acts as an obstacle placed in the path of the flowing fluid, causing localized changes in velocity. Concurrently with velocity change, there will be pressure change. At the points of maximum restriction, and hence maximum velocity, minimum pressures are found. A certain portion of this pressure drop becomes irrecoverable owing to dissipation of kinetic energy; therefore, the output pressure will always be less than the input pressure.

For an incompressible flow, a relation between pressure drop across an obstruction meter and flow rate can be obtained by applying the mass conservation equation and Bernoulli's equation (Momentum equation).

For incompressible fluids,

$$
\begin{gathered}
\rho_{1}=\rho_{2}=\rho \\
G=A_{1} V_{1}=A_{2} V_{2} \\
\frac{P_{1}}{\rho g}+Z_{1}+\frac{V_{1}^{2}}{2}=\frac{P_{2}}{\rho g}+Z_{2}+\frac{V_{2}^{2}}{2}
\end{gathered}
$$

If we let $Z_{1}=Z_{2}$ and substitute $V_{1}=\left(A_{2} / A_{1}\right) V_{2}$ in Eq. (3), we get

$$
P_{1}-P_{2}=\frac{V_{2}^{2} \rho}{2}\left[1-\left(\frac{A_{2}}{A_{1}}\right)^{2}\right]
$$

and 


$$
G_{\text {ideal }}=A_{2} V_{2}=\left[\left.\frac{A_{2}}{\sqrt{1-\left(A_{2} / A_{1}\right)^{2}}}\right|_{\rfloor} ^{7} \sqrt{\frac{2\left(P_{1}-P_{2}\right)}{\rho}}\right.
$$

For a given meter, $A_{1}$ and $A_{2}$ are established values, so Eq. (5) can be rewritten as

$$
G_{\text {ideal }}=A_{2} V_{2}=E A_{2} \sqrt{\frac{2\left(P_{1}-P_{2}\right)}{\rho}}
$$

where

$$
E=\frac{1}{\sqrt{1-\left(A_{2} / A_{1}\right)^{2}}}
$$

In reality, $G_{\text {actual }}$ is not the same as $G_{\text {ideal }}$ because of some irreversible factors. Two additional factors are introduced for obstruction meter calculations. The first one is the discharge coefficient, $C$, and the other is flow coefficient, $K$. They are defined as following:

$$
\begin{gathered}
C=\frac{G_{\text {actual }}}{G_{\text {ideal }}} \\
K=C E=\frac{C}{\sqrt{1-\left(A_{2} / A_{1}\right)^{2}}}
\end{gathered}
$$

Finally, the equation for an obstruction meter is

$$
G_{\text {actual }}=K A_{2} \sqrt{\frac{2\left(P_{1}-P_{2}\right)}{\rho}}
$$




\section{A.3 Design of a Special Obstruction Meter}

In the present experiments, the cross sectional area of the outdoor air duct is very large (1219 mm wide and $914 \mathrm{~mm}$ high). A venturi or a flow nozzle is not suitable for the present experimental setup since they both need long installation space that is very valuable for the present situation. In addition, large air flow rates are required for the present experiments. However, a typical orifice may affect the flow field significantly and thus affect the downstream temperature measurement. Unfortunately, a large diameter orifice is very costly to fabricate.

In the present study, a new type of obstruction meter was designed and fabricated as seen in Figure A.2. The meter was made from of 117 holes with an inner diameter of $25 \mathrm{~mm}$. Since these small holes are uniformly arranged over the entire cross sectional area of the outdoor air duct, the flow and thermal fields are rather uniform for the present situation.

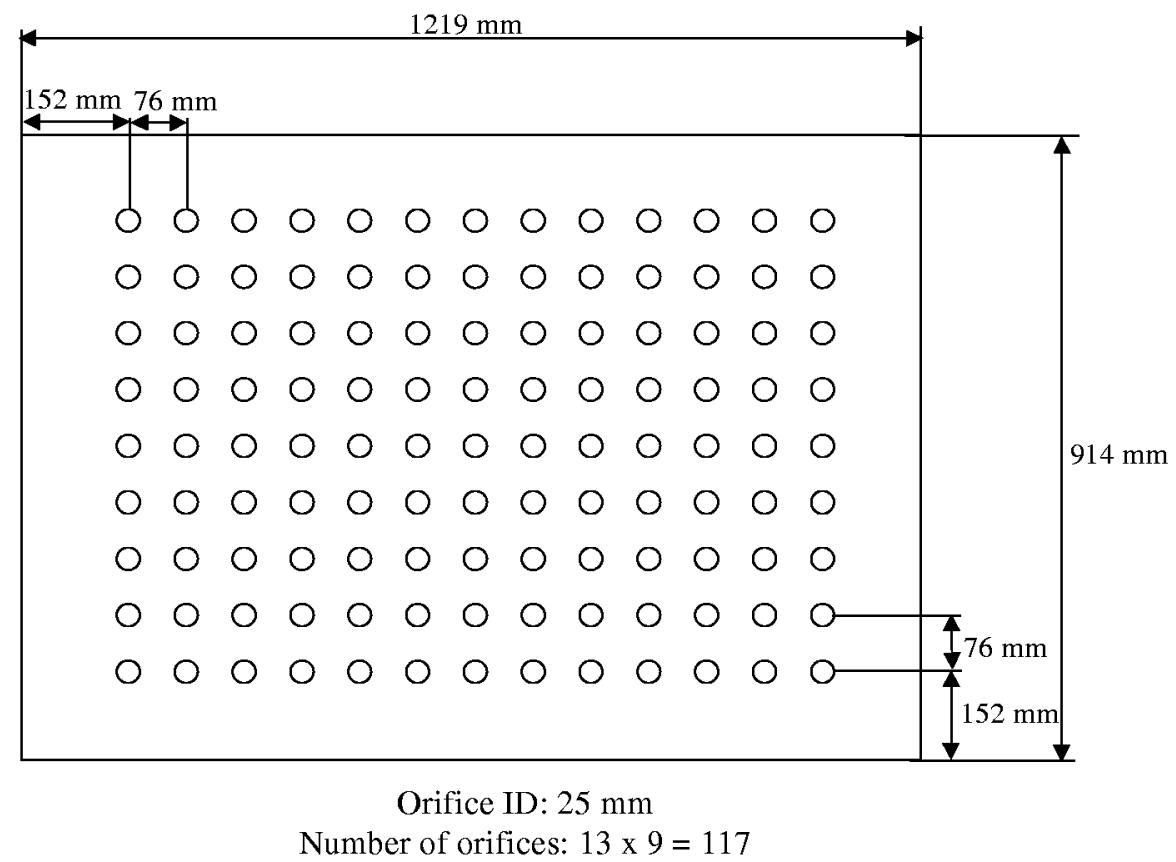

Figure A.2 Obstruction meter 


\section{A.4 Calibration of the Obstruction Meter}

Equation 9 is a general equation for an obstruction meter. The present obstruction meter also satisfies Equation 9, although it has a special geometry. Therefore, in the process of calibrating the obstruction meter, the flow factor $(K)$ was also determined.

Six finned strip heaters were installed in the outdoor air duct to calibrate the obstruction meter. The heat input to the heaters could be adjusted between $0.75 \mathrm{~kW}$ and $4.2 \mathrm{~kW}$. The outdoor air duct was carefully sealed and insulated with $25 \mathrm{~mm}$ thick thermal insulation material.

To calibrate the obstruction meter, the heat loss through the outdoor air duct was first estimated. A 1-D heat conduction model was used to estimate the heat loss analytically. Since the outdoor air duct and the air duct of the indoor loop were designed and fabricated according to the same procedure and using the same material and same thickness, the overall heat transfer coefficient for the two air ducts should be approximately the same. The overall heat transfer coefficient of the air duct of the indoor loop can be determined from the energy balance. The overall heat transfer coefficients determined analytically strongly agree with those of obtained from the indoor loop within $\pm 9 \%$.

Therefore, the heat loss through the outdoor air duct can be determined by the overall heat transfer coefficient and temperature difference between the air inside the duct and the room. The results are shown in Figure A.3. 


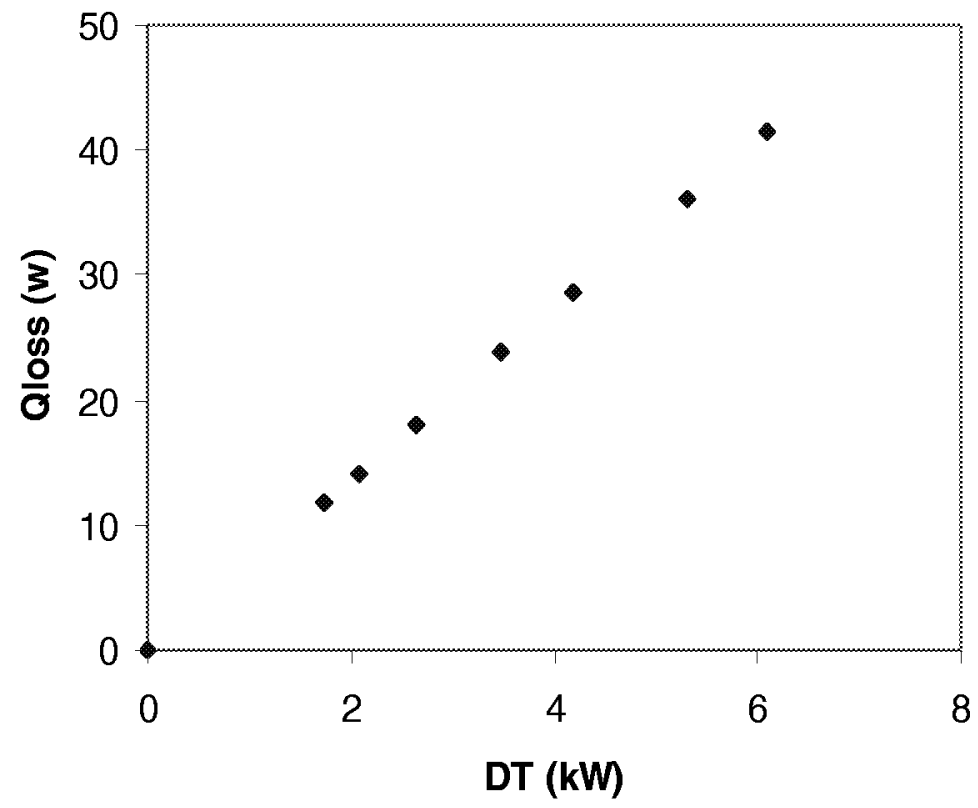

Figure A.3 Heat losses from the outdoor air duct

As the starting point, the present obstruction meter can be approximated as 117 parallel orifice meters. The total airflow rate is the sum of the airflow rates through these 117 orifices. Each orifice can be considered as a standard orifice, and flow coefficient $K$ can be determined from Figure A.4. 


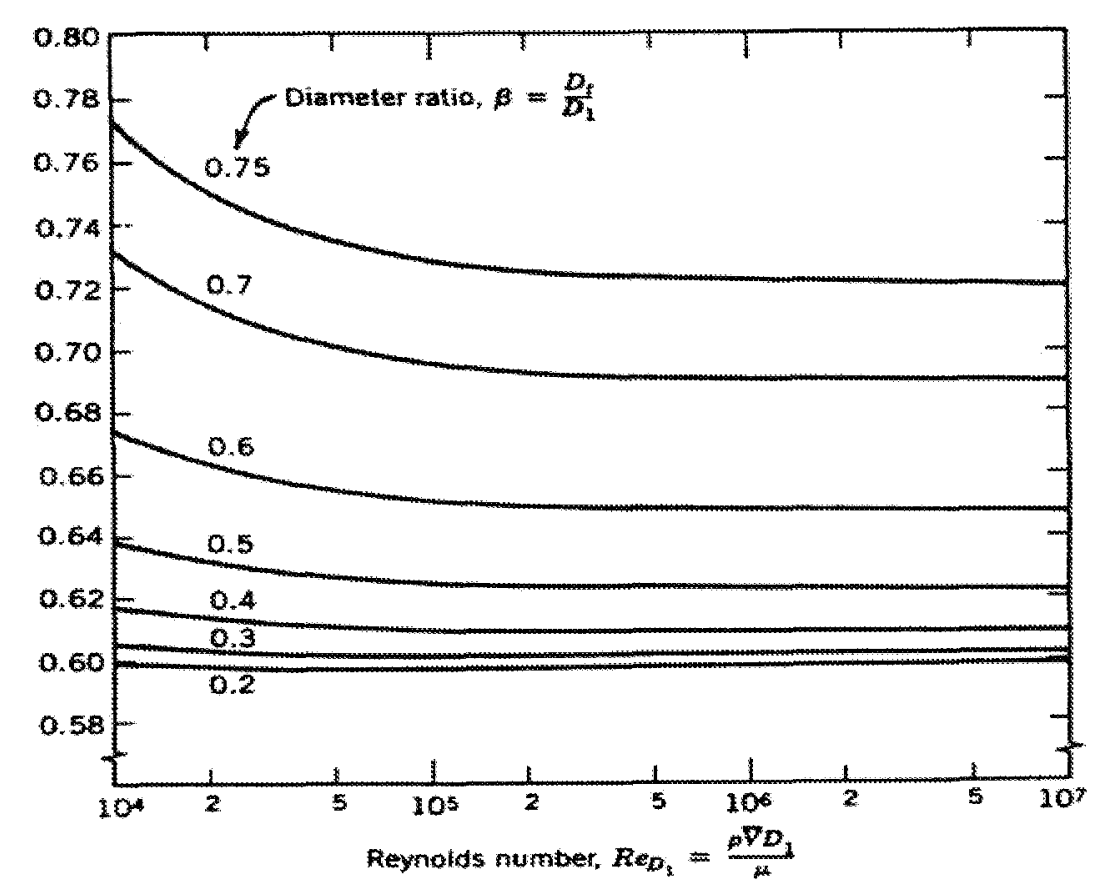

Figure A.4 Flow coefficient as function of Reynolds number

where $\beta=\frac{D_{\text {orifice }}}{D_{\text {duct }}} \approx 0.0243$. From the above figure, flow coefficient $K$ was determined to be approximately 0.59 . This value remains almost independent of Reynolds number, for Re ranged from $10^{4}$ to $10^{7}$

The airflow rate can be calculated from

$$
G_{\text {actual }}=117 K A_{\text {hole }} \sqrt{\frac{2\left(P_{1}-P_{2}\right)}{\rho}}
$$

where

$$
A_{\text {hole }}=\frac{\pi D_{\text {hole }}}{4}=0.000507 \mathrm{~m}^{2}
$$

Based on the airflow rate determined from the above equation and the temperature difference between the upstream and downstream thermocouples, the heat absorbed by the airflow through the duct can be calculated from 


$$
Q_{\text {air }}=G \rho C_{p}\left(T_{\text {downstream }}-T_{\text {upstream }}\right)
$$

Two series of experimental tests were performed, and the results are shown in Figures A.5 and A.6. These results show a relatively large difference between $Q_{\text {heater }}$ and $Q_{a i r}$ This reflects that the flow factor $K$ for a standard orifice was not directly applicable to the present obstruction meter. However, more careful observation of the test results suggested that the difference between $Q_{a i r}$ and $Q_{\text {heater }}$ is nearly a constant value and is independent of the temperature difference between the air inside the duct and ambient air. A rather constant ratio between the $Q_{a i r}$ and $Q_{\text {heater }}$ was observed and found to be 1.29 for both of the two test series. Since the present obstruction meter is not a standard orifice meter, the flow factor determined for standard orifices might not be applicable directly. However, since the obstruction meter was made from many standard orifices, it is likely to have some correlation between the present obstruction meter and standard orifice meters. Thus, a correction factor based on the flow factor for standard orifice meter was developed for the present obstruction meter. The constant was found to be 1.29. The flow factor for the obstruction meter is equal to 1.29 times 0.59 , which is the value for a single standard orifice with ID of $25 \mathrm{~mm}$.

Figure A.7 depicts the comparison between the $Q_{a i r}$ and $Q_{\text {heater }}$ after the flow coefficient was corrected. 

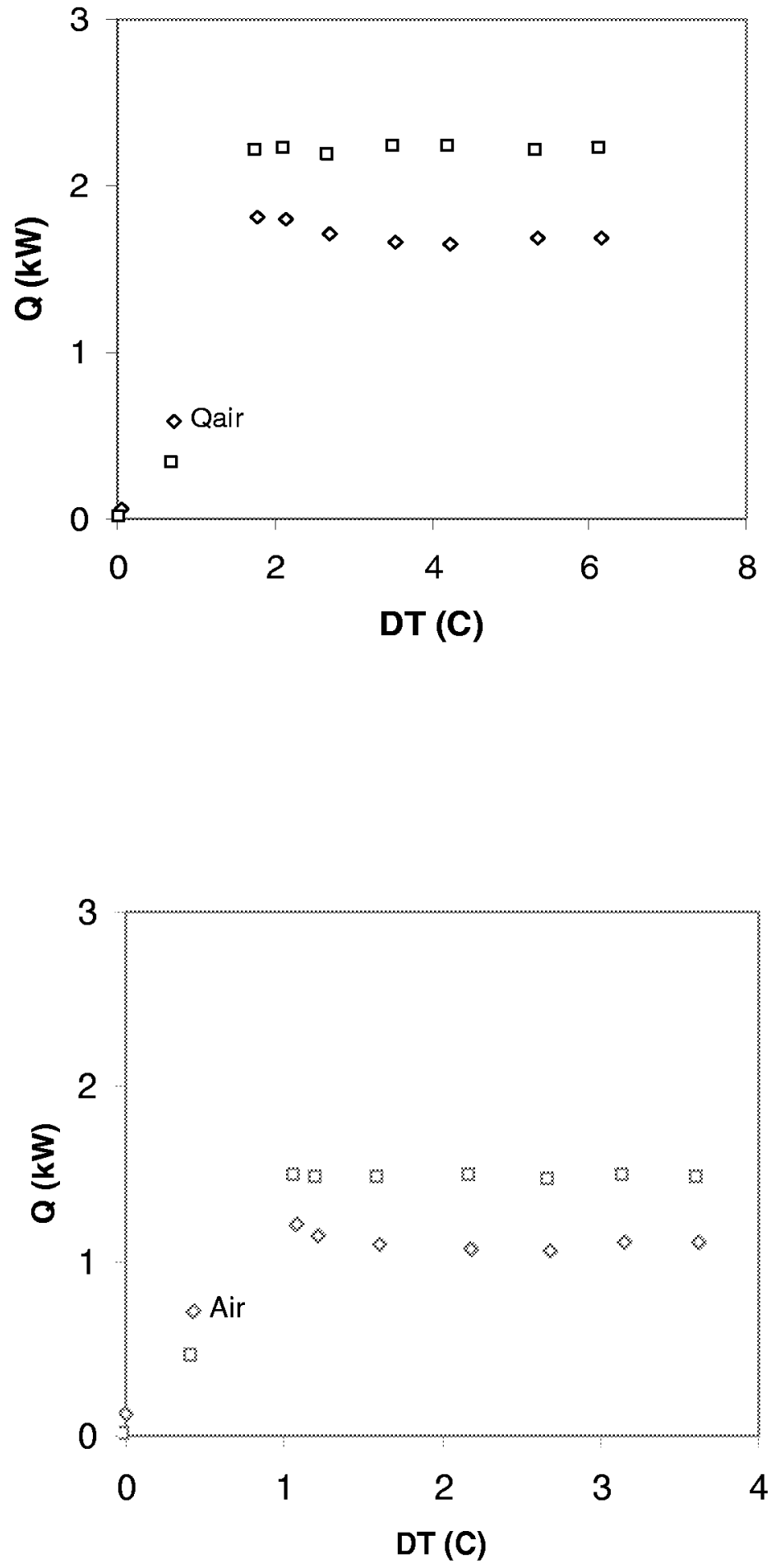


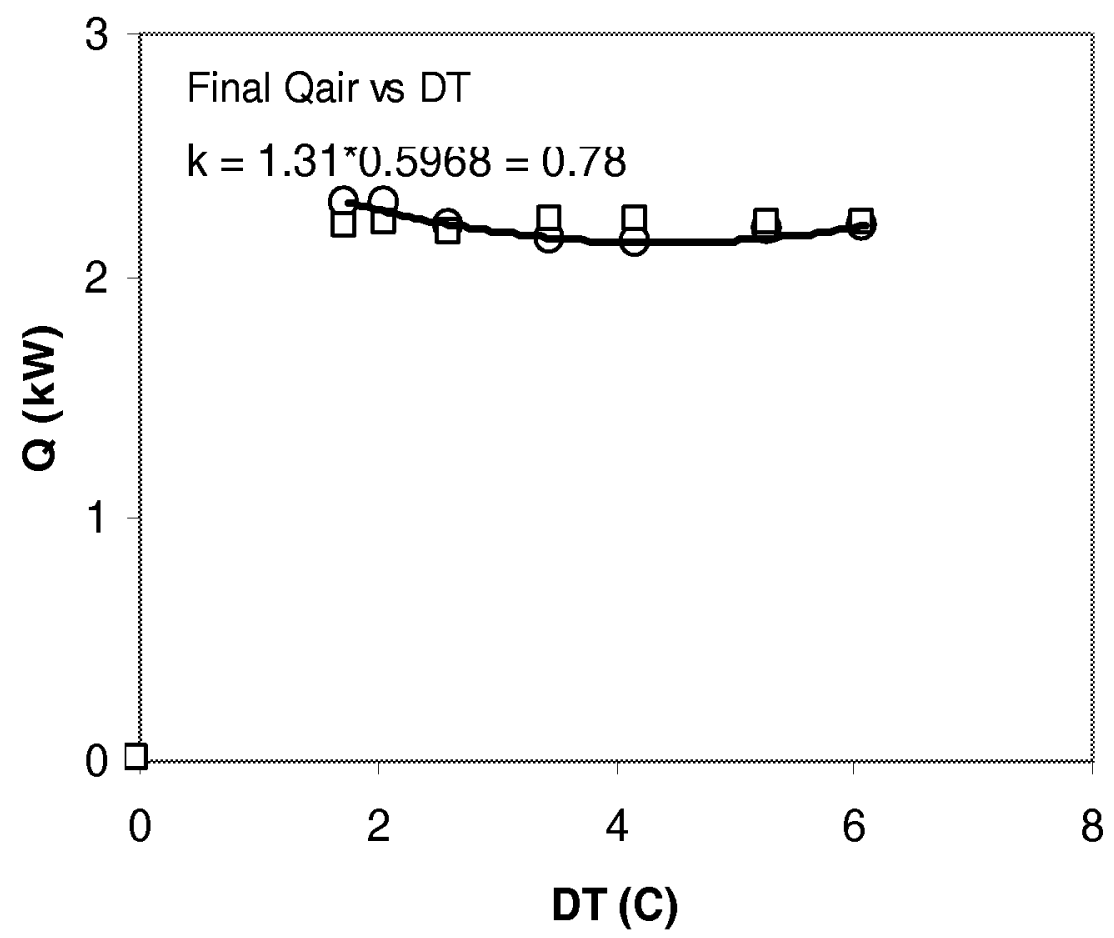

Figure A.7 Comparison between the heating determined by air and by heaters after correction

New experimental tests were conducted based on the modified flow factor. The energy balance results are shown in Figure A.8. It was found that the energy balance was within $\pm 3 \%$. However, energy balance is within $\pm 3 \%$ when temperature difference between the upstream and downstream thermocouples is large enough. This reflects that a relatively larger error in the energy balance might be due to the insufficient temperature difference (around $1 \mathrm{C}$ ). It also shows that the flow factor determined above is accurate for the present obstruction meter. 


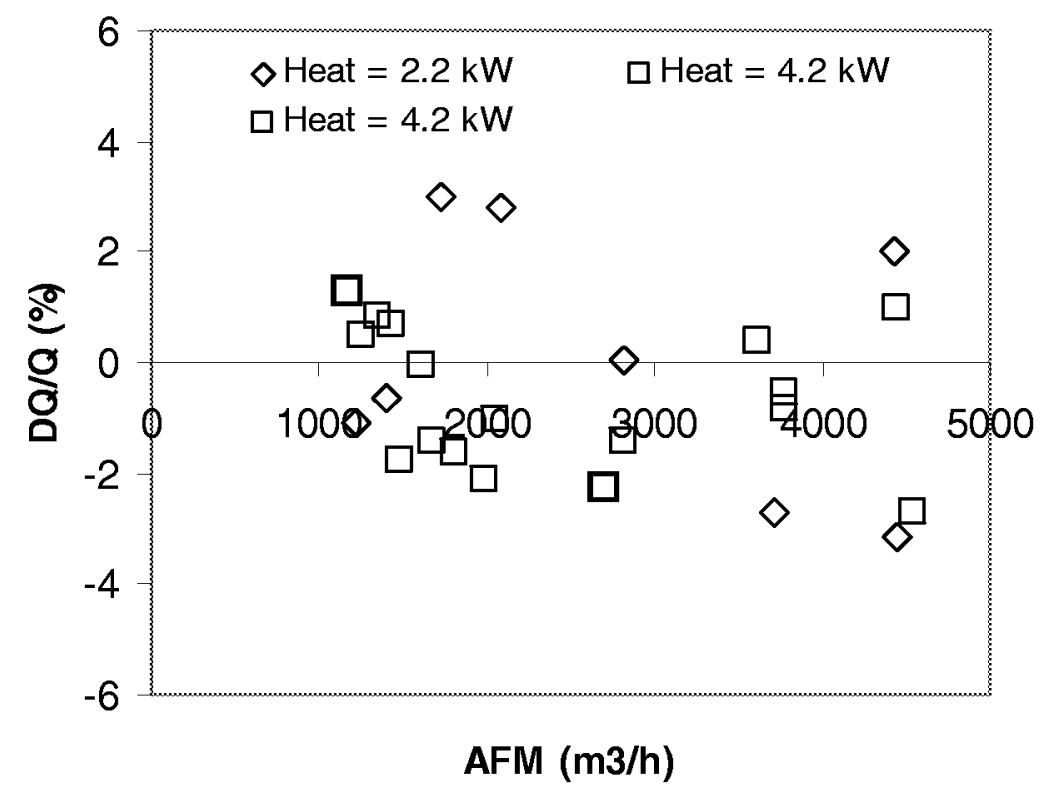

Figure A.8 The results of energy balance

Figure A.9 depicts the air flow rate as a function of the fan frequency. Three different test series showed the same results. The repeatability is within $\pm 2 \%$.

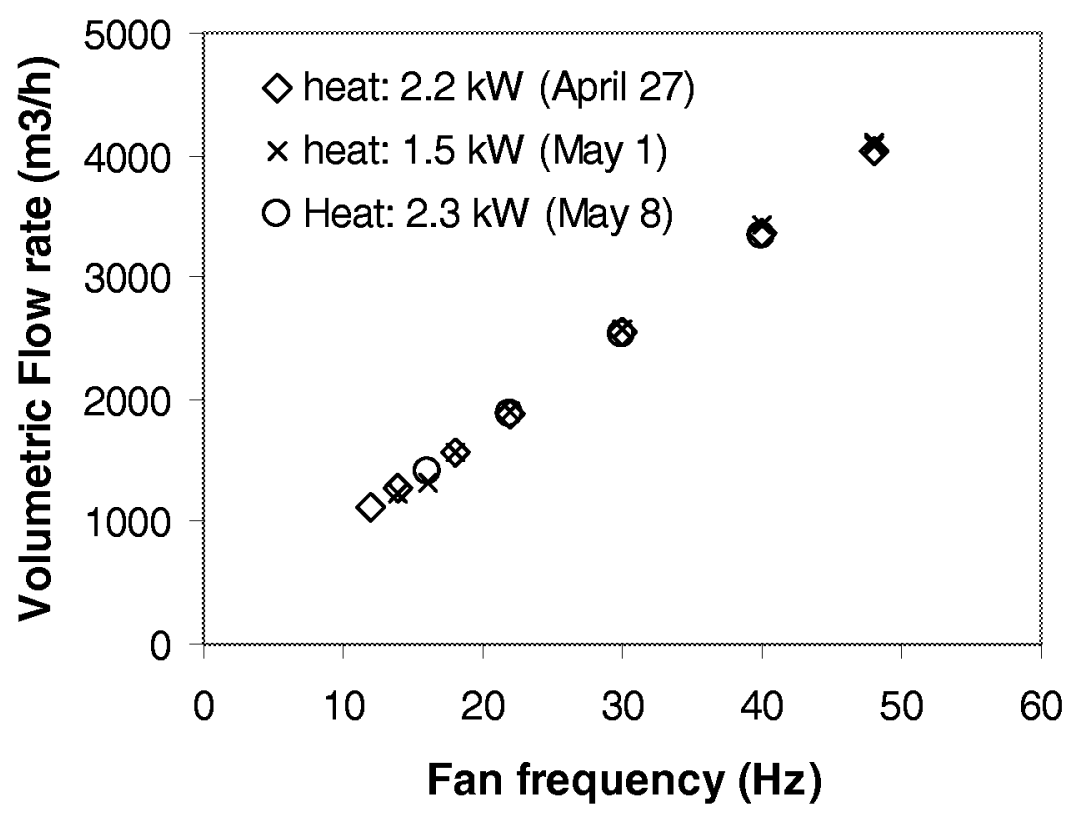

Figure A.9 Volumetric flow rate vs. fan frequency 
In summary, a new type of obstruction flow meter was designed, constructed and calibrated experimentally. The flow meter was constructed by uniformly drilling 117 holes with an inner diameter of one inch on a plate. Extensive experimental tests were conducted at different test conditions, heat input, and air flow rate.

It was shown that typical flow coefficients for flat-plate orifices could not be applied directly to the present obstruction meter. This is due to the special geometry of the present obstruction meter. However, since the present meter is similar to a typical orifice meter, experimental results showed that a typical procedure used to obtain the flow coefficient for a single orifice could be applied with some modifications.

The final energy balance results showed that the results were within $\pm 3 \%$ for the different test conditions ranging from $1.5 \mathrm{~kW}$ to $4.2 \mathrm{~kW}$, and air flow rate from 1000 to $4000 \mathrm{~m}^{3} / \mathrm{h}$. 


\section{REFERENCES}

Acosta, R., R. Muller, and C. Tobias, 1985, “Transport Processes in Narrow (Capillary) Channels," J. of AIChE 31: 473-482.

Admas, T.M., S.I. Abdel-Khalik, S.M. Jeter and Z.H. Qureshi, 1998, "An Experimental Investigation of Single-phase Forced Convection in Microchannels, " Int. J. Heat Mass Transfer 41(6): 851-857.

Akers, W.W., H.A. Deans and O.K. Crosser, 1959, "Condensing Heat Transfer within Horizontal Tubes," Chemical Engineering Progress Symposium Series 55(29): $171-176$.

ASHRAE Handbook of Fundamentals, 1997, SI Edn, ASHRAE Inc., Atlanta, GA

Bau, H.H., 1998, “Optimization of Conduits' Shape in Micro Heat Exchangers," Int. J. Heat Mass Transfer 41(1): 2717-2723.

Bennet, D.L. and J.C. Chen, 1980, "Forced Convection Boiling in Vertical Tubes for Saturated Pure Components and Binary Mixtures," J. of AIChE 26: 454-461.

Bowers, M.B. and I. Mudawar, 1994, "High Flux Boiling in Low Flow Rate, Low Pressure Drop Minichannel and Microchannel Heat Sinks," Int. J. Heat Mass Transfer 37(2): 321-332.

Bredesen, A.M., A. Hafner, J. Pettersen, P. Neksa, and K. Aflekt, 1997, "Heat Transfer and Pressure Drop for In-Tube Evaporation of $\mathrm{CO}_{2}$," Proceedings, International Conference on Heat Transfer Issues in Natural Refrigerants, Nov. 6-7, College Park, pp. $1-15$. 
Chen, J.C., 1966, “A Correlation for Boiling Heat Transfer to Saturated Fluids in Vertical Flow," Int. Chemical Engineering Proceedings: Design and Device 5(3): 322339.

Chisholm, D., 1983, Two-Phase Flow in Pipelines and Heat Exchangers. New York: Longman Inc.

Choi, S.B., R.F. Barron and R.O. Warrington, 1991, "Liquid Flow and Heat Transfer in Microtubes," Micromechanical Sensors, Actuators and Systems, ASME DSC 32: $123-134$.

Cutler, B., Y.H. Hwang, L. Bogdanic, and R. Radermacher, 2000, "Development of A Transcritical Carbon Dioxide Environmenral Control Unit," IIF-IIR Commission B1, B2, E1, and E2, Purdue University, USA.

Darabi, J., M. Salehi, M.H. Saeedi and M.M. Ohadi, 1995, "Review of Availble Correlations for In-tube Boiling in Smooth and Enhanced Tubes," ASHRAE Trans. 101(1): $965-975$.

Friedel, L., 1979, "Improved Friction Pressure Drop Correlations for Horizontal and Vertical Two Phase Pipe Flow," Paper E2, European Two Phase Flow Group Meeting, Ispra, Italy.

Gambill, W. and R. Bundy, 1961, "HFIR Heat Transfer Studies of Turbulent Water Flow in the Rectangular Channels," ORNL-3079 UC-80-Reactor Technology, Oak Ridge National Laboratory, Oak Ridge, TN.

Gungor, K.E. and R.H.S. Winterton, 1987, "A General Correlation for Flow Boiling in Tubes and Annuli," International Journal of Heat and Mass Transfer, Vol. 29(3): 351-358. 
Hwang, Y., 1997, "A Feasibility Study on Carbon Dioxide Refrigerant Cycle," Ph.D. Thesis, University of Maryland, College Park, MD.

Hwang, Y., B. Kim, and R. Radermacher, 1997, "Boiling Heat Transfer Correlation for Carbon Dioxide," Proceedings, International Conference on Heat Transfer Issues in Natural Refrigerants, Nov. 6-7, College Park, pp. 44-57.

Jung, D. S., and R. Radermacher, 1989, "Prediction of Pressure Drop during Horizontal Annular Flow Boiling of Pure and Mixed Refrigerants," Int. J. Heat Mass Transfer 32(12): 2435-2446.

Kandlikar, S.G., 1990, "A General Correlation for Saturated Two-phase Flow Boiling Heat Transfer Inside Horizontal and Vertical Tubes," J. of Heat Transfer, Trans. ASME 112(2): 219-228.

Kasza, K. E., T. Didascalou, T., and M.W. Wambsganss, 1997, "Microscale Flow Visualization of Nucleate Boiling in Small Channels: Mechanisms Influencing Heat Transfer," in Proc. Conf on Compact Heat Exchangers for the Process Industries, ed. R. K. Shah. New York: Begell House, Inc.

Kasza, K. E., and M.W. Wambsganss, 1995, "Flow Visualization of Microscale Thermal Mechanics of Boiling in Small Channels," in Flow Visualization VII - Proc. 7th International Symposium on Flow Visualization, ed. J. P. Crowder. New York: Begell House, Inc., pp. 262-267.

Klimenko, V.V., 1990, "A General Correlation for Two-phase Forced Flow Heat Transfer - Second Assessment," Int. J. Heat \& Mass Transfer 33(10): 2073-2088.

Kureta, M., T. Kobayashi, K. Mishima, and H. Nishihara, 1997, "Pressure Drop and Heat Transfer for Flow-Boiling of Water in Small-Diameter Tubes," B 
Hen/Transactions of the Japan Society of Mechanical Engineers, Part B 63(615): 37063714.

Lancet, R., 1959, "The Effect of Surface Roughness on the Convection HeatTransfer Coefficient of Fully Developed Turbulent Flow in Ducts with Uniform Heat Flux, "J. of Heat Transfer 1: 168-174.

Liu, Z. and R.H.S. Winterton, 1991, "A General Correlation for Saturated and Subcooled Flow Boiling in Tubes and Annuli, Based on a Nucleate Pool Boiling Equation," Int. J. Heat Mass Transfer, Vol. 34(11): 2759-2766.

Lorentzen, G., 1995, “The Use of Natural Refrigerants: A Complete Solution to the CFC/IICFC Replacement," Int. J. Refrig., Vol. 18(3): 190-197.

Ohadi, M.M. and B. Mo, 1997, "Natural Refrigerants-Historical Development, Recent Research, and Future Trends," Proceedings, 1997 Taipei International Conference on Ozone Layer Protection, December 9-10, Taipie,Taiwan.

Ohadi, M.M., R. Radermacher, and M. Molki, 1999, "Microchannel Heat Exchangers with Carbon Dioxide," Proposal submitted to Air-Conditioning \& Refrigeration Technology Institute, Arlington, VA.

Olson, D.A. and D. Allen, 1998, "Heat Transfer in Turbulent Supercritical Carbon Dioxide Flowing in a Heated Horizontal Tube,” NISTIR 6234.

Ortiz, T.M. and E.A. Groll, 2000, "Steady-State Thermal Finite-Element Analysis of A Microchannel CO2 Evaporator," IIF-IIR Commission B1, B2, E1, and E2, Puerdue University, USA.

Peng, X.F., G.P. Peterson and B.X. Wang, 1996, "Flow Boiling of Binary Mixtures in Microchanneled Plates," Int. J. Heat Mass Transfer 39(6): 1257-1264. 
Peng, X.F. and G.P. Peterson, 1996, "Convective Heat Transfer and Flow Friction for Water Flow in Microchannel Structures," Int. J. of Heat Mass Transfer 39(12): 25992608.

Peng, X.F., H.Y. Hu and B.X. Wang, 1998, "Boiling Nucleation During Liquid Flow in Microchannels," Int. J. Heat Mass Transfer 41(1): 101-106.

Peng, X.F. and B.X. Wang, 1994, "Cooling Characteristics with Microchanneled Structures," J. of Enhanced Heat Transfer 1(4): 315-326.

Pettersen, J., A. Hafner, G. Skaugen and H. Rekstad, 1998, "Development of Compact Heat Exchangers for $\mathrm{CO}_{2}$ Air-Conditioning Systems," Int. J. Refri. 21(3): 180193.

Pfahler, J., J. Harley, H.H. Bau, and J. Zemel, 1991, "Gas and Liquid Flow in Small Channels," Micromechanical Sensors, Actuators and Systems, ASME DSC 32: 49-60.

Pitla, S., K. Bhatia, V. Khetarpal, and G. Strikis, 2000, "Numerical Heat Transfer Analysis in Heat Exchangers for Transcritical $\mathrm{CO}_{2}$ System," IIF-IIR Commission B1, B2, E1, and E2, Purdue University, USA.

Ravigururajan, T.S., J. Cuta, C.E. McDonald, and M.K. Drost, 1996, "SinglePhase Flow Thermal Performance Characteristics of a Parallel Micro-Channel Heat Exchanger," ASME, Heat Transfer Division, (Publication) HTD Proceedings of the 31st ASME National Heat Transfer Conference. Part 7 (of 8), v 329, n 7, Houston, TX, USA.

Ravigururajan, T.S. and M.K. Drost, 1996, "Liquid Flow Characteristics in a Diamond-Pattern Micro-Heat-Exchanger," ASME, Dynamic Systems and Control Division (Publication) DSC Micro-Electro-Mechanical Systems (MEMS) Proceedings of 
the 1996 ASME International Mechanical Engineering Congress and Exposition, v 59, Atlanta, GA, USA.

Ravigururajan, T.S., 1998, "Impact of Channel Geometry on Two-phase Flow Heat Transfer Characteristics of Refrigerants in Microchannel Heat Exchangers," ASME J. Heat Transfer 120: 485-491.

Shah, M.M., 1976, "A New Correlation for Heat Transfer During Boiling Flow Through Pipes," ASHRAE Transactions, Vol. 82(2): 66-74.

Shah, M.M., 1982, "Chart Correlation for Saturated Boiling Heat Transfer: Equations and Further Studies," ASHRAE Transactions, Vol. 88(2): 185-196.

Tong, W., A.E. Bergles and M.K. Jensen, 1997, "Pressure Drop with Highly Subcooled Flow Boiling in Small-Diameter Tubes," Experimental Thermal Fluid Sciences 15: 202-212.

Tran, T. N., 1998, "Pressure Drop and Heat Transfer Study of Two-Phase Flow in Small Channels," Ph.D. Dissertation, Texas Tech University, Lubbock, Texas.

Tran, T. N., M.W. Wambsganss, M.C. Chyu, and D.M. France, 1997, "A Correlation for Nucleate Flow Boiling in Small Channels," in Compact Heat Exchangers for the Process Industries, ed. R. K. Shah. New York: Begell House, Inc., pp. 353-363.

Tran, T. N., M.W. Wambsganss, and D.M. France, 1996, "Small Circular and Rectangular Channel Boiling with Two Refrigerants," Int. J. Multiphase Flow, 22(3): 485-498.

Tran, T. N., M.W. Wambsganss, and D.M. France, 1999, "Two-phase Pressure Drop of Refrigerants During Flow Boiling in Small Channels: An Experimental Investigation and Correlation Development," Int. Conference On Compact Heat 
Exchangers and Enhancement Technology for the Process Industry, Banff, Canada, July 18-23, 1999.

Wambsganss, M.W., J.A. Jendrzejczyk, and D.M. France, 1994, "Two-Phase Flow and Pressure Drop in Flow Passages of Compact Heat Exchangers," in Vehicle Thermal Management, SAE PT-46, ed. A. C. Alkidas. Warrendale, PA: Society of Automotive Engineers pp. 257-266.

Wambsganss, M.W., D.M. France, J.A. Jendrzejczyk, and T.N. Tran, 1993, "Boiling Heat Transfer in a Horizontal Small-Diameter Tube," ASMEJ. Heat Transfer, 115(4), 963-972.

Wang, B.X. and X.F. Peng, 1994, "Experimental Investigation on Liquid ForcedConvection Heat Transfer through Microchannels," Int. J. Heat Mass Transfer 37(Suppl. 1): $73-82$.

Webb, R.L. and M. Zhang, 1997, "Heat Transfer and Friction in Small Diameter Channels," Presented at Workshop on Thermophysical Phenomena in Microscale Sensors, Devices and Structures, 1997 National Heat Transfer Conference, Baltimore, MD.

Wu, P. and W.A. Little, 1984. "Measurement of the Heat Transfer Characteristics of Gas Flow in Fine Channel Heat Exchangers Used for Microminiature Refrigerators," Cryogenics 24: 415-420.

Zhao, Y., M.M. Ohadi, S.V. Dessiatoun, A. Schuster, A. McNair, R. Radermacher, and J. Darabi, 1997, "Evaporation Heat Transfer Coefficients of Ammonia And $\mathrm{CO}_{2}$ Inside a Smooth Tube," Proceedings, International Conference on Heat Transfer Issues in Natural Refrigerants, Nov. 6-7, College Park, MD, pp. 93-107. 
Zhao, Y., M. Molki and M.M. Ohadi, 2000, "Heat Transfer and Pressure Drop of $\mathrm{CO}_{2}$ Flow Boiling in Microchannels," Proceedings of the ASME Heat Transfer Division2000, HTD-366(2): $243-248$.

Zhao, Y., M. Molki, M.M. Ohadi, and S.V. Dessiatoun, 2000, "Flow Boiling of $\mathrm{CO}_{2}$ in Microchannels," ASHRAE Transactions 106 (1): 437-445.

Zhao, Y., M.M. Ohadi, S.V. Dessiatoun, M. Molki, and J. Darabi, 1999, "Forced Convection Boiling Heat Transfer of $\mathrm{CO}_{2}$ in Horizontal Tubes," AJTE99-6249, 5th ASME/JSME Thermal Engineering Joint Conference, San Diego, California, USA, Mar 14-19, 1999. 